UNIVERSIDADE FEDERAL DE PERNAMBUCO

PROGRAMA DE PÓS-GRADUAÇÃO EM ENGENHARIA DE PRODUÇÃO

\title{
CONTRIBUIÇÃO CAD/CAE EM ANÁLISE DA CONFIABILIDADE DO PROCESSO DE DESENVOLVIMENTO DE PRODUTO
}

\author{
DISSERTAÇÃO SUBMETIDA À UFPE \\ PARA OBTENÇÃO DE GRAU DE MESTRE \\ POR \\ JOSÉ RICARDO MENEZES OLIVEIRA \\ Orientador: Prof. Enrique Andrés López Droguett, PhD
}

RECIFE, ABRIL / 2012 
O48c Oliveira, José Ricardo Menezes.

Contribuição $\mathrm{CAD} / \mathrm{CAI}$ em análise da confiabilidade do processo de desenvolvimento de produto / José Ricardo Menezes Oliveira - Recife: O Autor, 2012.

87f. il., figs., gráfs., tabs.

Orientador: Prof. Enrique Andrés López Droguett, $\mathrm{PhD}$

Dissertação (Mestrado) - Universidade Federal de Pernambuco. CTG.

Programa de Pós-Graduação em Engenharia Mecânica, 2012.

Inclui Referências e Apêndice.

1. Engenharia de Produção. 2. Recursos CAD e CAI. 3. Análise da confiabilidade . 4. Elementos Finitos (FEA). I. Droguett, Enrique López

(Orientador). II. Título.

658.5 CDD (22.ed) UFPE/BCTG-2012/176 


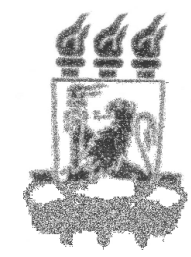

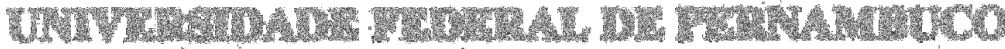

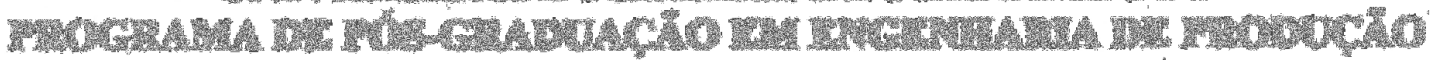

PARECER DA COMISSAO EXAMTNADORA

DE DEFESA DE DISSERTAÇAO DE

MESTRADO PROFISSIONAL DE

\section{JOSÉ RICARDO MENEZES OLIVEIRA}

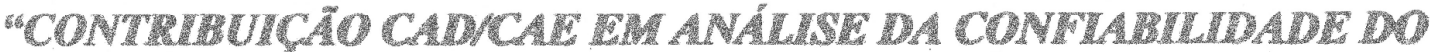

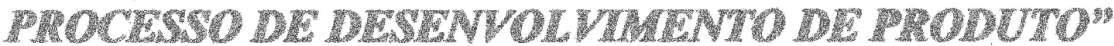

\section{AREA DE CONCENTRACAO PBSOUUSA OPERACIONAL}

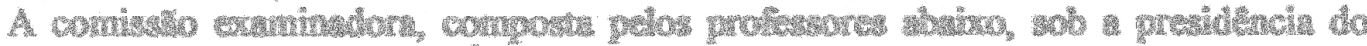

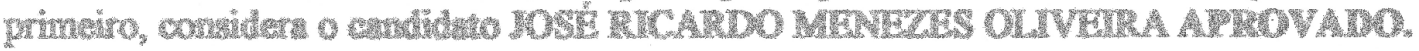

Recife, 17 de abril de 2012.

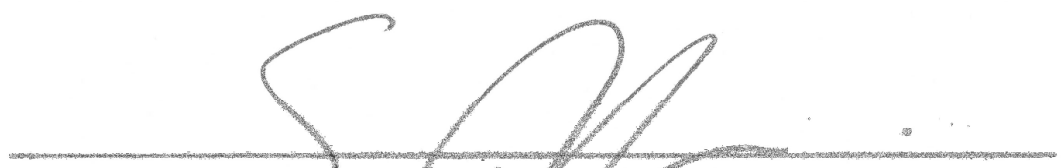

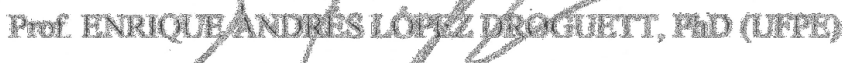

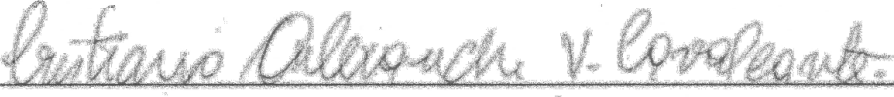

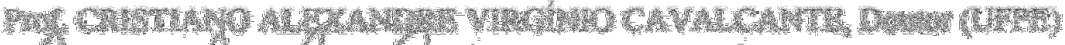

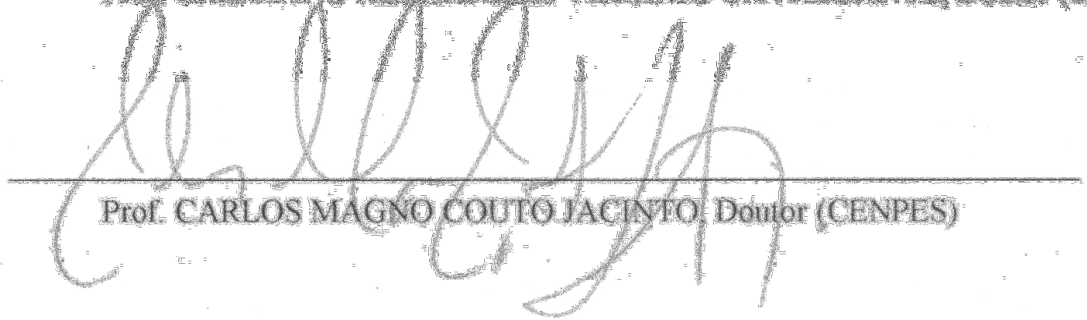




\section{DEDICATÓRIA}

Este estudo é dedicado a José Oliveira e Yolanda Teles de Menezes Oliveira. 


\section{AGRADECIMENTOS}

A todos os meus irmãos.

A Edmilson Silva, José Augusto, e ao meu amigo Eudson Maia.

A Marianna Menezes, Marconi Menezes, e Igor Menezes, que logo trilharão este caminho.

Aos irmãos espirituais, Jefferson Arlen Freitas e Helenice Leite Garcia.

Aos amigos institucionais André Maciel Passos Gabillaud, Douglas de Moura Andrade, e Anderson de Oliveira.

Aos novos amigos Anderson Oliveira, Iran Cosme, Simone, André Santos.

A Ionaldo Vieira de Carvalho, pelo suporte providencial.

Ao meu orientador Prof. Enrique Andrés López Droguett, pela oportunidade do aprendizado.

A Flávio Leandro e Ricardo Ferreira, pela contribuição oportuna.

A Josias Gonçalves Júnior, cujas informações de relevância indescritível tornaram possível o estudo. Pela benevolência e caráter lapidado.

A Juliane, pelo zelo, paciência, e profissionalismo.

A todo o corpo docente de engenharia de produção. 


\section{RESUMO}

Este estudo apresenta a utilização de recursos CAD e CAE como ferramentas de desenvolvimento de novos produtos com proposição ao aumento dos índices de confiabilidade. Para atingir esta meta buscou-se a implementação de um componente do sistema de conformação mecânica por injeção em uma indústria fabricante de chuveiros elétricos. A aplicação de ferramentas qualitativas detectou as falhas críticas do referido sistema e delimitou uma especificação de projeto para concepção de alternativa de solução. A análise por elementos finitos (FEA), permitiu a construção de um novo modelo de agulha para o molde de injeção em consonância às premissas estabelecidas. Decorrido o período da implantação e ajustes pertinentes coletou-se novas amostras da aplicação prática, cujo objetivo foi comparar aos resultados do sistema convencional. Os resultados consolidados corroboram para um aumento significativo dos critérios de desempenho observados, sobretudo no que concerne às funções taxa de falhas, MTTF, e confiabilidade, permitindo-se inferir que os recursos computacionais, constituem-se como alternativa insofismável para resolução dos problemas projetuais desta natureza.

Palavras Chave: Análise da confiabilidade; Tecnologia CAD/CAE; Análise por elementos finitos; Desenvolvimento de produto. 


\begin{abstract}
This study presents the use of resources CAD and CAE as tools of development of new products with proposition to the increase of the rates of reliability. To reach this aim researched the implementation of a component of the system mechanic conformation by injection in a factory industry of electrical showers. The application of qualitative tools detected the critical failures of the referred system and limited the specification of the project for the conception of alternative of solution. The Finite Elements Analysis (FEA) allowed the construction of a new model of needle for the mold of injection according to the establishment premises. When the time of implantation past and pertinent adjustment picket new samples of practical application, whose aim was to compare to the results of the conventional system. The consolidated results contribute for a meaning full increase of the criteria of the observed performance above all concerning the function of rate of failure, MTTF, and reliability, allowed inferring that the computational resources constitute as unambiguous alternative for solving of the projectual problems of this nature.
\end{abstract}

Keywords: Reliability analysis; Technology CAD / CAE, Finite elements analysis, Product development. 


\section{SUMÁRIO}

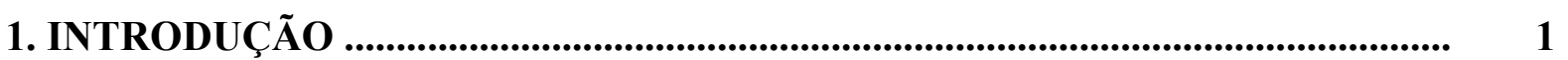

1.1 Justificativa e Relevância .................................................................................... 2

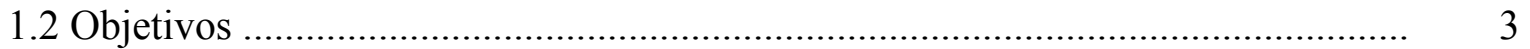

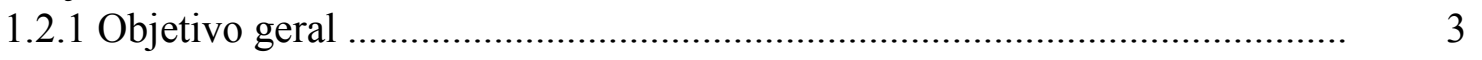

1.2.2 Objetivos específicos .................................................................... 3

2. FUNDAMENTAÇÃO TEÓRICA ……............................................................... 4

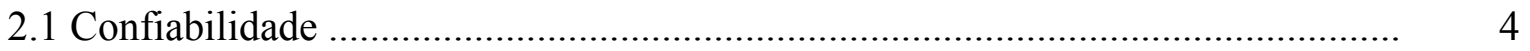

2.2 Sistemas Reparáveis e Não Reparáveis ............................................................. 5

2.3 Indicadores das Funções de Confiabilidade ........................................................ 6

2.4 Distribuições de Probabilidade em Confiabilidade ............................................... 8

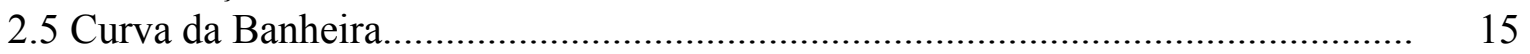

2.6 Análise de Falhas................................................................................... 16

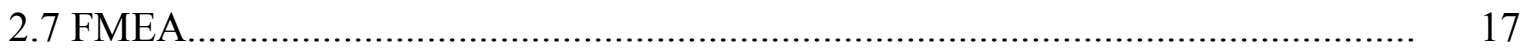

2.8 Tecnologia CAD/CAE .............................................................................. 17

2.9 Métodos de elementos finitos (FEA) ................................................................ 19

2.10 Falhas em Componentes Estruturais ................................................................ 21

2.11 Conformação Mecânica por Injeção Plástica....................................................... 23

2.12 Custo Relacionado à Manutenção ..................................................................... 28

3. PROPOSIÇÃO METODOLÓGICA PARA MODELAGEM DE DADOS ......... 30

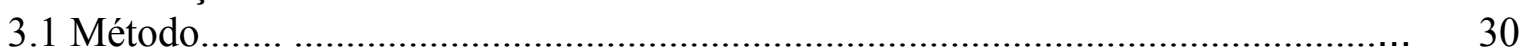

3.2 Tipo de Pesquisa ............................................................................... $\quad 30$

3.3 Estudo de Caso........................................................................................... 31

3.4 Gráfico de Pareto............................................................................................... 32

3.5 Problemas Ocorridos no Setor de Injeção Plástica .............................................. 32

3.6 Parâmetros para Utilização da FMEA ................................................................... 37

3.7 Plano de Aplicação da FEA e Análise dos Dados de Confiabilidade ................... 37

4. ANÁliSE DA CONFIABILIDADE, MODELAGEM E SIMULAÇÃo DO NOVO PRODUTO ....................................................................................................... 38

4.1 Processo para produção do produto espalhador ................................................. 38

4.2 Aplicação da FMEA ......................................................................................... 44

4.3 Dados operacionais de tempos até ocorrência de falha para agulha convencional 49

4.4 Ajustes de Distribuição de Probabilidade ao Modelo de Agulha Convencional ... 51

4.5 Modelagem e Simulação e Novo Produto ............................................................... 54

4.6 Dados operacionais de tempos até ocorrência de falha para o novo componente $\quad 66$

4.7 Ajustes de Distribuição de Probabilidade ao Novo Modelo de Agulha ................. 68

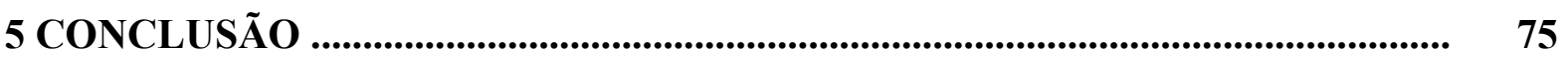


REFERÊNCIAS BIBLIOGRÁFICAS _........................................................... 77

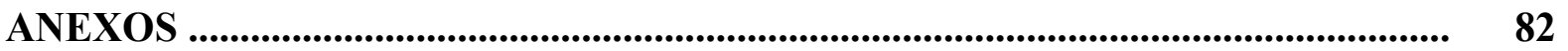

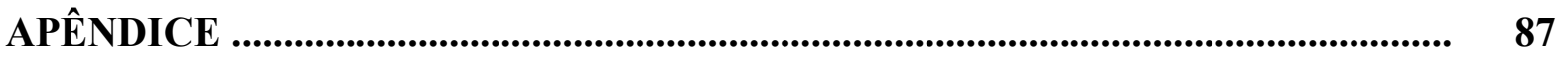




\section{LISTA DE FIGURAS}

Figura 2.1: Função de distribuição acumulada e densidade de probabilidade................. 7

Figura 2.2: Plotagem da função taxa de falhas de distribuição Normal ...........................

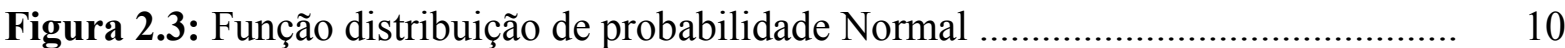

Figura 2.4: Distribuição de probabilidade acumulada Normal ...................................... 10

Figura 2.5: Função densidade de probabilidade e função acumulada Logonormal ........ 11

Figura 2.6: Função densidade de probabilidade e densidade acumulada Exponencial.... 12

Figura 2.7: Plotagem da confiabilidade em distribuição contínua exponencial .............. 13

Figura 2.8: Função densidade de probabilidade Weibull ................................................ 14

Figura 2.9: Plotagem da confiabilidade em distribuição Weibull .................................. 14

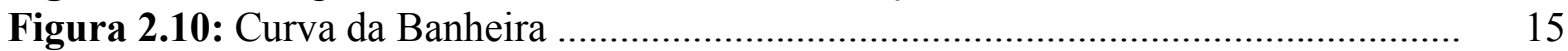

Figura 2.11: Variantes de modelo de Curva da Banheira para dispositivos específicos.. 16

Figura 2.12: Aplicação de malha em modelo CAD ........................................................ 20

Figura 2.13: Discretização e resultado FEA ….................................................................. 21

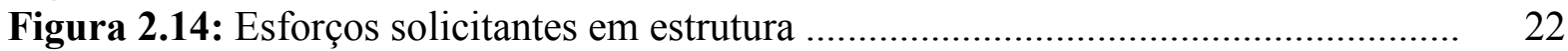

Figura 2.15: Diagrama de Tensão x Deformação para estrutura de aço ......................... 22

Figura 2.16: Fratura, ruptura e trincas nos materiais ..................................................... 23

Figura 2.17: Componentes do processo de conformação mecânica por injeção ............ 24

Figura 2.18: Composição de molde para processo de injeção plástica ........................... 26

Figura 3.1: Produto com agulha quebrada ............................................................... 36

Figura 4.1: Chuveiro modelo Mega Banho ................................................................ 38

Figura 4.2 Especificações técnicas do modelo mega banho - Vista Frontal ................... 39

Figura 4.3: Detalhe do furo do espalhador - Vista Latera ....1........................................ 39

Figura 4.4: Agulha, mavica, e conjunto montado ..................................................... 40

Figura 4.5: Disposição da sub-montagem agulha/mavica no molde fêmea ................... 40

Figura 4.6: Montagem do molde do espalhador à base (Parte fixa) ............................... 41

Figura 4.7: Parte fixa do molde disposta na máquina injetora ....................................... 41

Figura 4.8: Parte móvel do molde disposta na máquina injetora ................................. 42

Figura 4.9: Visão esquemática de comportamento de operação ...................................... 43

Figura 4.10: Quebra da agulha na extração do produto espalhador ............................. 43

Figura 4.11: Detecção de defeito em produto não conforme ......................................... 44

Figura 4.12: Extremidade da agulha rompida do corpo ................................................

Figura 4.13: Agulhas incrustadas no produto injetado ................................................ 45

Figura 4.14: Determinação de Modos Potenciais de Falha .......................................... 46

Figura 4.15: Relação entre Modos Potenciais de Falha, seus Efeitos, e Severidade ....... 47

Figura 4.16: Relação entre causas potenciais de falhas, ocorrências, detecção, e ações . 48

Figura 4.17: Papel de probabilidade Exponencial para operação do sistema de injeção. 51

Figura 4.18: Papel de probabilidade Weibull para operação do sistema de injeção ....... 52

Figura 4.19: Papel de probabilidade Normal para operação do sistema de injeção ........ 53

Figura 4.20: Papel de probabilidade Lognormal para operação do sistema de injeção .. $\quad 53$

Figura 4.21: Densidade acumulada de falha para distribuição Lognormal .................... 53

Figura 4.22: Densidade de probabilidade de falha para distribuição Lognormal ........... 52

Figura 4.23: Taxa de falha para distribuição Lognormal ............................................. 54

Figura 4.24: Confiabilidade para distribuição Lognormal ........................................... 54

Figura 4.25: Modelagem, aplicação de material e especificações técnicas da agulha Convencional

Figura 4.26: Pré-processamento - Aplicaçã

's de fixação

Figura 4.27: Aplicação de Carga - Pressãc 
Figura 4.28: Aplicação de Carga - Temperatura …....................................................... 57

Figura 4.29: Aplicação de Carga - Efeitos Térmicos ..................................................... 57

Figura 4.30: Características da aplicação de malha sólida em modelo convencional...... 58

Figura 4.31: Aplicação de Malha Sólida ..................................................................... 58

Figura 4.32: Plotagem da tensão de nós dos elementos .............................................. 59

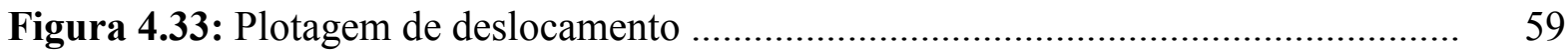

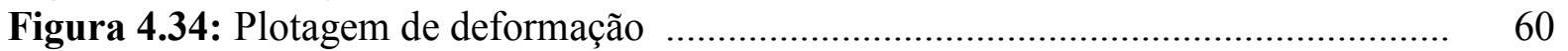

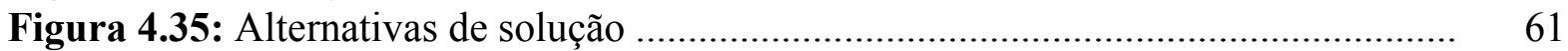

Figura 4.36: Aplicação de material - VND (DIN 1.2510) ............................................ 61

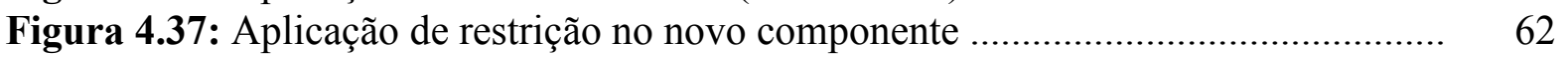

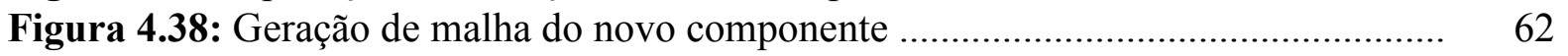

Figura 4.39: Detalhes da aplicação de malha sólida em novo componente .................... 63

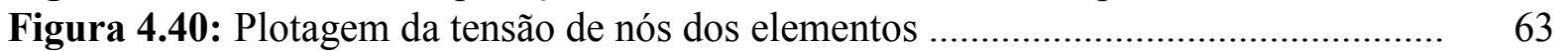

Figura 4.41: Recorte ISO da Plotagem de tensão na terminação do corpo da agulha ..... 64

Figura 4.42: Plotagem de deslocamento do novo componente ..................................... 64

Figura 4.43: Plotagem de deformação do novo componente .......................................... 65

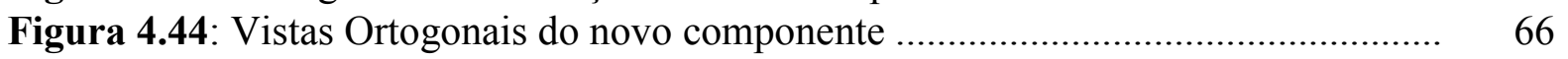

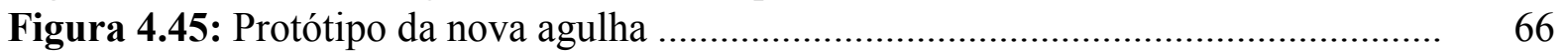

Figura 4.46: Papel de probabilidade exponencial para operação do sistema de injeção . $\quad 68$

Figura 4.47: Papel de probabilidade Normal para operação do sistema de injeção ........ 69

Figura 4.48: Papel de probabilidade lognormal para operação do sistema de injeção.... 69

Figura 4.49: Papel de probabilidade Weibull para operação do sistema de injeção ....... 70

Figura 4.50: Densidade acumulada de falha para distribuição Weibull .......................... 70

Figura 4.51: Densidade de probabilidade de falha para distribuição Weibull ................ $\quad 70$

Figura 4.52: Taxa de falha para distribuição Weibull ................................................... 71

Figura 4.53: Confiabilidade para distribuição Weibull .............................................. 71

Figura 4.54: Agulhas quebradas - Modelo Convencional x Modelo Novo..................... 71

Figura 4.55: Funções de Confiabilidade - Modelo Convencional x Modelo Novo ........ 72

Figura 4.56: Funções de Taxa de Falha - Modelo Convencional x Modelo Novo ........ 74

Figura 4.57: Comparação do número de falhas dos modelos convencional e novo ........ 74

Figura 7.1: Propriedades mecânicas Aço SAE 1045 ...................................................... 82

Figura 7.2: Propriedades do Aço VCO (Complemento) ................................................ 83

Figura 7.3: Propriedades do Aço VND ........................................................................ 84

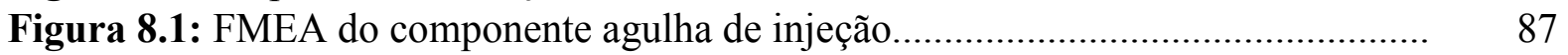




\section{LISTA DE TABELAS}

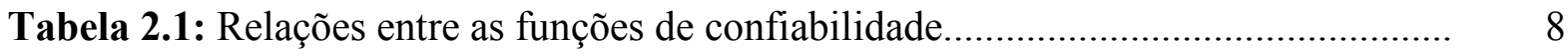

Tabela 2.2: Comportamento do parâmetro $\beta$ na distribuição Weibull............................... 13

Tabela 3.3: Custos de Manutenção ................................................................................. 35

Tabela 3.4: Tempo médio de reparo .................................................................... 35

Tabela 4.1: Levantamento de falhas por ocorrências e quantidade de agulhas quebradas no ano de 2011 - Modelo de Agulha Convencional ..................................... 50

Tabela 4.2: Propriedades do Aço 1045 ...................................................................... 55

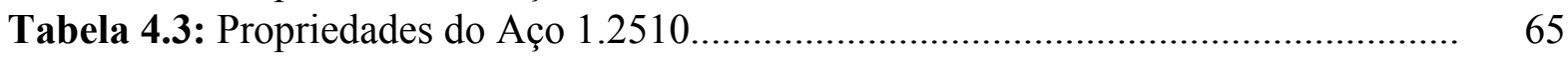

Tabela 4.4: Levantamento de falhas por ocorrências de agulhas quebradas - Modelo de

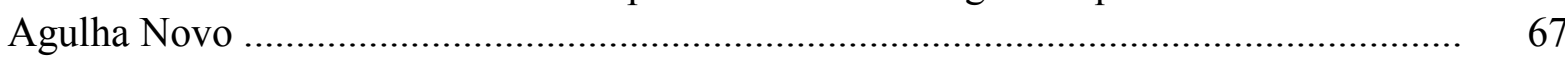

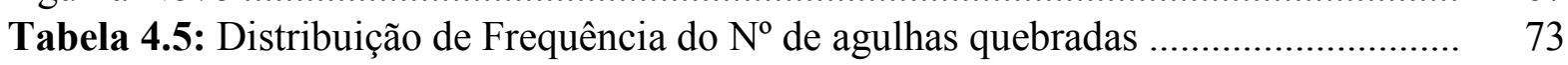

Tabela 4.6: Teste $\mathrm{T}$ de Student para igualdade de médias ............................................. 73 


\section{LISTA DE GRÁFICOS}

Gráfico 3.1: Ocorrências de parada de máquina ............................................................ 33

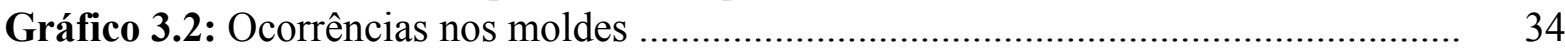

Gráfico 3.3: Quantitativos de ocorrências no molde espalhador ................................... 34

Gráfico 3.4: Custos referentes à manutenção do molde .............................................. 35 


\section{LISTA DE QUADROS}

Quadro 2.1: Características dos componentes do molde ............................................. 26

Quadro 2.2: Elementos e efeitos na liga de aço................................................................ 27

Quadro 7.1: Descrição da escala de severidade ............................................................. 82

Quadro 7.2: Descrição da escala de ocorrência .............................................................. 83

Quadro 7.3: Descrição da escala de deteç̧ão ................................................................. 83 


\section{LISTA DE ACRÔNIMOS}

CAE - Computer Aided Engineering - Engenharia Auxiliada por Computador

CAD - Computer Aided Design - Desenho Auxiliado por Computador

CAM - Computer Aided Manufacturing - Fabricação Assistida por Computador

CDF - Cumulative Distribution Function - Função de Distribuição Acumulada

DOF - Degree Of Freedom - Grau de Liberdade

DP - Desenvolvimento de Produtos

EDM - Electronic Document Management - Gerenciamento Eletrônico de Documentos

FE - Finite Element - Elemento Finito

FEA - Finite Element Analisys - Análise de Elementos Finitos

FMEA - Failure Mode and Effects Analisys - Análise de Modos e Efeitos de Falhas

FOM - Force Of Mortality - Força de Mortalidade

FOS - Factor Of Safety - Fator de Segurança

MTTF - Mean Time to Failure - Tempo Médio até Falha

MTBF - Mean Time Between Failures - Tempo Médio entre Falhas

PDF - Probability Density Function - Função Densidade de Probabilidade

PDM - Product Data Management - Gerenciamento de dados do produto

PDP - Processo de Desenvolvimento de Produtos

ROCOF - Rate of Occurence of Failure - Taxa de Ocorrência de Falha

RPN - Risk Priority Number - Grau de Prioridade de Risco

TTF - Time To Failure - Tempo até Falha 


\section{SIMBOLOGIA}

$R(t)$ - Função probabilidade de confiabilidade.

$n_{0}$ - Total de componentes iguais dispostos para testes.

$n_{f}$ - Total de componentes em que ocorreram falhas durante os testes.

$n_{s}-$ Total de componentes que resistiram aos testes.

$t$ - Total de componentes que resistiram aos testes.

$F(t)$ - Função de Distribuição Acumulada

$f(t)$ - Função Densidade de Probabilidade

$\lambda(t)$ - Taxa de Falha

$h(t)$ - Taxa de Risco

$\mu$ - Média

$\sigma^{2}-$ Variância

L(t) - Função de Vida Residual Média

$\alpha$ - Parâmetro de escala

$\eta$ - Parâmetro de posição

$\beta$ - Parâmetro de forma

$\sigma$ - Tensão Normal

$P$ - Forças

$A$ - Seção Transversal 


\section{INTRODUÇÃo}

Inerente ao atendimento às necessidades dos consumidores somam-se atributos que relacionam aspectos como a incorporação de inovação, reciclagem, e desenvolvimento sustentável, defronte aos paradigmas tradicionais de eficiência e lucratividade. Nesse ínterim a evolução tecnológica possibilitou a inserção de novas ferramentas ao sistema produtivo, como meio de atender as novas demandas, e consequente expansão da dimensão da qualidade, que abrange hoje como um dos fatores primordiais de competitividade, o controle de desgastes, para que se obtenha o pleno funcionamento dos sistemas (SAUNDERS, 2007).

O escopo do processo de desenvolvimento de produto expandiu-se nas últimas décadas incorporando o processo de produção (ROZENFELD, 2006). Inserida no contexto das atividades da fase de desenvolvimento a engenharia da confiabilidade atua como fator determinante na fase de preparação para a produção, pois as características de projeto de um determinado produto somente serão atendidas na medida em que matrizes, moldes, ferramentas e demais instrumentos de execução, traduzam as metas estabelecidas para o produto final (RICHTER, LOPES, 2004).

Como ferramenta de auxílio ao desenvolvimento de produtos, e desdobramentos que tangenciam os processos, a tecnologia Computer Aided Design - CAD surgiu na década de 70, e serviu como base para a plataforma Computer Aided Engineering - CAE. Com utilização bastante reduzida, uma vez que os custos de aquisição eram elevados, rara mão-de-obra especializada, poucos fabricantes e uma incipiente interface gráfica, os recursos somente difundiram-se de forma mais abrangente entre as décadas de 80 e 90 com a popularização da computação, da competitividade baseada no dilema confiabilidade x custo, e pela inserção destas ferramentas em diversos segmentos industriais (FIALHO, 2008; FILHO, 2008).

Atualmente, haja vista a reduzida curva de aprendizagem, e facilidade para representação e resolução de problemas projetuais, com desdobramentos que abrangem simulações e análises estáticas e dinâmicas, sua capacidade de interatividade nas diversas etapas de desenvolvimento de produto ainda é pouco explorada, e num período de franca evolução tecnológica, novas funcionalidades são incrementadas, integrando estes a sistemas Computer Aided Manufacturing - CAM, Electronic Document Management - EDM, Product Data Management - PDM, dentre outros. Constata-se que a cada dia concentra-se nos recursos tecnológicos o controle dos sistemas que geram produtos, em contrapartida à resistência de sua utilização, devida empiricamente, ao desconhecimento de suas potencialidades. 
Busca-se no estudo de caso desta pesquisa, através de uma metodologia de análise da confiabilidade estimar a vida em um sistema cujos índices críticos de falhas concentram-se em um componente do molde de injeção do processo de fabricação em uma indústria fabricante de chuveiros elétricos, para em seguida, com o suporte de tecnologia de projeto Auxiliado por Computador CAD, e engenharia auxiliada por computador - CAE, obter uma alternativa que produza um incremento na confiabilidade do processo. Comparar-se-á os dados pré e pós-intervenção através de modelagem e simulação computacional com o objetivo de comprovar cientificamente a plausibilidade de utilização do recurso proposto, verificandose ao final o impacto das modificações sobre os custos operacionais.

\subsection{Justificativa e Relevância}

Devido à globalização, o mercado tornou-se mais competitivo, em consequência as indústrias buscam melhorar seus produtos e processos de modo a reduzir o tempo de Processo de Desenvolvimento de Produto - PDP, os custos incorridos, e agregar mais valor aos produtos diminuindo as possibilidades de falhas. Em paralelo ao Desenvolvimento de Produto - DP desenvolvem-se as atividades de análise de viabilidade econômica, que contabiliza toda a espécie de recursos utilizados no processo e seus referentes custos. O quantitativo da incidência de falhas é, portanto um dos indexadores para o aumento dos custos de fabricação.

De acordo com o levantamento de informações obtidas sobre as ocorrências no processo de conformação mecânica por injeção plástica da Indústria Ducha Corona LTDA. detectou-se um excessivo número de paradas para manutenção corretiva devido às avarias ocorridas na produção de chuveiros elétricos. Pode-se inferir empiricamente que devido à alta taxa de falhas no sistema há o comprometimento da confiabilidade do processo, e como consequência destas avarias eleva-se substancialmente os custos de manutenção diminuindo a margem de lucratividade.

Pretende-se em decorrência deste cenário, utilizando os princípios da engenharia da confiabilidade, analisar a performance do sistema definindo, classificando e quantificando os seus modos de falhas, e desenvolver uma proposta de solução com o auxílio das tecnologias $\mathrm{CAD} / \mathrm{CAE}$ como mecanismos para redução dos custos operacionais na manutenção do sistema de produção de injeção da Indústria Ducha Corona, e desta forma demonstrar como este tipo de tecnologia pode corroborar para o aumento da confiabilidade no produto. 


\subsection{Objetivos}

\subsubsection{Objetivo geral}

Desenvolver a análise da confiabilidade de componente do processo de conformação mecânica por injeção na fabricação de um chuveiro elétrico, e propor alternativa de redução de falhas utilizando os recursos de tecnologia CAD/CAE.

\subsubsection{Objetivos específicos}

Coletar e analisar os dados referentes ao processo de injeção do componente denominado espalhador;

Identificar, classificar e quantificar os itens críticos no desenvolvimento do processo produtivo;

Modelar e simular alternativas de solução empregando tecnologia CAD/CAE;

Promover melhoria na produtividade em decorrência da redução dos quantitativos de falhas;

Comparar a confiabilidade no sistema antes e pós intervenção. 


\section{FUNDAMENTAÇ̃̃o TEÓRICA}

Neste capítulo serão apresentadas as bases teóricas com as definições fundamentais utilizadas para o cumprimento do objetivo desta pesquisa. Os temas abordados referem-se a: confiabilidade, análise de falhas, conformação mecânica por injeção, e análise por elementos finitos.

\subsection{Confiabilidade}

Há uma grande diversidade de conceitos para a confiabilidade, mas para a importância relativa à qualidade o termo relaciona na engenharia as variáveis tempo e falhas para o cumprimento de uma norma. Hamada (2008), apud (ISO, 1986), confere ao termo "a capacidade de um item para desempenhar uma função necessária, em determinadas condições ambientais e operacionais e por um determinado período do tempo".

Poder-se-ia ainda definir informalmente a confiabilidade como a probabilidade de que um produto mantenha sua capacidade de funcionamento ao longo do tempo. Piazza (2000), corrobora para o conceito acrescentando que "numa operação o sistema apresentará uma performance desejada para um intervalo de tempo especificado", e McPherson (2010) chama a atenção para o fato de que aos materiais são atribuídas diversas formas de degradação, que relacionam-se ao cenário a que é submetido, porquanto o dilema da confiabilidade está em discernir por quanto tempo espera-se para um dispositivo/produto funcionar plenamente.

Almeida e Campelo (2001, p.19) inferem que o não funcionamento do equipamento, sistema ou instalação implica em falha. Essa falha tem origem quando a missão a qual se destina o item não pode ser executada sendo classificada em função dos seus efeitos (sistêmicos, parcial), origem (configuração, composição material) e causa (operação indevida, fora de condições operacionais, anormalidade de fabricação). Entre os autores há um consenso entre as relações de probabilidade, tempo e condições para avaliação do que alguns denominam capacidade, performance, desempenho, e outros, falhas, o que remete à condição de avaliação quantitativa de um sistema, uma medida de grandeza, expressa conforme Piazza (2000) apud Elsayed, pela função probabilística de confiabilidade:

$$
R(t)=\frac{n_{s}(t)}{n_{s}(t)+n_{f}(t)}=\frac{n_{s}(t)}{n_{0}}
$$

Em que: 


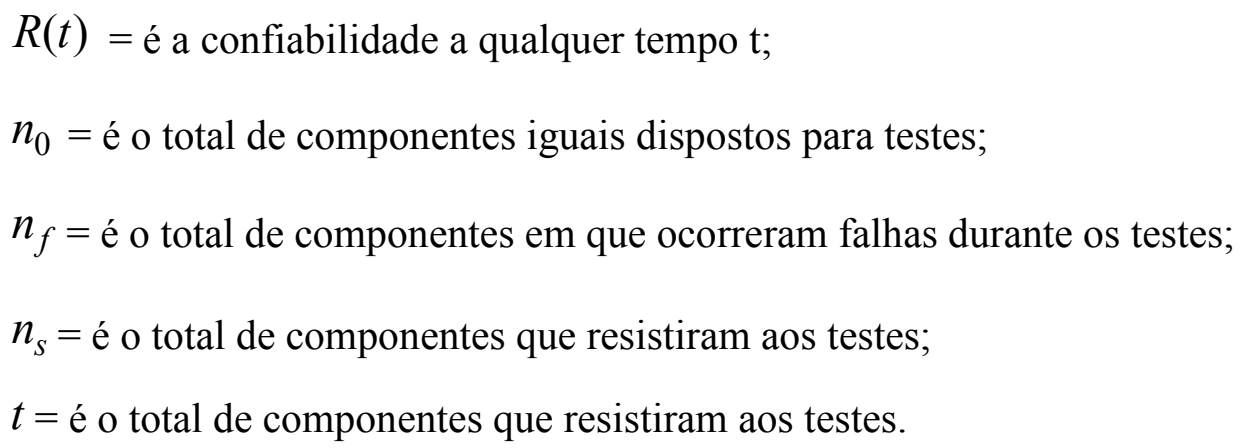

\subsection{Sistemas Reparáveis e Não Reparáveis}

A utilização de indicadores para medição da confiabilidade requer uma definição do objeto de estudo em termos de sistemas, nesse contexto convencionou-se a classificação em dois grupos caracterizados pela condição de um ou mais itens após ocorrência de uma falha:

Sistemas Reparáveis - Saunders (2007, p 273), cita que após uma falha no sistema, haverá interrupção do serviço, e a parada deve ocorrer para que haja manutenção, ou reparo. Piazza (2000), corrorobora com a definição, e complementa ressaltando a caracterização do sistema através de índices concernentes à taxa de falha, taxa de ocorrência de falha (Rate of Occurence of Failure - ROCOF), e pelo tempo médio entre falhas (Mean Time Between Failures - MTBF). Droguett (2011), assevera que, consideram-se como componentes reparáveis, aqueles que, excetuando-se a substituição, nas demais ações de restauração de uma operação, recondiciona-se um sistema à plena disponibilidade, retornando este ao desempenho de suas funcionalidades.

Sistemas Não Reparáveis - Nesse tipo de sistema, de acordo com Droguett (2011, p2), confere-se as seguintes características após a ocorrência de uma falha:

- O componente deverá ser descartado, pois não desempenha satisfatoriamente a função a qual está destinado;

- O componente deverá ser substituído. Não havendo a possibilidade deste vir a ser reparado, necessitar-se-á de uma peça nova;

Confere-se a este o sistema adequado aos objetivos do estudo de caso em voga, uma vez que a ocorrência de falhas no molde de injeção danificam as agulhas de modo que são necessárias paradas para sua troca, e tornam-se inutilizáveis.

\subsection{Indicadores das Funções de Confiabilidade}


Para os componentes Não Reparáveis a confiabilidade é medida através de indicadores como a função densidade de probabilidade (Probability Density Function - PDF), função de densidade acumulada (Cumulative Distribution Function - CDF), taxa de falha (Número de falhas por unidade de tempo), estimados através do levantamento de dados de falhas.

A Função de Distribuição Acumulada (CDF), refere-se ao somatório das ocorrências de falhas, ou ainda à quantidade de componentes que falharam sobre o número de componentes submetidos a teste durante um determinado período em que desempenha a sua função, a qual denota-se por (RAUSAND, HOYLAND, 2004; DROGUETT 2011, PIAZZA, 2000 apud ELSAYED, 1992):

$$
\begin{aligned}
& R(t)+F(t)=1 \\
& F(t)=1-R(t)
\end{aligned}
$$

Por conseguinte:

$$
F(t)=P(T \leq t)=\int_{0}^{t} f(t) d t \quad \text { para } t>0
$$

A Função Densidade de Probabilidade (PDF), é uma forma de representação dos dados históricos de falha a partir da distribuição de probabilidade que demonstre maior compatibilidade com o tipo de caso, possibilitando assim a medição e prevenção de falhas. Droguett (2011), a conceitua como "a representação visual da distribuição do tempo de falha", ou seja, como estas estão distribuidas ao longo do tempo. O termo "visual" deve-se portanto ao fato de possibilitar-se através da $\mathrm{f}(\mathrm{t})$ um mapeamento das falhas, a qual representa-se matematicamente associada à função acumulada (quando diferenciável) pela equação (PIAZZA, 2000 apud ELSAYED, 1992):

$$
f(t)=\frac{d F(t)}{d t}=-\frac{d R(t)}{d t} \text { parat }>0
$$

Assim:

$$
R(t)=1-F(t)=1-\int_{0}^{t} f(u) d u=\int_{t}^{\infty} f(t) d u
$$

A figura 2.1 demonstra a representação gráfica das funções, acumulada $F(t)$ e densidade de probabilidade $\mathrm{f}(\mathrm{t})$ : 


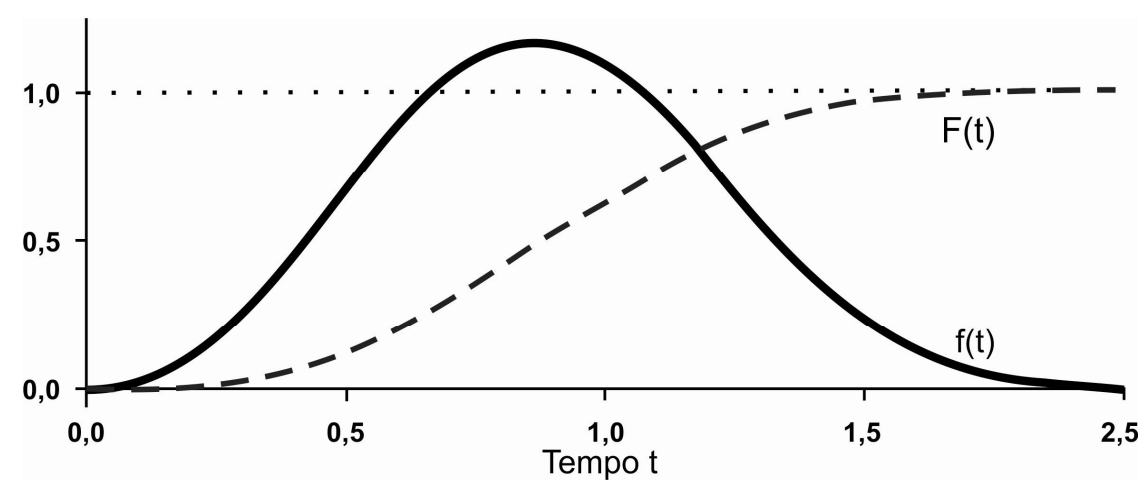

Figura 2.1: Função de distribuição acumulada e densidade de probabilidade Fonte: RAUSAND, HOYLAND, 2004

A Taxa de Falha (Force of Mortality - FOM), refere-se à propensão à ocorrência de falha em um único componente após este ter decorrido o tempot. Sob a forma de probabilidade, associa-se instantaneamente as funções de densidade (PDF), e de confiabilidade (R). Assim a função de risco é descrita (MURTHY, RAUSAND, OSTERAS, 2008; DIAS, 2011; DROGUETT, 2011; PIAZZA, 2000 apud ELSAYED, 1992):

$$
h(t)=\frac{f(t)}{R(t)}
$$

Fogliatto e Ribeiro (2009), apresentam a Tabela 2.1, proposta por Leemis (1995), em que as funções $\mathrm{F}(\mathrm{t}), \mathrm{f}(\mathrm{t}), \mathrm{R}(\mathrm{t})$, e $\mathrm{h}(\mathrm{t})$, estão relacionadas, e as estimativas podem ser determinadas para este estudo de caso a partir do histórico de ocorrências de falhas obtendose a distribuição do tempo de vida do componente. Há diversas situações em que a confiabilidade é medida sob a ausência de dados estatísticos, nestes casos utiliza-se metodologia e ferramentas específicas.

Tabela 2.1: Relações entre as funções de confiabilidade

\begin{tabular}{|l|l|l|l|l|}
\hline & $\mathbf{f}(\mathbf{t})$ & $\mathbf{R}(\mathbf{t})$ & $\mathbf{h}(\mathbf{t})$ & $\mathbf{H}(\mathbf{t})$ \\
\hline
\end{tabular}




\begin{tabular}{|c|c|c|c|c|}
\hline $\mathbf{f}(\mathbf{t})$ & . & $\int_{t}^{\infty} u f(u) d u$ & $f(t) / \int_{t}^{\infty} f(u) d u$ & $-\ln \left[\int_{t}^{\infty} f(u) d u\right.$ \\
\hline$R(t)$ & $-R^{\prime}(t)$ & & $\frac{-R^{\prime}(t)}{R(t)}$ & $-\ln R(t)$ \\
\hline$h(t)$ & $h(t) e^{-\int_{0}^{t} h(u) d u}$ & $e^{-\int_{0}^{t} h(u) d u}$ & . & $\int_{0}^{t} h(u) d u$ \\
\hline $\mathbf{H}(\mathbf{t})$ & $H^{\prime}(t) \cdot e^{-H(t)}$ & $e^{-H(t)}$ & $H^{\prime}(t)$ & \\
\hline $\mathbf{L}(\mathbf{t})$ & $\frac{1+L^{\prime}(t)}{L(t)} e^{-\int_{0}^{t 1+L^{\prime}(u)} \frac{L^{\prime}(u)}{d u}}$ & $e^{-\int_{0}^{t} \frac{1+L^{\prime}(u)}{L(u)} d u}$ & $\frac{1+L^{\prime}(t)}{L(t)}$ & $\int_{0}^{t} \frac{1+L^{\prime}(u)}{L(u)} d u$ \\
\hline
\end{tabular}

Fonte: Fogliatto e Ribeiro (2009), originalmente proposta por Leemis (1995).

\subsection{Distribuições de Probabilidade em Confiabilidade}

Para aplicabilidade da análise dos dados de confiabilidade deve-se adotar um modelo de distribuição de probabilidade compatível às características do sistema. Os valores de ocorrência de falhas em um componente podem comportar-se como variáveis aleatórias discretas ou contínuas. As variáveis discretas são caracterizadas pela necessidade de determinação da probabilidade de um valor específico de resultados que podem ocorrer, e em sua saída os quantitativos específicos são em muitos casos números inteiros. Nesses sistemas as distribuições de probabilidade mais utilizadas são as de Bernoulli, Binomial, e a Poisson. (PIAZZA, 2000; DIAS 2011; LEWIS, 1994).

De acordo com Piazza (2000), as variáveis contínuas caracterizam-se pela propriedade que tem em assumir quaisquer valores em uma escala contínua, que especificamente para este estudo de caso é o tempo. A literatura aponta uma grande quantidade de distribuições utilizadas para sua representação, porém as mais utilizadas são a Normal ou Gaussiana, Logonormal, Exponencial, e a Weibull.

\section{Distribuição Normal ou Gaussiana}

Para McPherson (2010), e Dias (2011), a distribuição normal é utilizada principalmente como recurso de produção, no controle estatístico da qualidade. Sua função taxa de falhas é parametrizada por $\mu$, que é a média, e $\sigma^{2}$ que é a variância, expressa por: 


$$
h(t)=\frac{\phi\left(\frac{t-\mu}{\sigma}\right)}{\sigma R(t)}
$$

Devido às suas propriedades, a representação da distribuição normal é simétrica, assim, esta não é compatível com a maior parte das distribuições de falhas de componentes ou sistemas. Neste caso sua aplicação dá-se com maior ênfase à representação do comportamento de desgaste, em geral, o final do ciclo de vida de equipamentos (Etapa III da Curva da Banheira). A figura 2.2, representa graficamente a função taxa de falhas (DROGUETT, 2011; DIAS, 2011; ALMEIDA e CAMPELO, 2001):

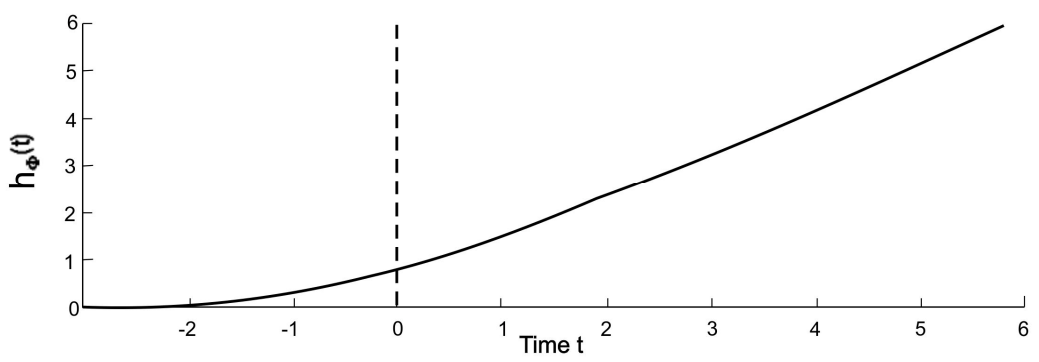

Figura 2.2: Plotagem da função taxa de falhas de distribuição Normal Fonte: RAUSAND, HOYLAND p42 (2004)

A função de distribuição será Normal quando expressa pela equação (GNEDENKO, USHAKOV, 1995):

$$
f(t)=\frac{1}{\sigma \sqrt{2 \pi}} \exp \left\{-\frac{1}{2}\left[\frac{t-\mu}{\sigma}\right]^{2}\right\} \quad \text { para: }-\infty<t<\infty,-\infty<\mu<\infty, \sigma>0
$$

A figura 2.3, demonstra a representação da distribuição Normal à simetria parametrizada pela média, e amplitude em decorrência da variância (BAUER, ZHANG, KIMBER, 2009): 


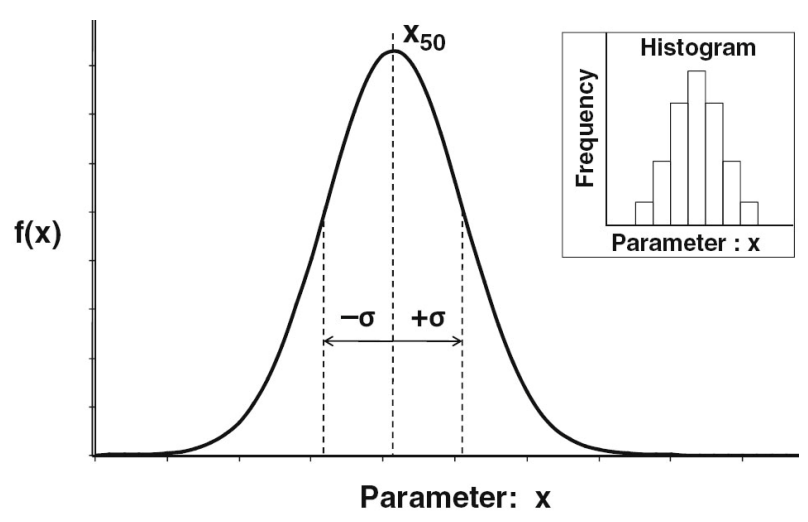

Figura 2.3: Função distribuição de probabilidade Normal

Fonte: McPherson (2010)

A função acumulada, como demonstrada na figura 2.4, é dada por (LEWIS, 1994):

$$
F(t) \equiv \Phi[(t-\mu) / \sigma] \quad \text { para }-\infty<t<\infty
$$

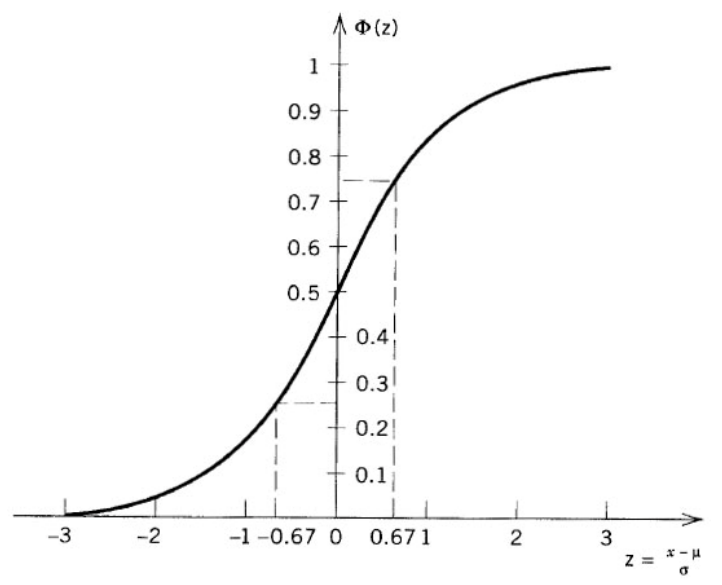

Figura 2.4: Distribuição de probabilidade acumulada Normal

Fonte: Lewis (1994)

A Confiabilidade de uma distribuição de probabilidade Normal é dada por:

$$
R(t)=1-\Phi\left(\frac{t-\mu}{\sigma}\right)
$$

\section{Distribuição Logonormal}

Este tipo de distribuição é comumente empregado para representar a fase de desgaste da Curva da Banheira (demonstrada na subseção 2.5), ainda que se possa utilizá-la para representação de qualquer uma das etapas. McPherson (2010), chama a atenção para o fato da representação das falhas ter uma distribuição logarítmica com relação ao tempo, bem como a vasta utilização em mecanismos cuja degradação expõe-se substancialmente relacionada à fadiga e corrosão, e sua Taxa de Falhas é expressa por: 


$$
h(t)=\frac{\phi\left(\frac{\operatorname{Ln}(t)-\mu}{\sigma}\right)}{\sigma R(t)}
$$

Semelhante à Normal, utiliza-se nesta distribuição dois parâmetros, um de escala, $\mu$ que é a média, e um de forma, $\sigma^{2}$ que refere-se à variância do logaritmo natural do tempo de falha. Sua densidade de probabilidade e função acumulada é definida de acordo com Saunders (2007), através das equações:

$$
\begin{gathered}
f(t)=\frac{1}{\sqrt{2 \pi} \sigma t} \exp \left[-\frac{1}{2}\left(\frac{\operatorname{Ln}(t)-\mu}{\sigma}\right)^{2}\right] \\
F(t) \equiv \Phi\left(\frac{\operatorname{Ln}(t)-\mu}{\sigma}\right)
\end{gathered}
$$

A figura 2.5, demonstra graficamente o comportamento da FDP e CDA Logonormal:
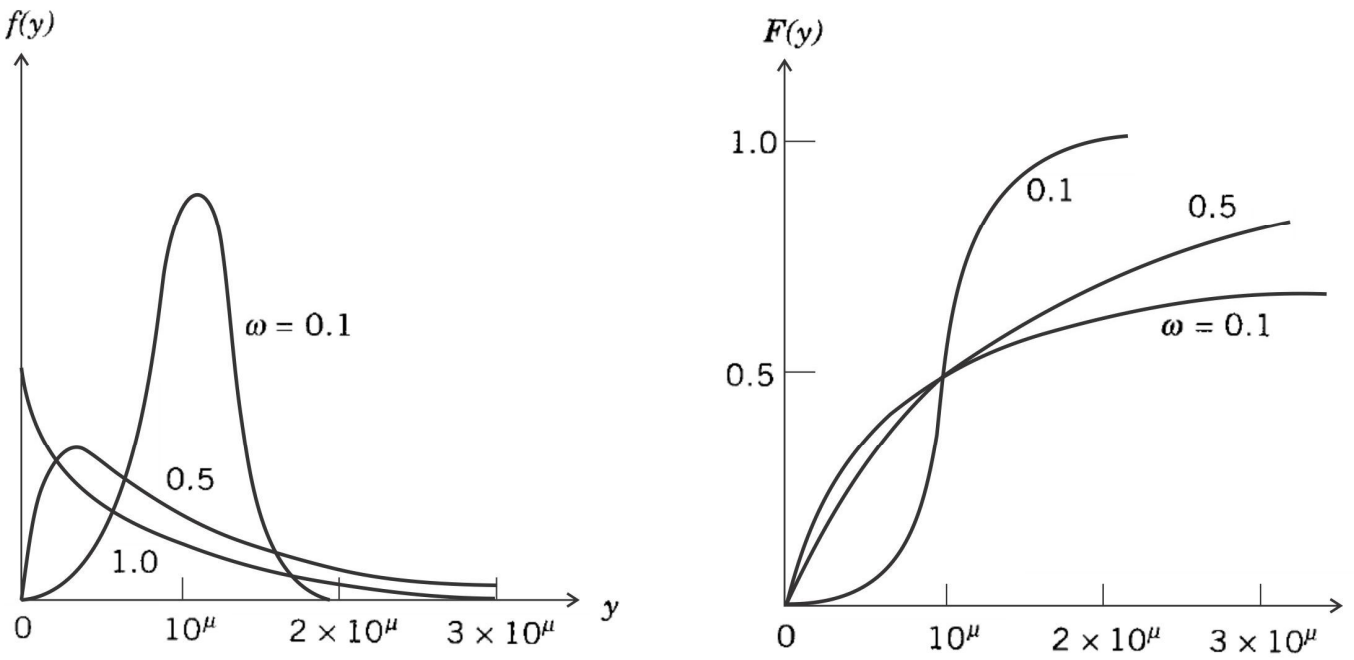

Figura 2.5: Função densidade de probabilidade e função acumulada Logonormal Fonte: LEWIS, p55 (1994)

E a expressão para cálculo da Confiabilidade é dada por:

$$
R(t)=1-\Phi\left(\frac{\operatorname{Ln}(t)-\mu}{\sigma}\right)
$$

\section{Distribuição Exponencial}


De acordo com Lewis (1994) e Nelson (1983), a distribuição exponencial caracteriza um dispositivo cuja Taxa de Falhas é constante, ou seja, a distribuição dos tempos de falha independe do seu ciclo de vida, expressa matematicamente por:

$$
h(t)=\lambda \quad \text { para } \lambda>0, t \geq 0
$$

Desta forma Dias (2011), enfatiza a sua utilização para representação da etapa intermediária (fase II da Curva da Banheira). Gnedenko e Ushakov (1995), mencionam a facilidade de utilização deste tipo de distribuição, tornando-a de uso mais comum em estudos de confiabilidade, e Droguett (2011), referenda o cálculo simples devido a utilização de um único parâmetro.

Uma Função Densidade de Probabilidade de distribuição exponencial pode ser descrita na forma:

$$
f(t)=\lambda e^{-\lambda t}
$$

De acordo com a equação (2.4), tem-se que a função acumulada é definida por:

$$
F(t)=1-e^{-\lambda t}
$$

A figura 2.6, representa graficamente a plotagem da PDF e CDA de uma distribuição de probabilidade exponencial:

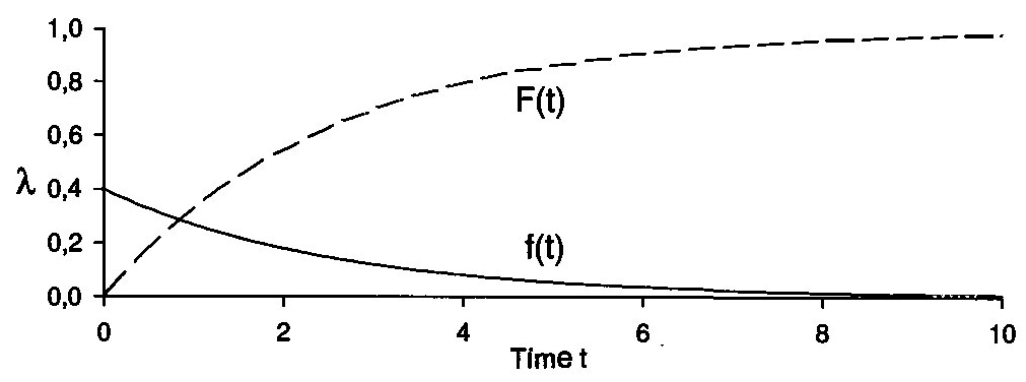

Figura 2.6: Função densidade de probabilidade e densidade acumulada Exponencial Fonte: RAUSAND, HOYLAND (2004)

Desse modo a confiabilidade, ou probabilidade de não ocorrência de falhas antes do tempo $t$ é expressa por:

$$
R(t)=e^{-\lambda t}
$$

Piazza (2000), enfatiza as causas aleatórias que regem este tipo de padrão de falhas, e a imprevisibilidade sugere a independência de resultados relativos ao tempo de processo, descartando-se assim o efeito de desgaste sobre o sistema/componente. A figura 2.7, exemplifica a plotagem de confiabilidade para valores distintos de taxas de falha: 


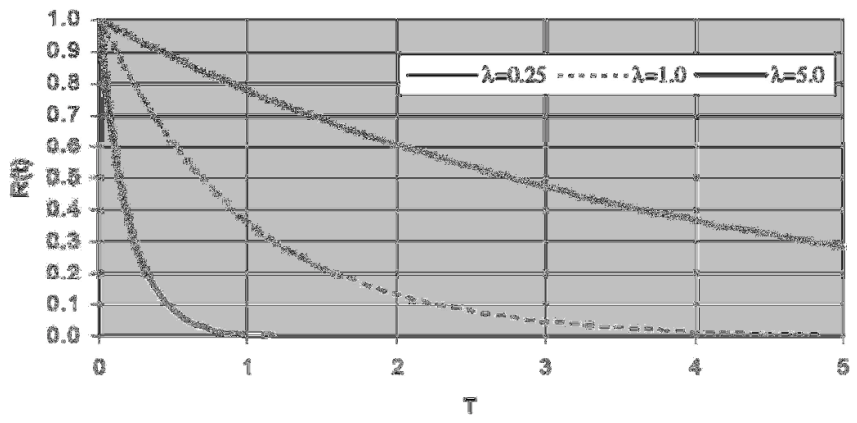

Figura 2.7: Plotagem da confiabilidade em distribuição contínua exponencial

\section{Distribuição Weibull}

Fonte: DROGUETT, p24 (2011)

A distribuição de probabilidade Weibull é considerada como a melhor representação para dispositivos providos por vários componentes, uma vez que pode-se caracterizar as três fases da curva da banheira utilizando-se de valores diferentes de parâmetro de forma, descrevendo a partir desse modelo taxas de falhas constantes, decrescentes e crescentes, expressas biparametricamente ou triparametricamente por (Piazza, 2000; Dias, 2011; Droguett, 2011):

$$
h(t)=\frac{\beta}{\alpha}\left(\frac{t}{\alpha}\right)^{\beta-1} \quad \text { para } \quad \alpha, \beta>0, t \geq 0
$$

Em que $\alpha$ é o parâmetro de escala, $\eta$ é o parâmetro de posição, e $\beta$, o principal parâmetro de suporte às decisões de projeto, e que define a "aparência" da distribuição dada as relações apresentadas na tabela 2.2.

Tabela 2.2: Comportamento do parâmetro $\beta$ na distribuição Weibull

\begin{tabular}{|c|l|l|}
\hline Valor & \multicolumn{1}{|c|}{ Propriedade } & \multicolumn{1}{c|}{ Característica } \\
\hline $0<\beta<1$ & $\mathrm{~h}(\mathrm{t})$ é decrescente & Parte Inicial do CVP \\
\hline$\beta=1$ & $\mathrm{~h}(\mathrm{t})$ é constante (Exponencial) & Fase de Vida Útil \\
\hline $1<\beta<2$ & $\begin{array}{l}\mathrm{h}(\mathrm{t}) \text { é crescente (praticamente } \\
\text { constante) e côncava (Logonormal) }\end{array}$ & $\begin{array}{l}\text { Rápido aumento da FDP para } \\
\text { curto período de vida. }\end{array}$ \\
\hline$\beta=2$ & $\mathrm{~h}(\mathrm{t})$ é crescente e linear (Rayleigh) & $\begin{array}{l}\text { Processo de envelhecimento } \\
\text { com aumento de falha. }\end{array}$ \\
\hline$\beta>2$ & $\mathrm{~h}(\mathrm{t})$ é crescente e convexa & $\begin{array}{l}\text { Processo de envelhecimento } \\
\text { com aumento de falha. }\end{array}$ \\
\hline $3 \leq \beta \leq 4$ & $\begin{array}{l}\mathrm{h}(\mathrm{t}) \text { é crescente e aproximadamente } \\
\text { simétrica (Normal) }\end{array}$ & $\begin{array}{l}\text { Tendência de concentração dos } \\
\text { pontos próximos a uma reta } \\
\text { paralela ao eixo das ordenadas. }\end{array}$ \\
\hline
\end{tabular}

Fonte: Adaptado de Droguett (2010) e Dias (2011).

As distribuições, Normal, Rayleight e Exponencial são casos aproximados de distribuição Weibull, que é utilizada frequentemente em situações de corrosão e desgaste de 
componentes e sistemas, daí resulta a sua vasta utilização em modelagem de confiabilidade, cuja Função Densidade de Probabilidade é expressa por:

$$
f(t)=\frac{\alpha}{\beta}\left(\frac{t}{\alpha}\right)^{\beta-1} e^{-(t / \alpha)^{\beta}}
$$

Representada na figura 2.8 com diversos valores de parâmetro de escala:

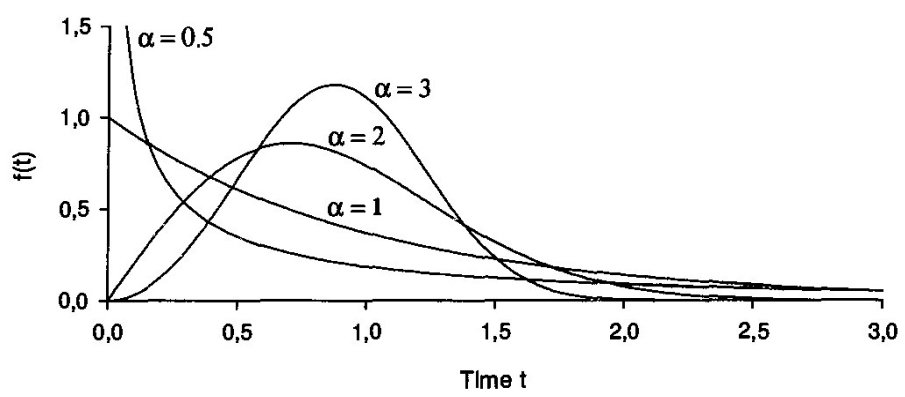

Figura 2.8: Função densidade de probabilidade Weibull

Fonte: RAUSAND, HOYLAND (2004)

De acordo com a equação (2.4), tem-se que a função acumulada de distribuição Weibull é definida por:

$$
F(t)=1-e^{-(t / \alpha)^{\beta}}
$$

E a função de Confiabilidade:

$$
R(t)=e^{-(t / \alpha)^{\beta}}
$$

A figura 2.9 mostra plotagem da função confiabilidade com vários parâmetros de forma e único parâmetro de escala.

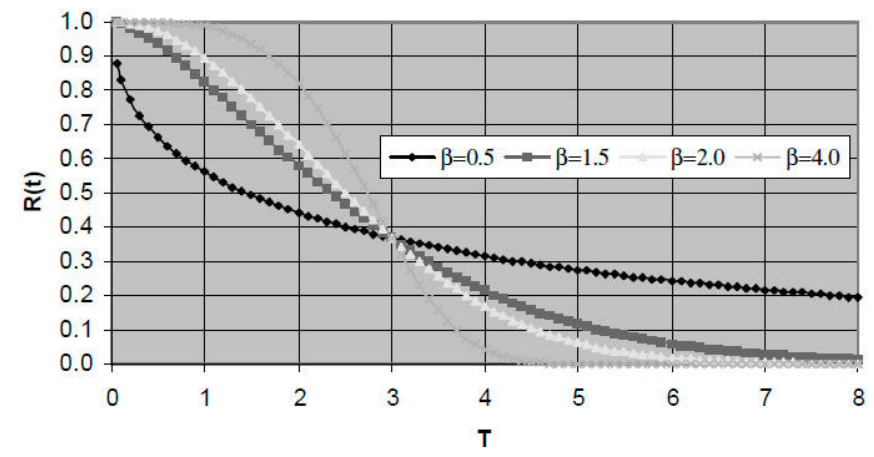

Figura 2.9: Plotagem da confiabilidade em distribuição Weibull

Fonte: DROGUETT, p34 (2010)

\subsection{Curva da Banheira}


De acordo com Almeida e Campelo (2001), tem-se a terminologia Curva da Banheira designada para a representação gráfica da Taxa de Falhas, $\lambda(\mathrm{t})$, em função do tempo devido à semelhança no formato. Droguett (2011), descreve três tipos distintos para a taxa de falhas, para descrever o ciclo de vida de um produto, quais sejam: Crescente, constante, e decrescente. Cada tipo de falha corresponde a uma fase da curva da banheira, demonstradas na figura 2.10 .

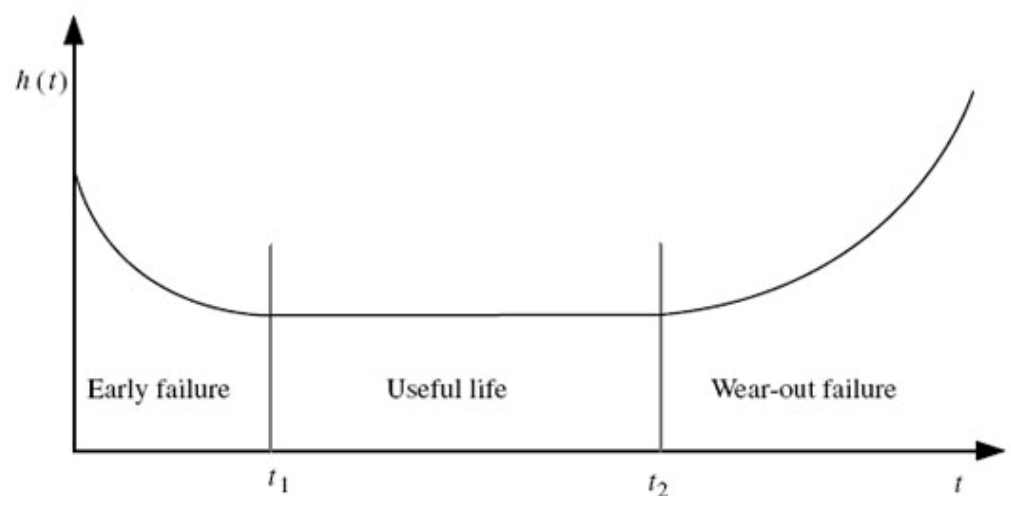

Figura 2.10: Curva da Banheira

Fonte: Kuo e Zuo, pg. 34 (2003)

Kuo e Zuo, 2003, caracterizam a primeira etapa como uma fase curta, com falhas prematuras (early failure), e as causas para ocorrências de falhas, e alta "mortalidade infantil”, corroboram Levin e Kalal (2003), são relativas principalmente a variações no processo de fabricação, que podem ser identificados através de técnicas de burn-in, e erros no projeto.

Ireson (1995), e Droguett (2011), citam que a fase II, é caracterizada por falhas com o comportamento aproximadamente constante, com aleatoriedade temporal, e as causas das falhas referem-se a sobrecargas a que é submetido o sistema/componente (overstress), e não obstante à combinação de fatores aleatórios gerados no ambiente a que estes estão submetidos. É também chamada de fase de Vida Útil do produto (usefull life).

Por fim, na fase III, tem-se o período em que a taxa de falhas é crescente, caracterizada pelo envelhecimento e desgaste (Wear-out failure) irreversível do sistema/componente. As causas mais comuns para o aumento do número de falhas residem em fatores como a corrosão, fadiga, e fricção, e a deterioração implicam numa ação de substituição (IRESON, 1995; ALMEIDA E CAMPELO, 2001; LEVIN E KALAL, 2003; KUO E ZUO, 2003; DROGUETT, 2010).

Ressalta-se ainda que o "comportamento" da Curva da Banheira é diversificado, conforme a natureza do produto. A figura 2.11, ilustra as variações de forma que podem ser 
obtidas a partir de dispositivos cuja aplicabilidade dá-se sob ambientes, formas de funcionamento, e materiais diferentes. Os dispositivos mecânicos, típicos para este estudo de caso, têm notadamente um período de vida que pode ser prolongado através de estratégias específicas para a fase III (KUO e ZUO, 2003).

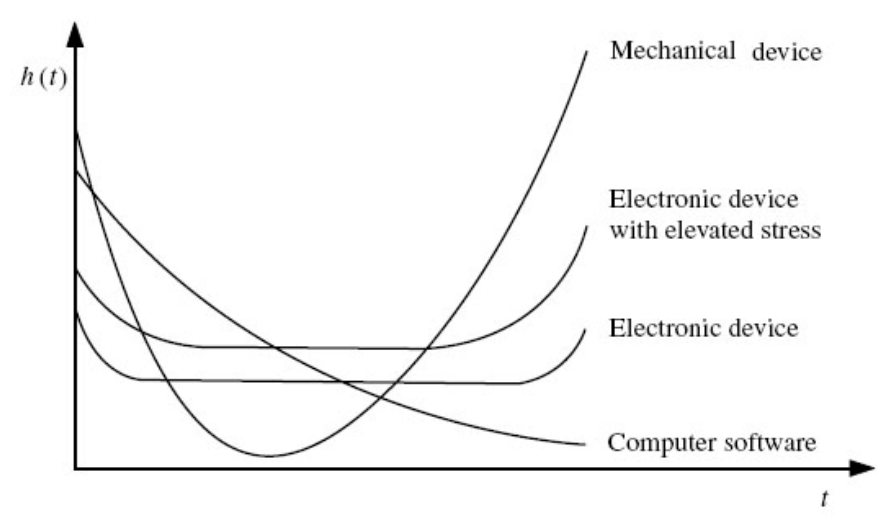

Figura 2.11: Variantes de modelo de Curva da Banheira para dispositivos específicos Fonte: Kuo e Zuo, pg. 35 (2003)

\subsection{Análise de Falhas}

De acordo com Scapin (1999), considera-se "componente" a unidade básica de um sistema, que pode variar de quantidade haja vista o sistema que se está avaliando, e o modo de falha está associado à probabilidade deste componente vir a falhar, ou seja, deixar de realizar a atividade. Ressalta-se para o autor diferenças significativas entre defeitos e falhas, uma vez que este interrompe as funções do sistema enquanto aquele "não atende a uma especificação técnica mensurável".

Saunders (2010), infere que a origem das falhas dá-se por razões diversas, em que muitas vezes esses fatores são coincidentes, e alcançam desde a negligência a aspectos contundentes nas definições dos requisitos dos projetos, até o comprometimento do operador do sistema que atua de forma ineficaz na construção ou inspeção dos inputs ou outputs, referindo-se a distúrbios no controle de materiais provenientes de fornecedores, constatandose que as deficiências inerentes a um componente podem refletir em imperfeições e consequente falha prematura e inesperada do sistema, redundando-se na incapacidade deste na execução de suas funções durante o tempo permíssível de vida.

$\mathrm{O}$ autor ainda destaca como principal fonte de fracasso dos sistemas a "diminuição gradual da autonomia dos componentes estruturais, causada pela repetição de seu ciclo de trabalho projetado”. Nesta visão incluam-se aspectos mecânicos clássicos dos quais cita-se a 
fricção ou desgaste, fadiga metálica, stress, corrosão ou degradação química. Neste contexto Scapin (1999), pressupõe que para a análise da confiabilidade, sendo esta a probabilidade de um sistema funcionar de acordo com as especificações, definí-la em função da existência de falhas, e porquanto baseada em modelos estatísticos de análises de sucesso/fracasso.

\subsection{FMEA}

A FMEA (Failure Mode and Effects Analysis), ou Análise dos Modos de Falha e Efeitos, é um método utilizado para previsão de falhas que preceitua-se na eliminação de problemas antes que estes possam vir a ocorrer em um produto, aplicando-se durante o plano, no processo de fabricação, ou no próprio produto, e seu processo analítico é formalmente documentado, permitindo que um perfil de estado das falhas estejam registradas, dessa forma promovendo a melhoria contínua (PALADY, 1997; HELMAN e ANDERY, 1995).

A equipe de FMEA deve ser composta por pessoas que detenham o conhecimento das áreas envolvidas, o que auxilia na análise das falhas mais graves ou com ocorrência mais frequente. Os membros devem discutir sobre aspectos como a severidade da falha para que haja um índice de consenso do grupo. A responsabilidade pela aplicação da ferramenta é atribuída a um indivíduo, no entanto seu desenvolvimento é o resultado dos esforços da equipe (PALADY, 1997).

Para o preenchimento do formulário Scapin (2007), recomenda a priorização das falhas baseando-se nos índices de ocorrência, probabilidade de detecção e risco das falhas. Na maioria dos formulários são contidos os elementos: funções, modo de falhas, efeitos, severidade, causas, ocorrência, controles, detecção, e as ações recomendadas.

\subsection{Tecnologia CAD/CAE}

A tecnologia CAD (Computer Aided Design) ofereceu aos projetistas a interface gráfica necessária à representação digital, possibilitando a modelagem dos elementos estruturais em um ambiente computacional. A princípio portanto, CAD, e CAE (Computer Aided Engineering) ferramenta de análise de elementos estruturais, não compartilhavam dos seus recursos. A inserção de ferramentas gráficas nos programas $\mathrm{CAE}$, potencializou as interações restritas no início aos recursos 2D. E, a partir da década de 1970, a tecnologia deixou o uso restrito nas pesquisas espaciais, e com o refinamento dos conceitos de qualidade passou a integrar o mercado industrial (FIALHO, 2008 (a); FIALHO, 2008 (b)). 
Segundo Cook (1995), atualmente existem inúmeros pacotes comerciais e de domínio público de programas que utilizam como base os sistemas de elementos finitos, e a grande maioria oferece capacidades especializadas muito semelhantes. Esses sistemas estão disponíveis desde as estações de trabalho de engenharia até os computadores pessoais. E conclui relatando que a extensão da utilidade de um sistema FEA está diretamente relacionada à extensão da sua biblioteca de elementos. Nesta pesquisa utilizar-se-á um software paramétrico $\mathrm{CAD} / \mathrm{CAE} / \mathrm{CAM}$ para modelagem e simulação do sistema observado.

$\mathrm{Na}$ última década, devido aos índices altos de desempenho, e proximidade significativa entre resultados reais e testes em protótipos virtuais há um esforço cada vez maior de inserção de tecnologias $\mathrm{CAD} / \mathrm{CAE}$ como elementos de contribuição efetiva para resolução de problemas projetuais. DENG et. al. (2002), propõem um modelo de CAD/CAE integradas para solução de problemas existentes em um processo de moldagem por injeção. A utilização de ferramentas CAD em ambientes CAE reduzem os esforços de desenvolvimento e tornam o processo iterativo com base nas atividades construir-testar-otimizar. Relatam ainda que poucos são os pacotes comerciais que utilizam esta integração, e nesse caso especificamente tratam o projeto do molde de injeção e a análise estrutural como adventos distintos.

Ressaltam por fim que apesar de alguns fabricantes de softwares, como a Dassault Systèmes, conseguiram fornecer um ambiente integrado, mas não um sistema integrado, temse como conseqüência que o projetista elabora o elemento em uma plataforma, para em seguida migrar este para uma outra a fim de realizar testes. O software citado, o SolidWorks, é o pacote que vai ser utilizado no desenvolvimento desta pesquisa para realização de modelagem e simulação. E em suas versões atualizadas utilizam por meio de features e sistema paramétrico uma melhor integração entre as tecnologias $\mathrm{CAD} / \mathrm{CAE}$ utilizadas, permitindo uma melhor interface para otimização de projetos.

Padilla et al (2006), em seu estudo fazem um comparativo entre os resultados das inconformidades obtidas em uma peça industrial fabricada por processo de injeção e os resultados coletados a partir de uma simulação do processo por meio computacional. A conclusão de seus experimentos corrobora de forma positiva para utilização de software, fato que não se restringe somente para a tarefa de modelagem de elementos estruturais, mas principalmente para o processo de otimização.

Os autores destacam porquanto a proximidade, e em algumas análises a coincidência dos resultados e a relevância dos recursos computacionais como preditor da qualidade das peças, considerando para a validação dos resultados a incorporação das condições a que estas são submetidas. 
Park e Dang (2010), realizaram estudos de caso utilizando métodos diferentes de integração e cooperação de tecnologias $\mathrm{CAD} / \mathrm{CAE}$, e novamente destaca-se essa desvantagem em grande parte dos pacotes comerciais. Neste contexto propõem a inserção do método de meta-modelo contribuindo para a redução do tempo de desenvolvimento e como alternativa de minimização de custos. As técnicas de otimização destacam-se aqui como fatores de alta relevância em sistemas computacionais uma vez que podem afetar a precisão, a confiabilidade, e usabilidade dos elementos que estão sendo projetados.

Ainda que existam limitações na interação de tecnologias CAD/CAE o desenvolvimento de ferramentas de integração está em expansão, principalmente no que se refere aos pacotes comerciais. O impacto de sua utilização tem gerado resultados práticos em termos de redução de tempo de desenvolvimento, custo de operação, e retrabalho. De acordo com esta premissa esta pesquisa busca contribuir com o emprego destas tecnologias para o aumento na confiabilidade de produtos e de processos, e da produtividade.

\subsection{Métodos de elementos finitos (FEA)}

De acordo com Akin (2005), os métodos de elementos finitos tornaram-se adaptativos às análises de engenharia, devido, em primeira instância ao aspecto de segurança e praticidade. As vantagens de utilização de uma ferramenta de Finite Elements Analysis - FEA contribui para análise de tensões estáticas e dinâmicas em uma estrutura, campos elétricos, campos magnéticos, fluxo de fluido, além do emprego em análise térmica, principalmente no que tange à análise de estresse térmico, e tornaram-se enfim um recurso claro para minimização de custos de desenvolvimento.

Ainda segundo o autor incluem-se para o universo de aplicações a análise de materiais não homogêneos e anisotrópicos, e ainda como vantagem do método a sua capacidade de lidar com geometria de formas ilimitadas. Assim, conforme Filho (2007), relacionando-se aos Métodos Analíticos Clássicos, enfatiza que em contrapartida a resposta exata que se obtém, estas são limitadas a um pequeno espectro de aplicações cujas geometrias sejam simples e de condições "bem comportadas".

Decorre desta situação o processo de discretização dos sistemas contínuos, e a criação dos Nós dos Modelos, denominados como princípio dos elementos finitos, que a partir do conhecimento dos deslocamentos nodais interpola os deslocamentos dentro dos elementos, e obtendo-se o comportamento de cada elemento, sendo este de geometria com um grau de complexidade qualquer, generaliza-se a inferência ao todo. 
A despeito das diversas aplicações de FEA, há procedimentos comuns para a grande maioria dos casos, quais sejam (FIALHO,2008; NAKASONE et al, 2006; ZIENKIEWICZ et al, 2005):

Pré-processamento - Etapa em que se define o tipo de estudo que será executado. A partir de um modelamento CAD pode-se executar análises estruturais estáticas ou dinâmicas, escoamento de fluidos, acústica, condução de calor, campo magnético, dentre outras. Ainda nesta fase são estabelecidas as condições de contorno do objeto análisado. Definem-se os materiais e respectivas propriedades utilizadas. Localizam-se as restrições e distribui-se a aplicação de cargas (esforços a que serão submetidos os componentes). Esta fase finaliza-se pela discretização do objeto, em que se dá a sua conversão em Nós e Elementos a partir da aplicação de uma "Malha". Na figura 2.12, pode-se observar a redução de tamanho da malha em regiões críticas, que tem por objetivo aproximar os resultados da análise da situação real de utilização (DASSAULT SYSTÈMES, 2011).

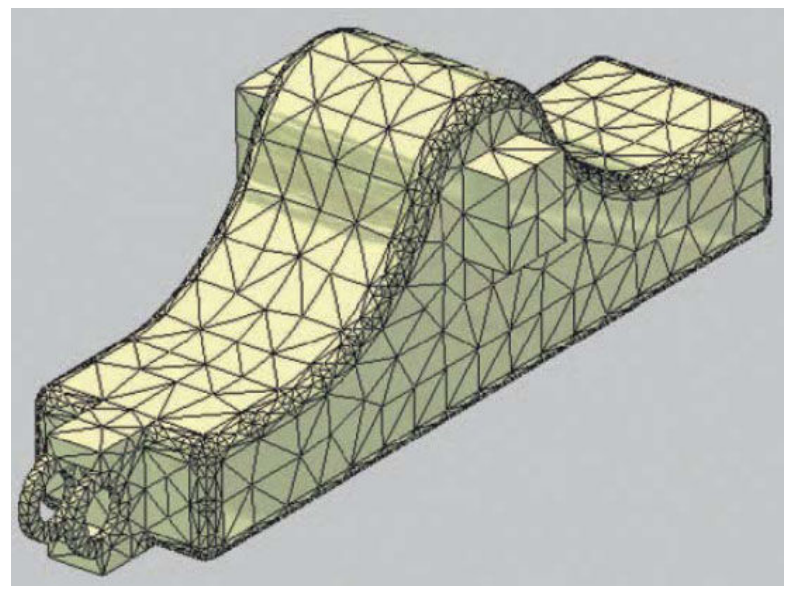

Figura 2.12: Aplicação de malha em modelo CAD Fonte: YOUNIS, 2009.

Solução - Nesta etapa dá-se a aplicação de um Solver Numérico (Dassault Systèmes, 2011), que tem por objetivo efetuar os cálculos dos deslocamentos nodais (Fialho, 2008 (a)). Cook (1995), refere-se ao método FEA como uma visão física do engenheiro sobre o comportamento matemático utilizando-se de métodos abstratos, e destaca que busca-se nestes os resultados referentes aos valores extremos a que podem ser submetidos os elementos, convertendo-se em uma forma de obtenção de uma solução numérica para um problema específico. O processo, segundo o autor, resulta em um conjunto de operações simultâneas de 
equações algébricas e o fato de haver várias centenas ou milhares de equações para resolução de um questionamento significa que o emprego de recursos computacionais é obrigatório.

Pós Processamento - Nesta fase apresentam-se os resultados, como mostra a figura 2.13, que se referem comumente à lista de deslocamentos nodais, elementos forças e momentos, distribuição de tensão, temperatura, dentre outros. A partir da visualização dos gráficos pode-se realizar a análise destes, e caso demontre-se oportuno submete-se o componente à otimização, ou nova rodada sob o fluxo de FEA, realização de testes sob diferentes restrições, valores de cargas, e materiais.

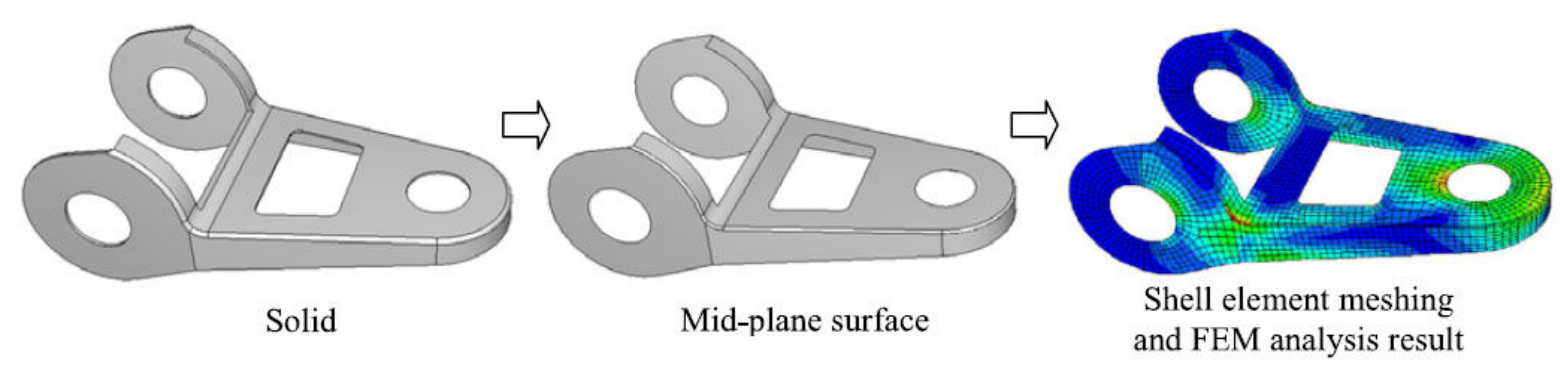

Figura 2.13: Discretização e resultado FEA

Fonte: PARK e DANG, 2010.

\subsection{Falhas em Componentes Estruturais}

As falhas mecânicas, ainda que existam outras inúmeras causas, ocorrem basicamente devido às cargas aplicadas, destarte a sobrecarga ocasiona a fratura, e a degradação da resistência, ocasiona a ruptura. As fraturas originam-se da concentração de tensões em locais com inconformidades como trincas ou estados de superfície irregulares. Tanto em um como em outro caso há solicitação de esforços cujo colapso das estruturas refere-se às tensões de cisalhamento, compressão, ou tração (PIAZZA, 2000; GERE, 2004; GROSS, 2011). No estudo de caso em voga encontram-se estas duas últimas, identificadas como forças presentes no desempenho hidráulico e mecânico do sistema. A figura 2.14, demonstra a deformação de uma estrutura quando da aplicação da tensão, cuja equação relacionando a força por unidade de área é representada por (TIMOSHENKO, 1979; TIMOSHENKO e GERE, 1983):

$$
\sigma=\frac{P}{A}
$$



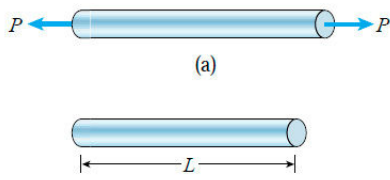

(b)

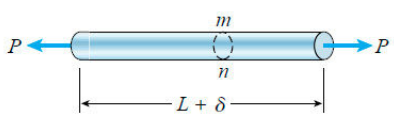

(c)

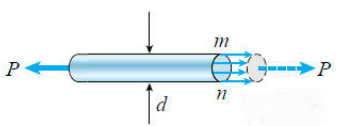

(d)

Figura 2.14: Esforços solicitantes de tração em estrutura

Fonte: Gere (2004)

Um esforço de tração relaciona as tensões e deformações para um determinado material e na medida em que a carga aumenta resulta-se maior deformação. O diagrama tensãodeformação expresso na figura 2.15, mostra a forma típica de gráfico do aço estrutural em que ocorrem, de $\mathrm{O}$ até $\mathrm{A}$, uma relação nomeada por limite de proporcionalidade e tem-se um comportamento linear, em seguida até o ponto B, aumentando-se a carga denota-se que o alongamento cresce mais do que a tensão, tal fenômeno é denominado de limite de escoamento. Entre os pontos $\mathrm{BC}$ há o "revigoramento" do material deformando-se plasticamente, a partir do ponto $\mathrm{C}$ o material resiste adicionalmente à carga com aumento da deformação até D. Após D ocorre a tensão de ruptura do material por (TIMOSHENKO, 1979; TIMOSHENKO e GERE, 1983).

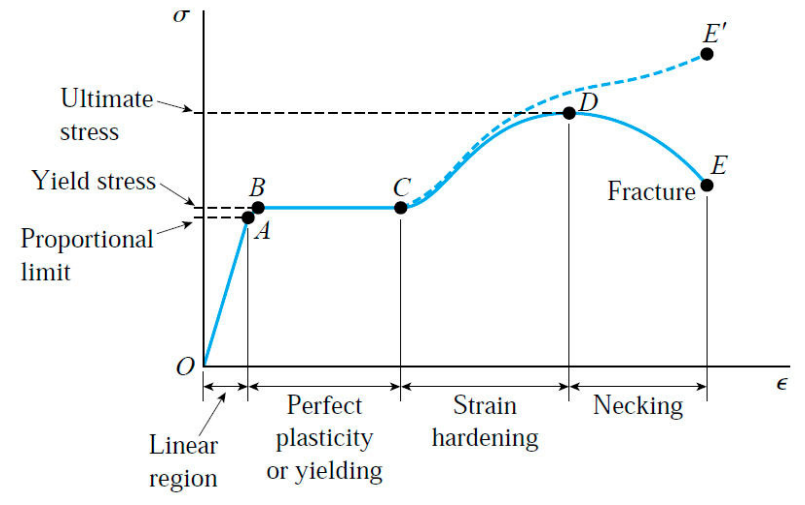

Figura 2.15: Diagrama de Tensão x Deformação para estrutura de aço

Fonte: Gere (2004)

Norton (2004), relata que partir do comportamento distinto do Diagrama Tensão $\mathrm{x}$ Deformação pôde-se definir duas classes de materiais: Os materiais dúcteis, em que estão presentes as características que o conferem uma deformação significativa antes que ocorra a ruptura; e os materiais frágeis caracterizados pela indefinição de ponto de escoamento e 
região de plasticidade insignificante. Ressaltando-se que a depender do processo de fabricação e do tratamento térmico, um material pode ser definido como frágil ou dúctil.

Quanto à degradação à resistência, suas causas são originadas por fadiga, desgaste, ou corrosão. Os autores ressaltam os casos de sensibilidade à fratura, ao inferirem sobre a influência da temperatura para ocorrência do evento, correlacionando a sua elevação ao desgaste prematuro. Uma segunda situação contundente à sensibilidade constitui-se nos dispositivos em que há aplicação impulsiva de cargas, neste caso o impacto compromete a fase plástica e consequentemente a capacidade de absorção de tensão sobre determinado material, nessas circunstâncias Piazza (2000), recomenda o aumento do fator de segurança, e Gere (2004) cita que para se evitar as falhas torna-se necessário capacitar a estrutura para um esforço maior às cargas a que serão submetidas quando em serviço, e da relação entre a resistência ao esforço real e a resistência necessária. A figura 2.16, mostra os casos de ruptura, fratura, e a fragilização do material em decorrência de trincas.
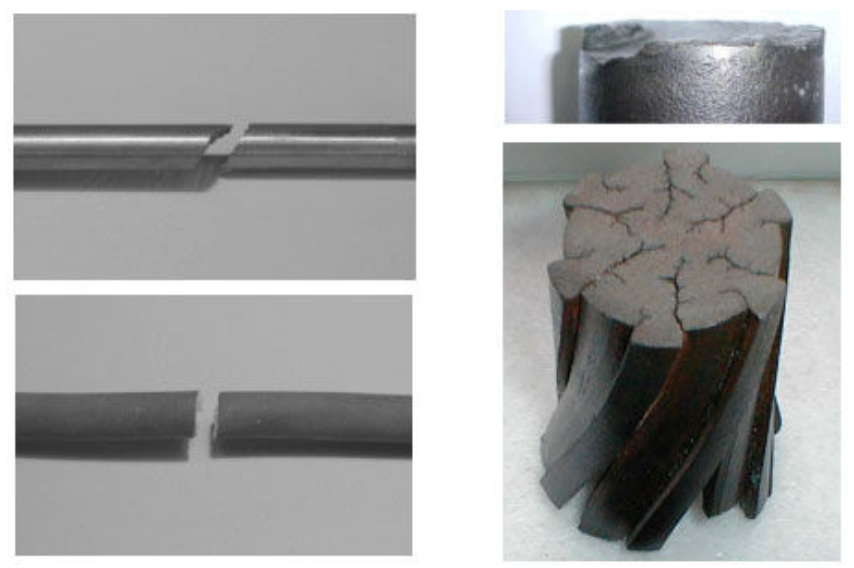

Figura 2.16: Fratura, ruptura e trincas nos materiais

Fonte: Render (2011)

\subsection{Conformação Mecânica por Injeção Plástica}

Para a fabricação de produtos através do processo de conformação mecânica por injeção plástica, independentemente dos aspectos relacionados à dimensão ou o perfil, grânulos de polímeros são depositados em compartimento da máquina injetora, local em que serão submetidos a aquecimento até o ponto de fusão. Já no estado líquido o polímero é injetado em moldes metálicos através de um pistão. $\mathrm{O}$ esforço para manutenção das características formais do produto final está intrinsicamente relacionado à regulagem de parâmetros técnicos da máquina, cujos principais componentes estão demonstrados na Figura 2.17 (GALDAMES e CARPINETTI, 2004). 


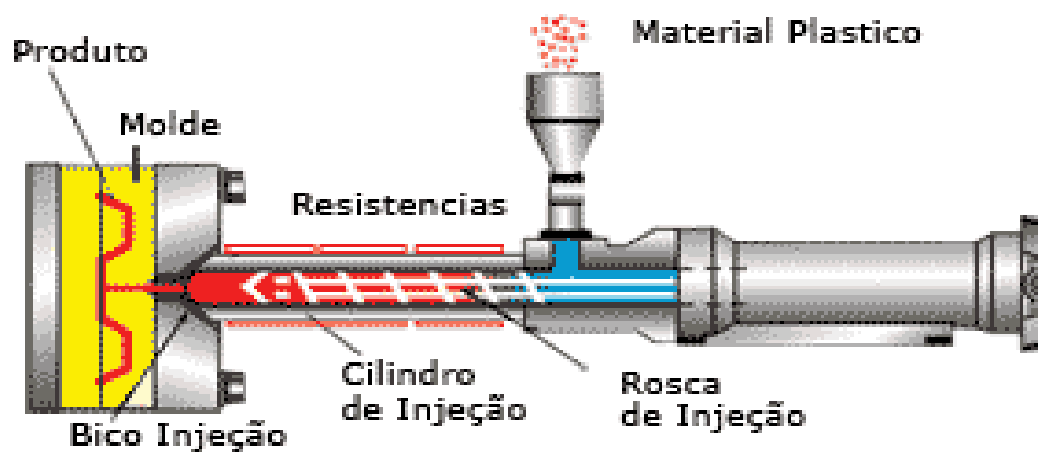

Figura 2.17: Componentes do processo de conformação mecânica por injeção Fonte: Galdames e Carpinetti (2004)

Cominatto (1997), cita que a performance eficiente do processo deve controlar parâmetros de:

- Tempo de ciclo, que é o tempo total para finalização do processo de um produto;

- Velocidade de injeção, que se relaciona ao tempo de preenchimento das cavidades do molde;

- Tempo de resfriamento, que contabiliza o tempo de máquina até que se dê a solidificação do material deposto;

- Temperatura do molde, que deve ser controlada pelo volume de água conduzida pelo sistema de refrigeração do molde;

- Temperatura da máquina, que determina a temperatura ideal para o material que deverá ser deposto no molde;

- Pressão de injeção, que é a pressão com que o polímero é deposto no molde; e,

- Pressão de recalque, que é a pressão exercida durante o processo de solidificação do polímero, necessária para que as cavidades sejam preenchidas.

Provenza (2005), cita ainda que para a conformação de um produto por injeção plástica se deve priorizar aspectos como: a estética do produto; facilidade de moldagem; facilidade de extração; facilidade de execução do molde, e; economia do material. E ressalta que na maioria dos casos pequenas alterações formais no produto são suficientes para que haja a simplificação e adequação à execução do processo, e consequente redução de custos. Essas modificações não deverão comprometer os aspectos funcionais, preservando-se, portanto, tanto a estética quanto a eficiência do produto final. De acordo com o autor estabelecendo-se as especificações técnicas do produto, para a construção do molde de injeção deve-se considerar aspectos como: 
- Abertura do molde, que deve propiciar uma fácil usinagem das partes do molde, além de garantir a extração do produto moldado, e evitar que este esteja isento de marcas no produto remanescentes do processo;

- Resfriamento, que se refere à aceleração do processo de solidificação e extração do produto, após deposição do material no molde;

- Aquecimento, especificamente no caso de utilização de materiais termoplásticos;

- Contração ou encolhimento do plástico, relacionando-se pela diferença entre as dimensões da peça injetada, após alcançar o equilíbrio térmico em temperatura ambiente, e o tamanho em que a peça foi injetada originalmente.

- Ciclo de moldagem, que considera o intervalo total de tempo entre o instante em que o molde se fecha e o período correspondente que encerra-se no ciclo seguinte, e;

- Força de fechamento, aplicada na linha de fechamento do molde mantendo-o fechado, uma vez que existe a pressão de injeção que provoca o enchimento das cavidades do produto, numa força oposta a do fechamento.

Assim, Glanvill e Denton (1994), inferem que o molde bem preserva a continuidade do fluxo plástico, resiste às pressões durante o processo, resfria de modo compatível ao melhor desempenho do material, e proporciona o acabamento especificado em projeto, permitindo uma boa extração. A Figura 2.18, mostra os nomes das placas e detalhes do molde de injeção plástica. 


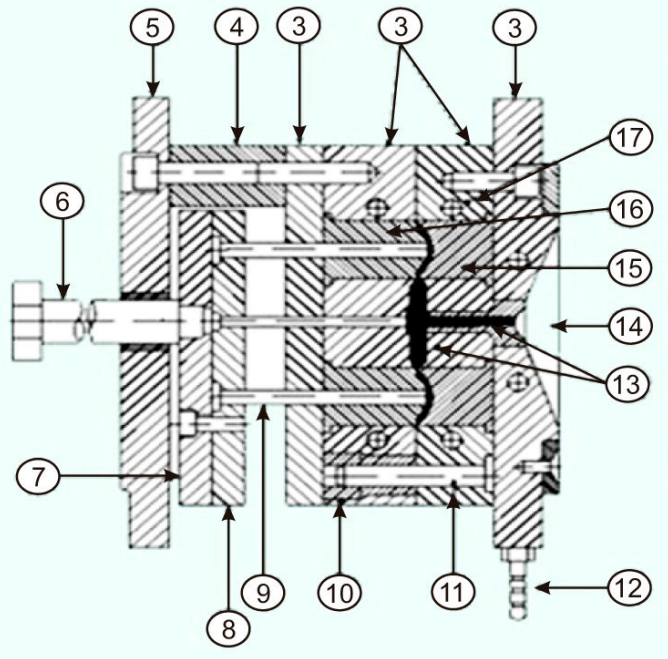

1- Placa de fixação

2 - Placa de sujeição da cavidade

3 - Placa suporte

4 - Bloco espaçador

5 - Placa de fixação

6 - Barra ejetora

7 - Placa extratora

8 - Placa porta-extratores

9 - Pino extrator

10 - Bucha-guia

11 - Pino-guia

12 - Conexão para o sistema de refrigeração

13 - Bucha de injeção e canais de injeção

14 - Cone de centragem

15 - Placa fêmea

16 - Placa macho

17 - Canal de refrigeração

Figura 2.18: Composição de molde para processo de injeção plástica Fonte: Glanvill e Denton (1994)

No Quadro 2.1, são relacionadas às principais características dos componentes de um molde:

\begin{tabular}{|l|l|}
\hline \multicolumn{1}{|c|}{ Componentes do molde } & \multicolumn{1}{c|}{ Características } \\
\hline Base do molde (1 e 5) & $\begin{array}{l}\text { Mantém as cavidades, e devem estar corretamente } \\
\text { posicionadas em relação ao bico da máquina. }\end{array}$ \\
\hline Pino guia (11) & Mantém o alinhamento entre as duas partes do molde. \\
\hline $\begin{array}{l}\text { Bucha de injeção e Canais de } \\
\text { injeção (13) }\end{array}$ & $\begin{array}{l}\text { Controla a entrada da matéria-prima para a parte interna } \\
\text { do molde. }\end{array}$ \\
\hline Cavidades e macho (2) & Controlam o tamanho, a forma e a superfície da peça. \\
\hline Sistema de refrigeração (17) & $\begin{array}{l}\text { Controla a temperatura das superfícies do molde para } \\
\text { solidificação do material. }\end{array}$ \\
\hline Pinos de retorno & $\begin{array}{l}\text { Retornam os extratores à posição inicial quando o molde } \\
\text { se fecha para o próximo ciclo. }\end{array}$ \\
\hline Mecanismo de extração (7,8 e 9) & Extrai a peça rígida da cavidade. \\
\hline Saídas & Permitem a saída de gás e ar. \\
\hline Barra ejetora (6) & Aciona a placa extratora para remoção da peça. \\
\hline Anel de centragem & Centraliza o canhão da máquina no molde \\
\hline Gaveta, pino, lateral & $\begin{array}{l}\text { Formam os furos, rasgos, rebaixos e roscas no produto } \\
\text { final. }\end{array}$ \\
\hline
\end{tabular}

Quadro 2.1: Características dos componentes do molde

Fonte: Glanvill e Denton (1994)

Segundo Harada (2004), a seleção dos materiais com os quais se confeccionará moldes para injeção depende de aspectos como: o nível de precisão; a quantidade de produtos que se deseja fabricar, e do tipo de tratamento superficial e térmico disponível. Provenza (2005), ressalta a importância em se observar que os materiais empregados na construção das cavidades e dos machos requerem normalmente tratamentos térmicos como normalização, 
recozimento, têmpera, revenimento, cementação, dentre outros. Desta forma os aços normalmente empregados compatíveis são:

- Aços de baixo teor de Carbono, temperados, cementados e polidos. Utilizados para confecção de moldes para injeção de polietileno de baixa densidade.

- Aços Ni-Cr e Ni-Cr-Mo, de fácil usinagem. Endurecidos em óleo ou ar, resistentes ao desgaste conforme exemplos: Villares: VCO, VMO, VH13. Uma parte integrante do catálogo de aços de um fornecedor contendo demais especificações técnicas do material VCO consta no anexo deste trabalho.

- Aços de alto teor de Carbono e Cromo, utilizados para moldes que requerem mínima distorção e máxima resistência a brasão conforme exemplos: Villares: VC-130, VC131, VND, e Phoenix: Triunphator.

O Quadro 2.2, identifica as propriedades mecânicas dos elementos especiais sobre as ligas de aço em geral (HARADA, 2004):

\begin{tabular}{|l|l|}
\hline Elemento & \multicolumn{1}{|c|}{ Efeitos } \\
\hline Silício & Dureza \\
\hline Carbono & Endurecedor \\
\hline Manganês & Desoxidante \\
\hline Níquel & Tenacidade e resistência \\
\hline Cromo & Dureza e melhora o polimento \\
\hline Vanádio & Purificador e aumenta a resistência à fadiga \\
\hline Molibdênio & Amplia a margem de tratamento térmico \\
\hline Tungstênio & Dureza e resistência ao calor \\
\hline
\end{tabular}

Quadro 2.2: Elementos e efeitos na liga de aço

Fonte: Harada (2004)

A escolha incorreta de um aço pode ocasionar consequências que redundam em não conformidade nos produtos acabados. Para selecionar o aço adequado a cada componente do molde ou até de um estampo de corte, deve-se considerar a função dos diversos esforços a que será submetida à peça. Para um rendimento satisfatório de um molde, aspectos como a resistência do material, e seu comportamento ao ser exposto em esforços térmicos são de extrema relevância. (AÇOESPECIAL, 1995)

De acordo com as especificações técnicas da Villares Metals (a) (2011), o aço VH13 é apropriado para o trabalho a quente, como no caso de moldes para injeção de plástico. E possui as seguintes características:

- Alta resistência à trinca ocasionada por fadiga térmica; 
- Boa tenacidade, usinabilidade e polibilidade;

- Boa estabilidade térmica;

- Boa resistência ao desgaste;

- Tem sua composição formada por $0,4 \%$ de carbono, $1,0 \%$ Silício, $0,35 \%$ manganês, 5,2\% cromo, 1,5\%molibdênio e $0,9 \%$ vanádio.

- Dureza máxima de 235 HB;

- Sua têmpera deve ser entre 1010 e $1030^{\circ} \mathrm{C}$.

\subsection{Custo relacionado à manutenção}

O custo de manutenção representa a soma dos valores dos bens e serviços utilizados na produção. O seu controle é uma atividade essencial para o gerenciamento da manutenção, pois garante a previsibilidade e prover subsídios para a análise e redução dos custos de forma sustentada. Para Almeida (1987 apud Almeida \& Campello 2001, p.76), o custo na operação/manutenção de equipamentos, sistemas e instalações é função de pessoal, reserva técnica, equipamentos de suporte e ferramentas, apoio logístico, estrutura de planejamento, dentre outros.

Conforme Kardec \& Nascif (2005, p.58) os custos de manutenção são classificados em três famílias que seguem:

- Custos diretos: são os custos necessários para manter o equipamento em operação. Neles estão inclusos os custos de manutenção preventiva, preditiva, detectiva e corretiva. Seus componentes são: custo de mão de obra direta, custo de materiais e custo de serviços terceirizados;

- Custos de perda de produção: são os custos causados pela perda de produção originada pela falha do equipamento principal sem que o reserva, quando existir, esteja disponível e pela falha do equipamento quando a causa seja a ação imprópria da manutenção;

- Custo indireto: são os custos relacionados com a estrutura gerencial, apoio administrativo e áreas de análise e estudo.

Ainda conforme os autores, o custo anual de manutenção representa, em média, 4,39 \% do faturamento bruto das empresas e, por este motivo, uma redução de custo na manutenção, mal conduzida, pode levar a perda de faturamento e lucro da organização. 
O custo total de uma parada de equipamento é a soma do custo de manutenção representada pelo custo de mão de obra e peças e pelo custo de indisponibilidade do equipamento representada pelo custo de perda de produção, penalidades comerciais e impactos na imagem da empresa. Experiências de avaliação de desempenho demonstram que o custo de indisponibilidade representa mais da metade do custo total da parada do equipamento, asseveram Almeida e Campello (2001, p.76). 


\section{PROPOSIÇÃO DE MÉTODO PARA MODELAGEM DE DADOS}

Neste capítulo são apresentados os procedimentos e ferramentas empregados na pesquisa. Delineia-se a abordagem para análise do sistema, coleta e modelagem dos dados de falha, estimação da confiabilidade e modo comparativo.

\subsection{Método}

Para os autores Lakatos e Marconi (2001), considera-se o método um sequenciamento de atividades dispostas de maneira lógica, afim de que se possam atingir os objetivos de forma sistemática e racional. A execução das etapas ocorrendo a mercê deste controle tende a demonstrar eventuais desvios, o que auxilia o pesquisador a suportar as tomadas de decisões.

O método neste estudo deverá ser aplicado por intermédio de pesquisas e avaliações com o intuito de se obter a identificação de requisitos que possam consubstanciar uma especificação de projeto de um componente, alternativa de resposta à situação problema. A implantação desta resposta deve possibilitar a caracterização, quantificação, e análise da inserção de tecnologias $\mathrm{CAD} / \mathrm{CAE}$ como uma contribuição para o aumento da confiabilidade em um produto, e consequentemente no processo de produção de um produto final. Este produto, a saber, é denominado de espalhador, e é um dos elementos que compõem a estrutura para montagem de um chuveiro elétrico.

\subsection{Tipo de Pesquisa}

Fachim (2003), relata que uma pesquisa caracteriza-se pelo emprego de procedimentos de caráter intelectual e tem como objetivo a aquisição de conhecimentos. O pesquisador, por conseguinte utiliza-se deste meio para investigar uma realidade e busca quebrar paradigmas propondo soluções, respostas a um determinado cenário cujos problemas intrínsecos permitem relacionar causas e efeitos. No caso desta pesquisa, caracterizando-a quanto ao objeto, definese como sendo de campo, considerando-se que os dados coletados serão obtidos numa indústria, local onde se encontra a situação-problema.

Hair (2005), destaca no tipo de pesquisa aplicada a característica intrínseca pelo interesse prático, em que haja uma franca relação entre proposta de solução e realidade. Há de se explicitar aqui o pragmatismo de solução real para um problema real. Nesses termos o 
estudo a que se propõe aqui enquadra-se por possuir uma finalidade imediata de resolver o problema que ocorre em um processo de uma indústria.

Quanto ao objetivo, Vergara (2004), comenta que as pesquisas podem ser exploratórias, descritivas, ou explicativas. Como o estudo em voga objetiva a descrição das características de um fenômeno específico, e deve estabelecer uma relação entre as variáveis deste fenômeno, considera-se como uma pesquisa descritiva. Porém a pesquisa busca ainda, através de ferramentas e técnicas de engenharia (Failure Modes and Effects Analysis - FMEA / Finite Element Analysis - FEA), a identificação das variáveis que determinam a ocorrência do fenômeno, e a explicação sobre as causas de ocorrência, correlacionando as causas e os efeitos, buscando os porquês para o fenômeno, configurando-se assim um aspecto explicativo de pesquisa. Em decorrência do exposto a pesquisa torna-se descritivo-explicativa.

\subsection{Estudo de Caso}

A modalidade da descrição da pesquisa será um Estudo de Caso. De acordo com Alencar apud Yin (2001), esta modalidade de pesquisa, quanto aos dados "tenta esclarecer o motivo pelo qual uma decisão ou conjunto de decisões foram tomadas, como foram implementadas e com quais resultados foram alcançados"

O estudo de caso desta pesquisa ocorrerá em uma indústria de chuveiros, situada no município de Aracaju, estado de Sergipe. Especificamente no setor de processos de injeção, onde ocorre a fabricação de peças para todos os modelos de produtos disponíveis no portfólio da empresa.

Serão coletados dados referentes ao comportamento dos sistemas de moldes de injeção. A abordagem de dados utilizada para análise será a quali-quantitativa. Richardison (2007), relata que quanto à natureza da pesquisa os dados destas informações são complementares, e ressalta que a diferença entre os dois métodos é que o quantitativo emprega recursos estatísticos para a coleta e tratamento das informações, já o qualitativo não se utiliza de quantificação.

Com a obtenção dos dados, tornar-se-á possível a realização de análises, e inferências, e a partir destas busca-se viabilizar uma proposta para implantação e coleta de novos dados e avaliação. A alternativa proposta como resposta ao modelo inicial deverá utilizar os recursos computacionais de tecnologia $\mathrm{CAD} / \mathrm{CAE}$, ou seja, a partir dos dados iniciais será modelado 
um aparato físico, cuja simulação utilizando software paramétrico deverá reproduzir as condições as quais são submetidos o sistema.

O setor de trabalho que está sendo estudado apresenta problemas de parada de produção por diversos fatores, na qual por conseqüência provoca atraso na produção. Apresenta-se aqui o estudo de avaliação do sistema envolvido, sua relação de causas, e ações recomendadas como proposta para solucionar as falhas detectadas.

\subsection{Gráfico de Pareto}

Segundo Scapin (2007), o gráfico de Pareto é uma ferramenta estatística, na qual se classifica e separa itens de acordo com sua prioridade, e é usado na identificação de problemas prioritários antes e após uma ação.

De acordo com Palady (1997), esse gráfico é utilizado para demonstrar as causas básicas que conduzem a ocorrência de falha. Através deste é possível avaliar os dados existentes em projetos semelhantes usando a análise para organizar dados de diários, formulários de inspeção ou relatórios de garantia. O autor infere que através do princípio de Pareto algumas causas identificadas contribuirão para a maioria dos modos de falha em potencial. Estas serão reconhecidas como causas básicas, e deverão ser transferidas para um formulário de FMEA.

Para a identificação dos problemas de um processo se faz necessário o uso do gráfico de Pareto em barras. Através da sua utilização é possível ordenar as ocorrências, da maior para a menor, possibilitando a hierarquia das prioridades para posterior solução. Toda a construção dos dados é elaborada através da coleta. O princípio de Pareto defende que os problemas são causados por várias causas, portanto separando os problemas vitais dos triviais pode-se priorizar a ação de correção (JÚNIOR, 2008).

\subsection{Problemas Ocorridos no Setor de Injeção Plástica}

Para que o processo de injeção plástica ocorra em conformidade com as especificações técnicas, diversos fatores devem ocorrer como programados, citam-se para este caso os seguintes critérios (SOARES, 2005):

- A matéria prima não pode conter umidade, pois esta influencia no processo de fusão; 
- Não deve haver contaminações, como por exemplo: materiais ferrosos e contaminações com materiais com diferentes composições;

- A máquina injetora deve estar em perfeitas condições de uso, para que não ocorra desperdício de matéria prima ou avarias no molde de injeção;

- A regulagem da máquina para o processo de injeção deve ser padronizada assim que for alcançada a regulagem satisfatória, ou seja, que o produto seja obtido dentro dos paramentos pré-estabelecidos; e,

- Avaliação do principal fator que influência na parada das máquinas injetoras: os moldes de injeção.

A partir do tratamento dos dados coletados entre os dias 02 de janeiro a 02 de fevereiro de 2011, foi elaborado um Gráfico de Pareto, para uma melhor visualização das ocorrências ocasionadas no setor de injeção, com base nas ordens de serviço solicitadas.

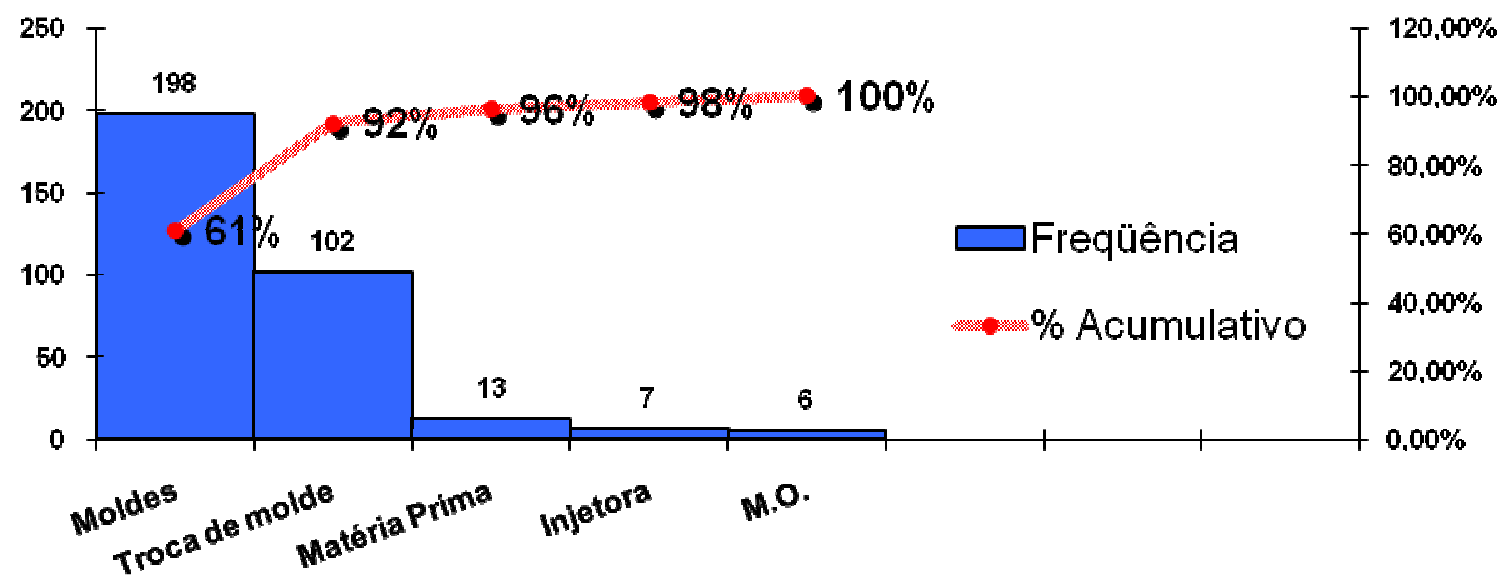

Gráfico 3.1: Ocorrências de parada de máquina Fonte: Corona (2011)

Após a elaboração do Gráfico 3.1, detectaram-se os maiores quantitativos de incidência para ocorrência de parada da máquina injetora. Com os dados obtidos e mensurados no Gráfico 3.1, foi elaborado o Gráfico 3.2, cujo principal objetivo dá-se para verificação do índice de freqüência das ocorrências de não conformidades dos moldes. 


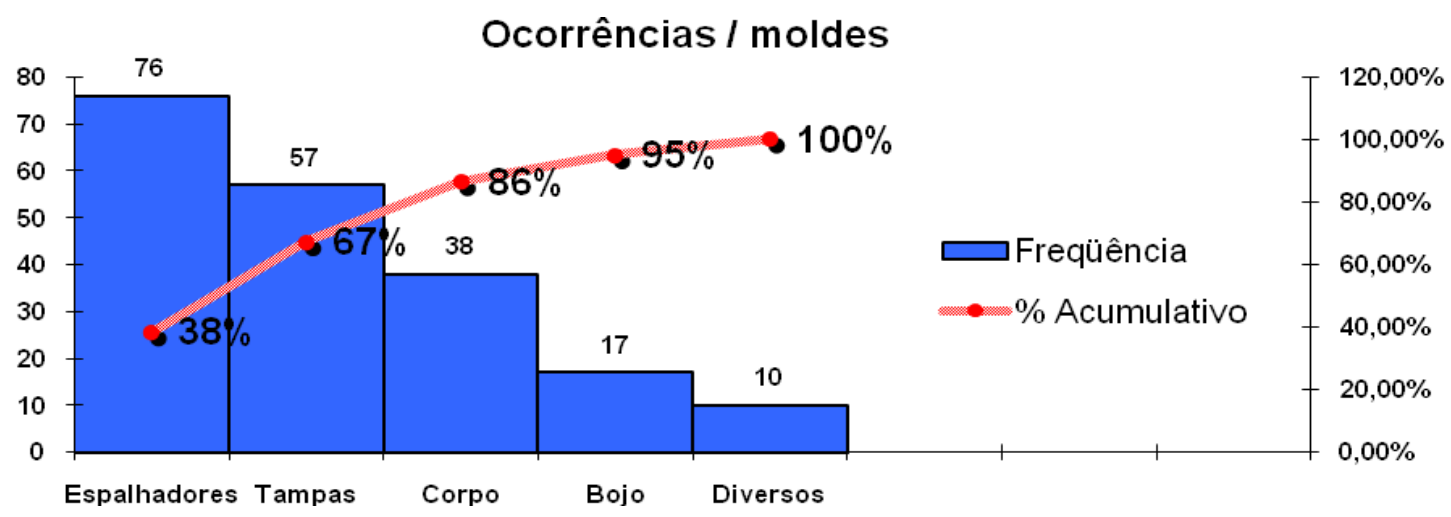

Gráfico 3.2: Ocorrências nos moldes

Fonte: Corona (2011)

Pode-se verificar então que no período de trinta dias o conjunto de moldes que mais ocasionou parada de produção foram os moldes dos espalhadores. Através desses dados formulou-se um novo gráfico, especificando as causas de parada do molde.

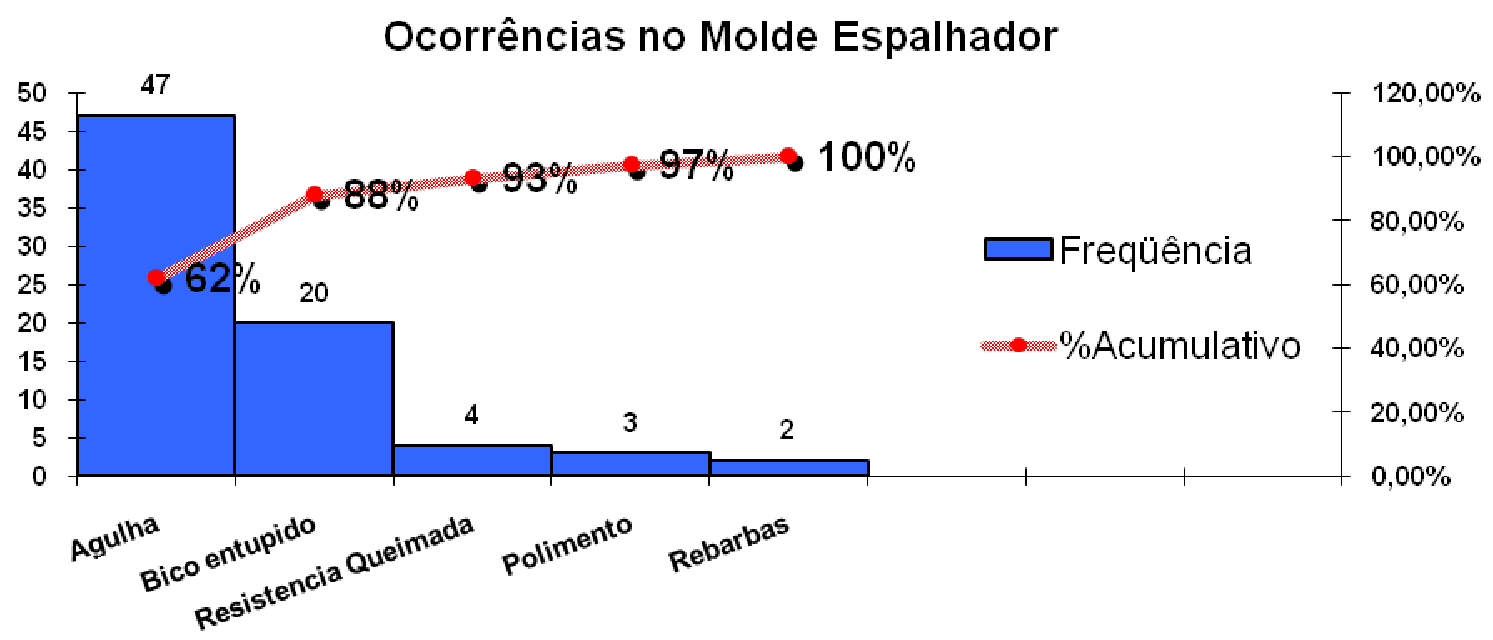

Gráfico 3.3: Quantitativos de ocorrências no molde espalhador

Fonte: Corona (2011)

Conforme os dados do Gráfico 3.3, a ocorrência que mais ocasiona a parada do molde espalhador é a quebra de agulha.

A partir dos dados obtidos no Gráfico de Pareto construiu-se a tabela do FMEA, que consta no capítulo de análise dos resultados, a fim de avaliar as condições qualitativas em que ocorre a quebra da agulha para definição de uma estratégia que possa ser implementada visando o aumento de produtividade e redução nos custos de manutenção, implementando melhorias ao processo.

No período de coleta de dados foram obtidas as seguintes informações referentes aos custos de manutenção, constantes nas tabelas 3.3 e 3.4 . 
Tabela 3.3: Custos de manutenção

\begin{tabular}{l|l}
\hline Item & Custo (em R\$) \\
\hline Valor unitário da agulha & 37,00 \\
\hline Valor da mão de obra/hora trabalhada & 35,00 \\
\hline Valor unitário da resistência & 300,00 \\
\hline
\end{tabular}

Tabela 3.4: Tempo médio de reparo

\begin{tabular}{l|c}
\hline \multicolumn{1}{c|}{ Operação } & Tempo (horas) \\
\hline Troca de resistência & 2 \\
\hline Troca de agulha quebrada & 2 \\
\hline Serviço de polimento & 4 \\
\hline Limpeza de bico entupido & 3 \\
\hline Eliminação de rebarbas & 8 \\
\hline
\end{tabular}

Com os dados coletados referentes ao custo foi elaborado o Gráfico 3.4 que demonstra os maiores custos para a manutenção das ocorrências no molde.

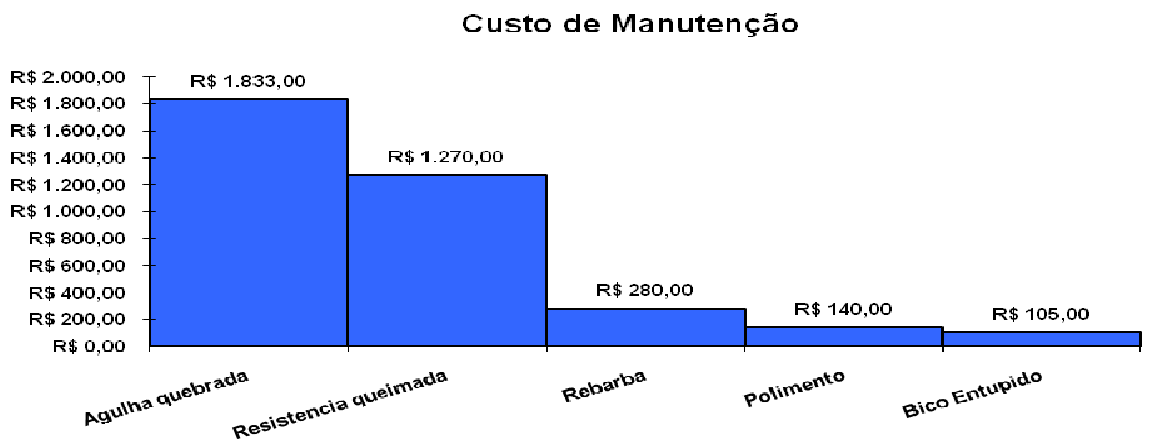

Gráfico 3.4: Custos referentes à manutenção do molde Fonte: Corona (2011)

Pode-se confirmar desse modo que a falha na agulha corresponde aos maiores custos de manutenção. Esta situação está expressa na figura 3.1, na qual se explicita um produto injetado com uma agulha quebrada fixada em um dos furos, obstruindo o fluxo. É comum nestas circunstâncias que uma parte da agulha danificada fique presa ao molde. 


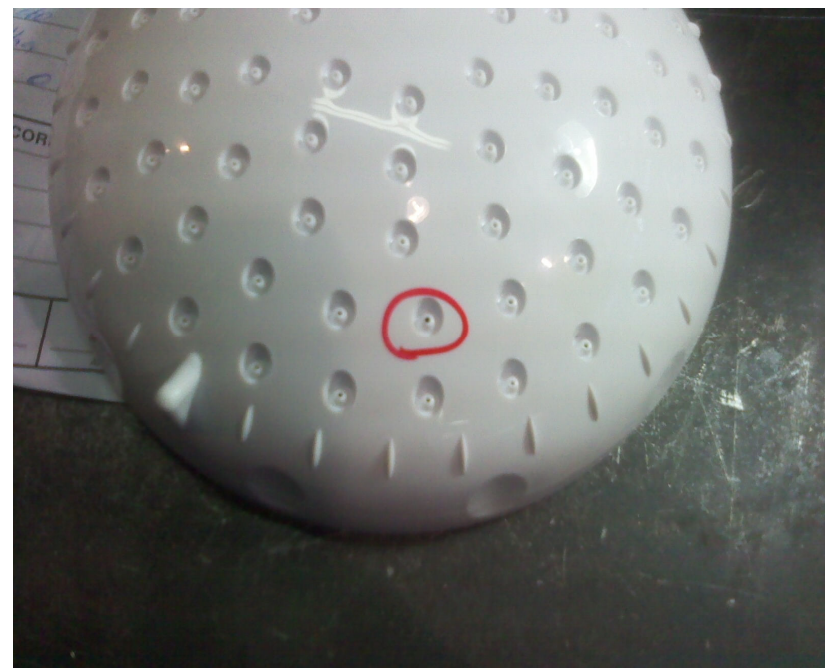

Figura 3.1: Produto com agulha quebrada Fonte: Corona (2011)

Constatou-se que o Molde do produto Mega Banho lidera a lista dos números de ocorrências. Nas ocorrências do molde do produto Mega Banho foram ainda constatados problemas como "agulha quebrada", "bico entupido", "polimento da matriz", "cavidade amassada", "rebarbas" e "resistência queimada". O problema de agulha quebrada foi a ocorrência que mais ocasionou a parada do molde, comprometendo a meta de produção e elevando os custos.

Esta agulha é adquirida em fornecedores de materiais pelo custo de $\mathrm{R} \$ 37,00$ a unidade. De acordo com informações dos funcionários da empresa, houve no último período observado 36 ocorrências, totalizando 50 (cinquenta) agulhas quebradas. A mão de obra para reposição tem um custo de $\mathrm{R} \$ 35,00$ por hora. Foi utilizada em média uma hora por ocorrência, totalizando um custo total de $\mathrm{R} \$ 3.110,00$. Os valores demonstrados não consideram o lucro cessante demonstrado no capítulo de análise dos resultados.

Custo Unitário X Quantidade $=$ Custo total de Agulhas

$\mathrm{R} \$ 37,00 \times 50=\mathrm{R} \$ 1850,00$

Valor mão de obra/hora X Horas utilizadas = Custo de mão de obra

$\mathrm{R} \$ 35,00 \times 36=\mathrm{R} \$ 1260,00$

Custo total $=$ Custo de agulhas + Custo de mão de obra

$\mathrm{R} \$ 3.110,00=\mathrm{R} \$ 1850,00+\mathrm{R} \$ 1260,00$

\subsection{Parâmetros para Utilização da FMEA}


Para a avaliação do processo que envolve a agulha de injeção foram utilizadas as escalas propostas por Palady (2007), cuja descrição de situação e referência de grau encontra-se descrita nos quadros 7.3, 7.4, e 7.5, do anexo.

\subsection{Plano de Aplicação da FEA e Análise dos Dados de Confiabilidade}

A modelagem dos dados com adoção de distribuição de probabilidade compatível darse-á tanto para o modelo de componente convencional quanto para o modelo novo. O mesmo procedimento é adotado para a análise por elementos finitos. $\mathrm{Na}$ análise do modelo convencional busca-se especificar requisitos para construção de uma alternativa de solução, e esta alternativa também deverá ser submetida à análise. Por fim, comparar-se-ão os respectivos resultados. 


\section{ANÁLISE DA CONFIABILIDADE, MODELAGEM E SIMULAÇÃO DO NOVO PRODUTO}

Neste capítulo está descrito o processo de conformação mecânica do produto e suas não conformidades. Em seguida apresenta-se a aplicação de uma análise de falhas utilizando-se da ferramenta qualitativa FMEA. Fez-se uma análise da confiabilidade para verificação do estado do sistema. De acordo com as ações recomendadas foram estipuladas especificações técnicas para desenvolvimento de um novo produto, após modelagem, simulação e implementação da solução faz-se nova análise de confiabilidade com o objetivo de comparação entre os dados pré, e pós-intervenção de tecnologia CAD/CAE.

\subsection{Processo para produção do produto espalhador}

O espalhador constitui-se como um dos principais componentes de desempenho das funcionalidades em um chuveiro, sendo o direcionador e distribuidor do volume de água. Em algumas opções de chuveiro de menor custo o espalhador e o corpo do chuveiro são soldados. Para este estudo de caso tem-se um modelo, como pode ser observado na figura 4.1, disponibilizado ao mercado nas versões de acabamento fosco e cromado. No modelo Mega Banho o componente espalhador é fabricado em termoplástico, material isolante térmico e elétrico, e fixado ao corpo por três pontos de aparafusamento.

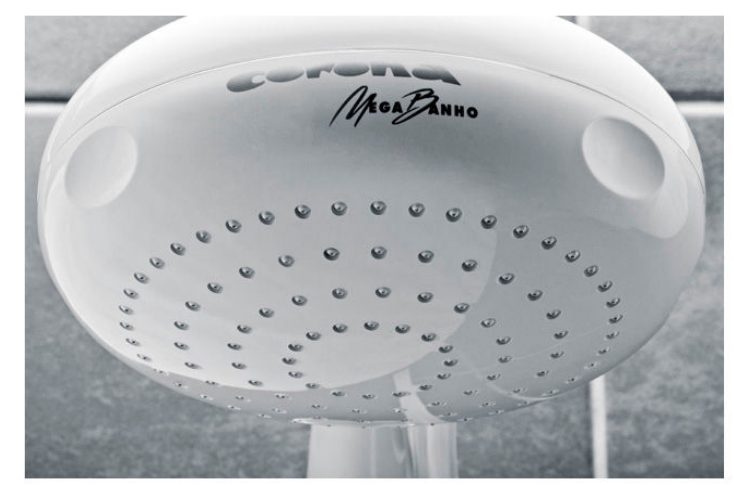

Figura 4.1: Chuveiro modelo Mega Banho

Fonte: Corona (2011)

A conformação mecânica deste produto dá-se através do processo de injeção plástica, e o maquinário utilizado para a execução do processo é uma injetora, cujo fabricante, a indústria Semeraro/Sandretto não mais a fabrica, no modelo Otto 612/150, com capacidade produtiva de 150 toneladas, adquirida pela empresa no ano de 1993. 
Nesse equipamento podem ser produzidos diariamente 2.208 espalhadores, quando de seu funcionamento pleno, de acordo com as especificações de projeto demonstradas na figura 4.2, em que pode-se verificar a quantidade de 101 furos para passagem de água, dispostos de forma circuncêntrica. Independentemente do posicionamento todos os furos, e sua base cônica correspondente, possuem dimensionamentos iguais, como demonstrado pela figura 4.3.

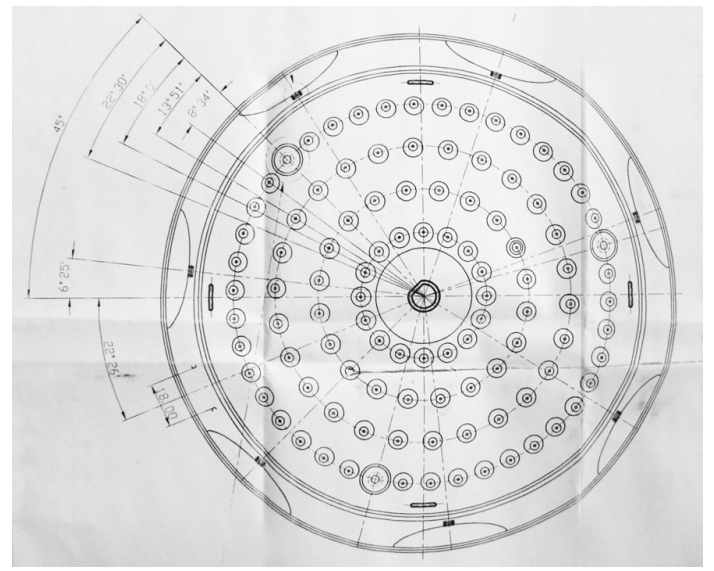

Figura 4.2: Especificações técnicas do modelo mega banho - Vista Frontal Fonte: Corona (2011)

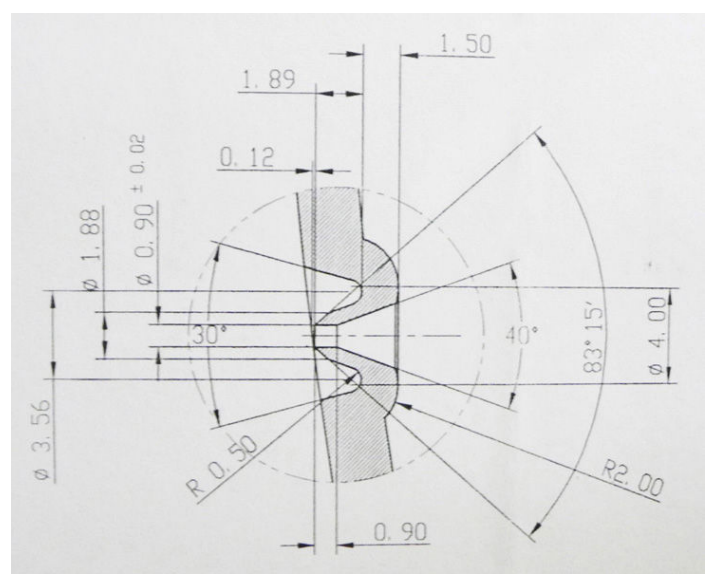

Figura 4.3: Detalhe do furo do espalhador - Vista Lateral

Fonte: Corona (2011)

A execução de cada um dos furos é feita através de agulhas, portanto o modelo de molde em estudo utiliza-se de 101 agulhas que são encaixadas em outro componente do molde, o qual é denominado por mavica. Na figura 4.4 pode-se observar a agulha utilizada no processo de injeção do modelo de chuveiro estudado que é fabricado nesta indústria. Ressaltase que a tarefa decorre de maneira semelhante há mais de 40 anos, e para adaptação aos diversos tipos de molde à agulha convencional sofre um corte, de forma artesanal, para atender a variação de comprimento das mavicas. Especificamente para o produto mega banho, 
a produção iniciou em 1998. Após executada estas submontagens, as mavicas com agulhas serão acopladas ao molde fixo da injetora, como demonstra a figura 4.5.

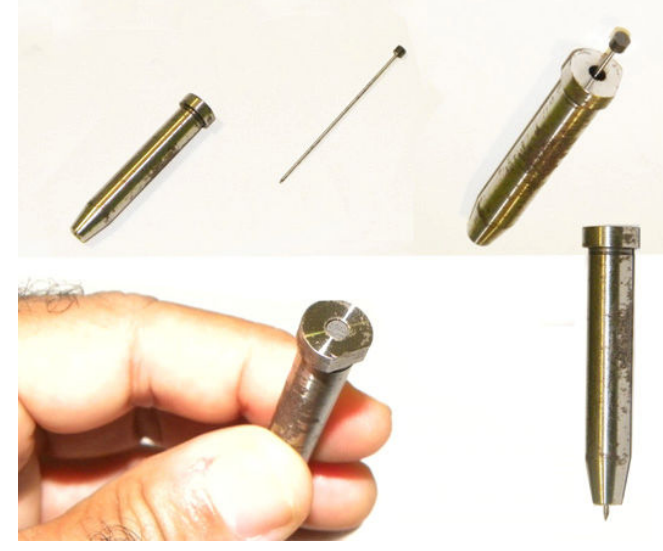

Figura 4.4: Agulha, mavica, e conjunto montado Fonte: Corona (2011)

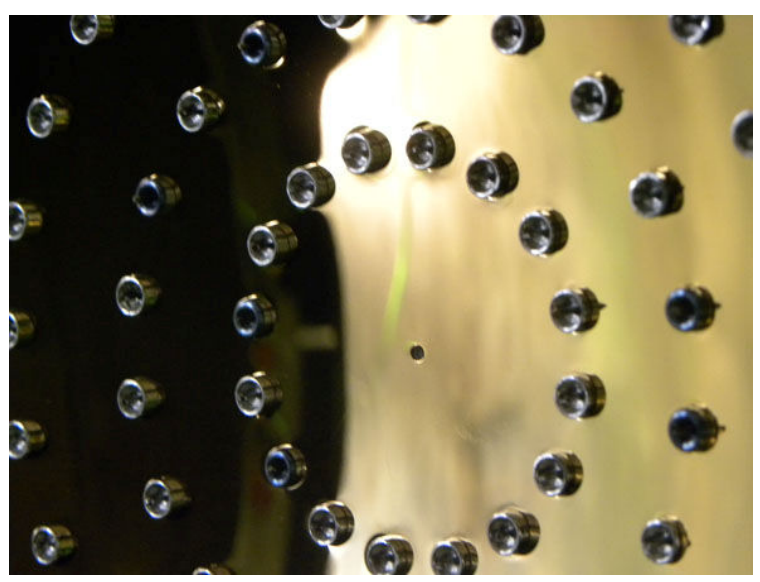

Figura 4.5: Disposição da sub-montagem agulha/mavica no molde fềmea Fonte: Corona (2011)

As agulhas de injeção atuais são compradas, e por sua vez fabricadas com o tipo de Aço SAE 1045, com teor médio de carbono (45\%). Essa composição lhe confere resistência ao desgaste, às temperaturas mais altas, e principalmente maior dureza, uma vez que são recomendados para utilização em ferramentas e componentes expostos às solicitações mecânicas. No anexo 1 deste estudo tem-se as especificações técnicas do fornecedor da matéria prima da agulha. As mavicas, invólucros da agulha, são fabricadas em aço ferramenta VCO (ref. L10 da ABNT e 1.2721 pela DIN), indicado para trabalhos a quente e situações que envolvam aspectos de alta resistência às solicitações mecânicas. 
Sendo esta a parte do molde que ficará fixa durante o processo de confinamento da massa de plástico, na figura 4.6 demonstra-se a sua montagem a uma das placas de sujeição.

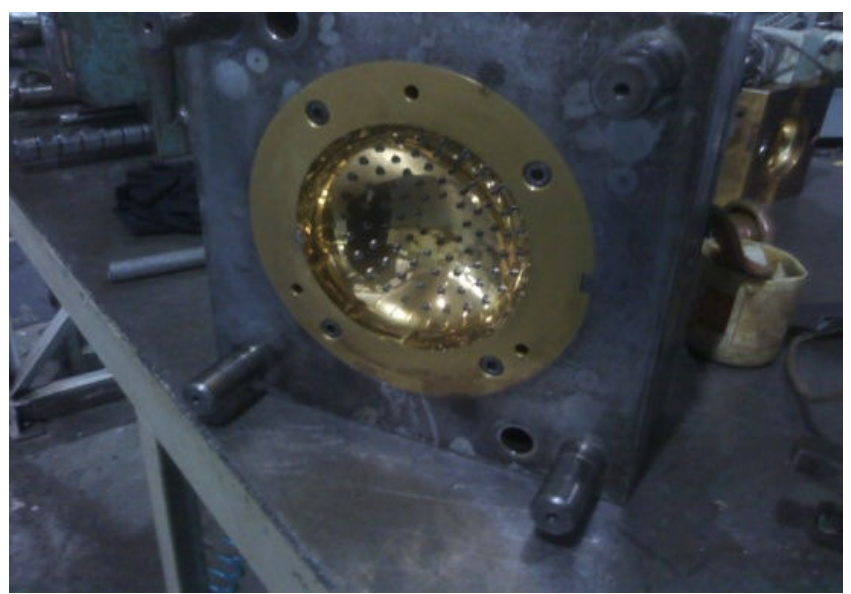

Figura 4.6: Montagem do molde do espalhador à base - Parte fixa Fonte: Corona (2011)

Observa-se aqui que apesar de ser confeccionado com o mesmo tipo de material da placa, o macho do molde é revestido com verniz de titânio, o que lhe confere o aspecto dourado (polido), que traduz-se em melhor nível de rugosidade ao produto acabado. A figura 4.7 mostra o molde montado disposto na máquina injetora. Quando ocorre falha no sistema referente à quebra de agulhas adota-se um tempo de espera para que haja resfriamento das placas, para em seguida iniciar a tarefa de desmontagem. A alocação e retirada dos moldes na máquina injetora são executadas através de guindastes manuais de corrente.

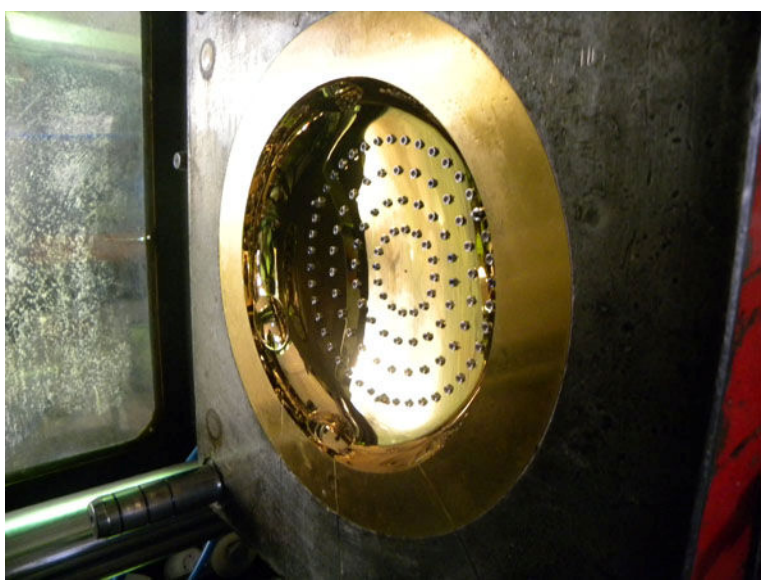

Figura 4.7: Parte fixa do molde disposta na máquina injetora

Fonte: Corona (2011)

O ferramenteiro é o profissional encarregado de fazer a desmontagem do molde, já na bancada de serviços, para efetuar a troca das agulhas quebradas por componentes novos, configurando-se assim como itens não reparáveis. Neste ínterim efetua-se uma inspeção visual e manual de todas as agulhas na busca por não conformidades. Via de regra, não há 
reposição de componentes quando se utiliza destas técnicas, senão das agulhas quebradas, excetua-se ainda quando as deformações no componente sejam detectáveis, demonstrando-se um recurso de percepção empírico extremamente ineficaz.

O turno de trabalho do ferramenteiro restringe-se ao período de segunda a sexta, das 08:00 as 12:00 e das 13:00 as 17:00h, sendo o sábado de meio expediente. Este fato influi diretamente no volume de produtos acabados haja vista que na ocorrência de falhas a partir do meio-dia do sábado, estas somente terão manutenção corretiva na segunda feira a partir das 08:00h. Considerando-se o intervalo sem manutenção (44 horas), e que a injetora possui um ciclo de 92 produtos/hora, deixa-se eventualmente de produzir até 4.048 espalhadores, considerando-se apenas uma máquina, como cada chuveiro do modelo Mega Banho é vendido no mercado local (Aracaju) à média de $\mathrm{R} \$ 260,00$, chegar-se-á a um custo de oportunidade de $\mathrm{R} \$ 1.052 .480,00$.

Para complementar o sistema, a figura 4.8 mostra a parte móvel disposta na injetora correspondente ao molde convexo. Esta placa mantém a massa plástica com a alta pressão necessária para mantê-la no interior do molde até que haja solidificação na forma desejada e posterior extração do produto acabado. Não há registro de não conformidades referente a esta placa, e os seus 101 furos servem como guia das agulhas, que os transpassa cerca de 2 a $3 \mathrm{~mm}$ a cada novo produto fabricado.

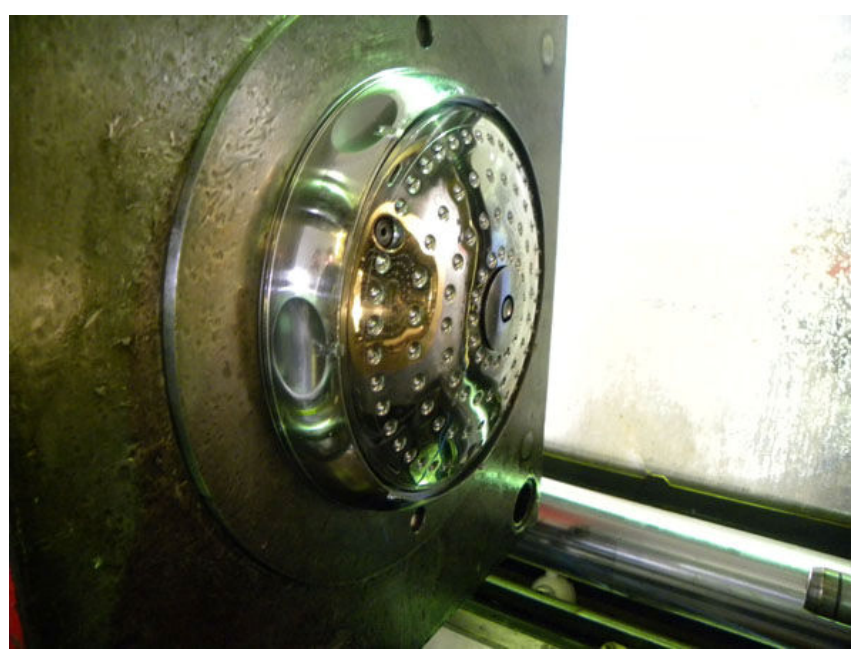

Figura 4.8: Parte móvel do molde disposta na máquina injetora

Fonte: Corona (2011)

$\mathrm{Na}$ figura 4.9, apresenta-se um desenho esquemático do processo de injeção do espalhador: no item 1, pode-se verificar o conjunto mavica e agulha montado na parte fixa da placa do molde; o item 2, mostra o mesmo conjunto em corte; a área do item 3 corresponde ao espaço vazio após o retorno da placa do molde móvel; e, no item 4, tem-se o polímero conformado como produto; no detalhe circundado em vermelho vê-se a massa plástica (em branco), que depois de depositada sofre resfriamento e solidificação. 


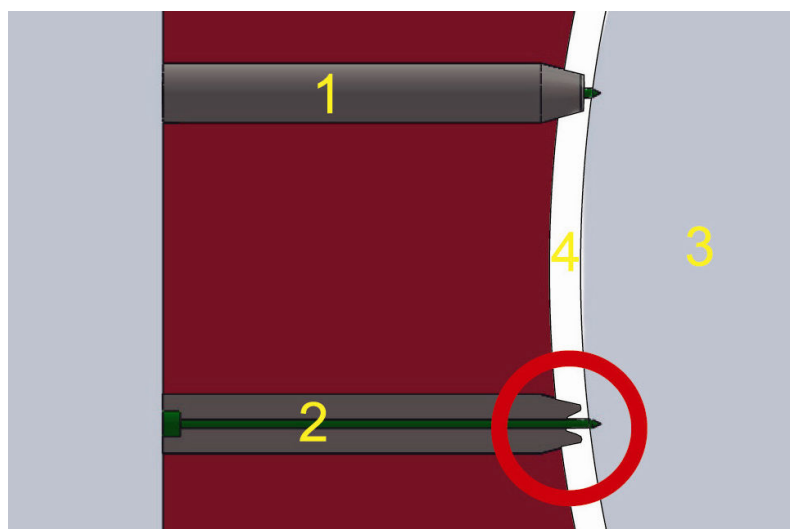

Figura 4.9: Visão esquemática de comportamento da operação

A figura 4.10, demonstra o instante em que o produto conformado é ejetado do molde provocando a quebra da agulha. A agulha sai acoplada ao produto, vedando o furo de saída da água, comprometendo sua funcionalidade, e nos casos em que são extraídas manualmente após a sua produção, constatou-se em testes, a saída de jato de água torto. A falha em apenas uma agulha determina a parada do sistema.

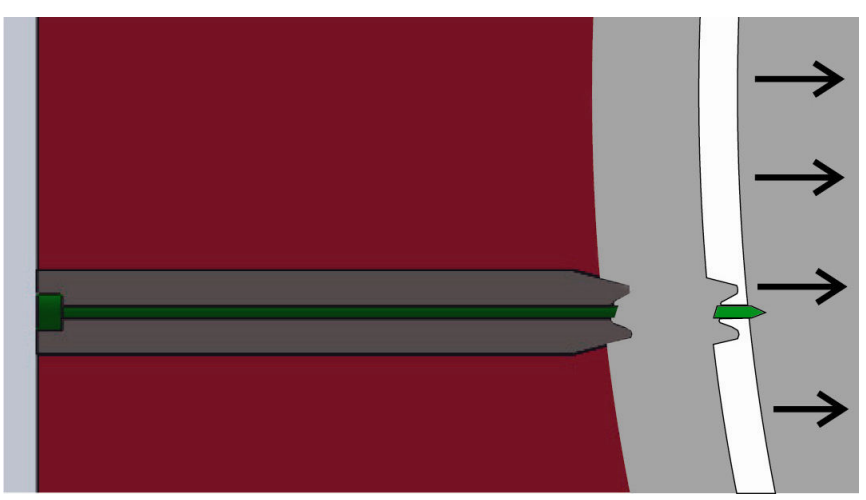

Figura 4.10: Quebra da agulha na extração do produto espalhador

A figura 4.11, apresenta o produto injetado não conforme. A inspeção da qualidade é feita através da visualização do produto sobre um emissor de luz, e podem-se verificar os furos tapados que impedem a passagem da luz. Fato é que não há estipulação de periodicidade para estes testes, e ao se detectar um produto com problemas um ciclo pode ter comprometimento quase que a totalidade da produção. Por outro lado a manutenção preventiva eleva demasiadamente os custos de produção. 


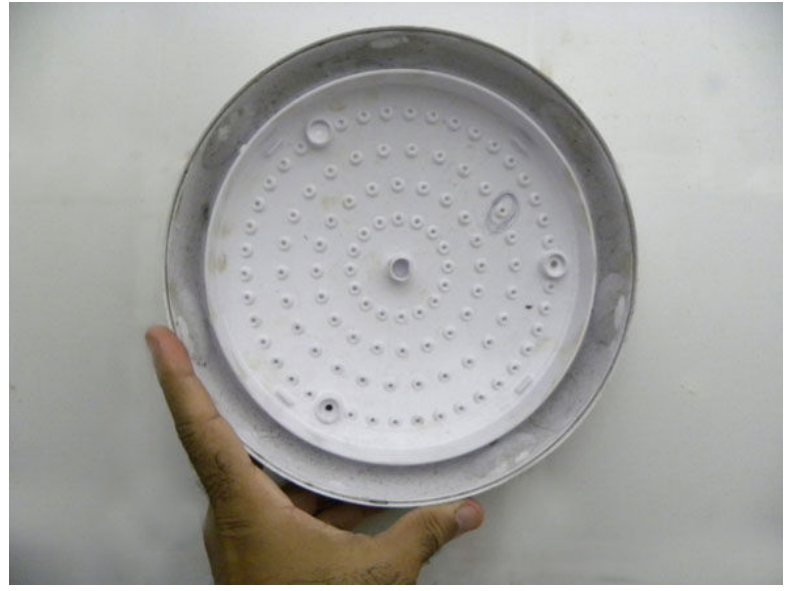

Figura 4.11: Detecção de defeito em produto não conforme

Fonte: Corona (2011)

\subsection{Aplicação da FMEA}

Submetidas a esforços que envolvem tensões de temperatura de trabalho, ambiente, e pressão, pode-se observar nas amostras das figuras 4.12 e 4.13, duas agulhas que sofreram quebra no molde e ao finalizarem o processo de conformação mecânica foram incorporadas ao produto final. A partir dessa constatação busca-se através da sistematização, aplicar uma análise qualitativa objetivada à identificação e avaliação dos modos de falha, através de um formulário de FMEA.

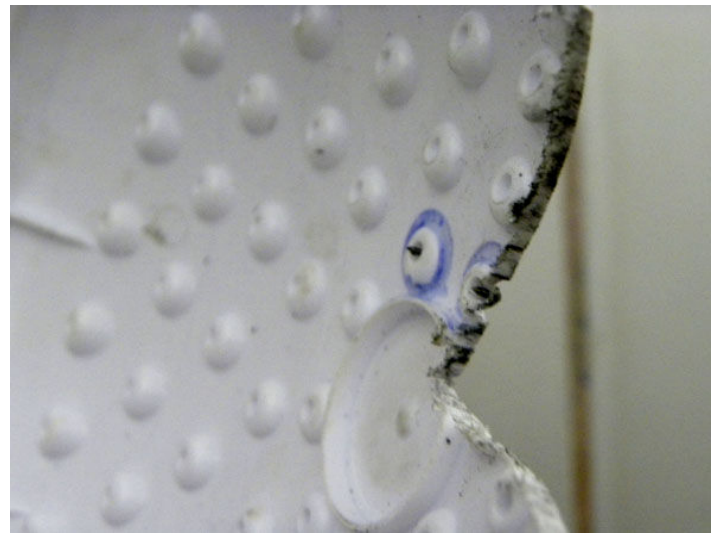

Figura 4.12: Extremidade da agulha rompida do corpo

Fonte: Corona (2011) 


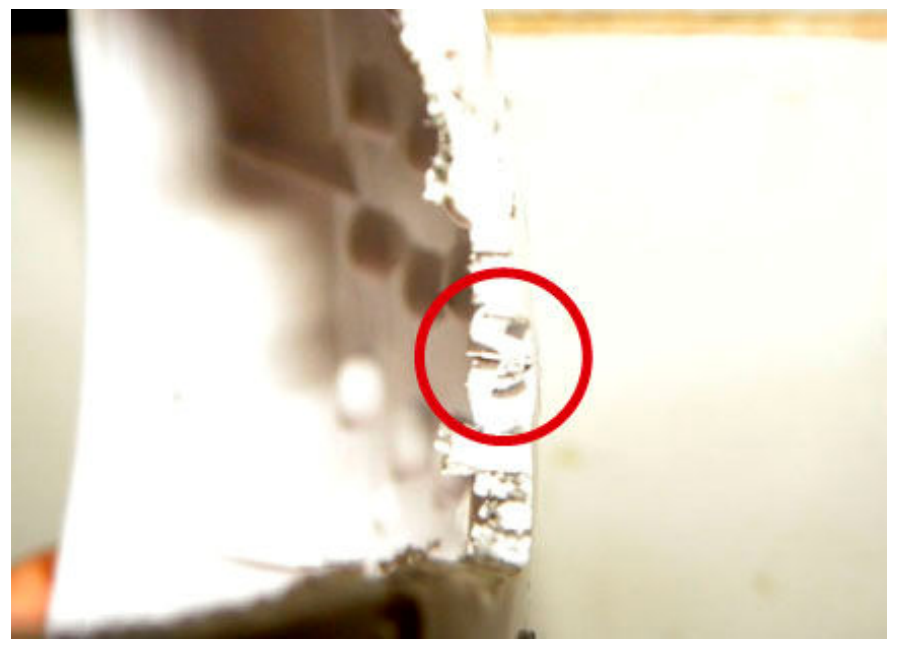

Figura 4.13: Agulhas incrustadas no produto injetado

Fonte: Corona (2011)

Por tratar-se de um componente crítico para os resultados da confiabilidade do sistema e do produto final, tornou-se ímpar a base de informações e análise em parceria com os profissionais da equipe de manutenção do processo. $\mathrm{O}$ ferramenteiro destacado pela equipe de engenharia prestou as informações concernentes às funções desempenhadas pelo sistema, seus subsistemas, e componentes, especificamente envolvidos nas atividades, cuja descrição sumária foi apresentada no item anterior deste estudo. Ressalta-se que o formulário de FMEA serve não só para a análise como também é o documento que poderá ser acessado auxiliando na resolução de problemas futuros.

De acordo com as prerrogativas balizadas na seção de metodologia analisou-se o item com a maior frequência de ocorrência de falhas e custo mais elevado, uma vez que as informações serão imprescindíveis à qualidade e confiabilidade no desenvolvimento de um novo produto. Determinou-se então que as funções primárias do sistema envolveriam atividades desde as etapas de montagem até a execução do produto espalhador, fase esta em que se provêm os furos uniformes.

Apos identificação das funções principais das agulhas e de seus modos potenciais de falhas buscou-se associá-las aos efeitos potenciais, que além de utilizar as referências técnicas baseou-se no comprometimento das funcionalidades no processo de injeção (efeito local), e seu impacto quando da utilização do produto pelo consumidor final (efeito global). A análise é demonstrada no preenchimento do formulário como disposto na figura 4.14. 


\begin{tabular}{|c|c|c|}
\hline Componente & Funções & Modo Potencial de Falha \\
\hline \multirow{10}{*}{ 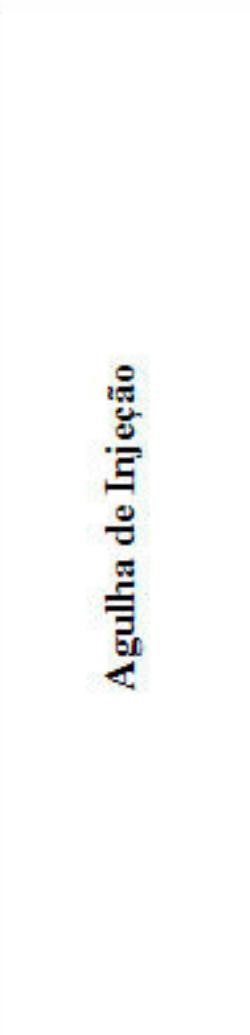 } & $\begin{array}{l}\text { Encaixar-se na mavica (Ajuste com } \\
\text { folga) }\end{array}$ & Não encaixar \\
\hline & Acoplar-se no furo do molde móvel & Não alinhar \\
\hline & \multirow{2}{*}{ Prover furos no produto espalhador } & Não furar \\
\hline & & Furar não conforme \\
\hline & $\begin{array}{l}\text { Prover uniformidade nas "paredes" do } \\
\text { furo }\end{array}$ & Furar não conforme \\
\hline & $\begin{array}{l}\text { Suportar as tensões de tração em } \\
\text { decorrência da saída da massa plástica } \\
\text { resfriada }\end{array}$ & $\begin{array}{l}\text { Dilatar linearmente em excesso } \\
\text { a agulha }\end{array}$ \\
\hline & \multirow{2}{*}{$\begin{array}{l}\text { Suportar choque mecânico com } \\
\text { variações de temperatura }\end{array}$} & Dilatação superficial excessiva \\
\hline & & $\begin{array}{l}\text { Não suportar variação de } \\
\text { temperatura }\end{array}$ \\
\hline & \multirow{2}{*}{$\begin{array}{l}\text { Deformar-se, mantendo-se nos limites } \\
\text { da tolerância dimensional dos furos } \\
(+-0,02) \text { em temperatura operacional } \\
\text { de até } 2000 \mathrm{C} \text {. }\end{array}$} & $\begin{array}{l}\text { Exceder tensão máxima do } \\
\text { material }\end{array}$ \\
\hline & & Desgaste prematuro da agulha \\
\hline
\end{tabular}

Figura 4.14: Determinação de Modos Potenciais de Falha

Para consolidação da análise utilizou-se ainda das informações fornecidas em históricos de manutenção e estabeleceram-se graduações para a gravidade de cada efeito. Considera-se ainda que para as relações de efeitos no que concerne ao furo não conforme cego tem-se como consequência a não passagem do jato de água. O estado desalinhado produz o jato de água torto, e os furos executados com diâmetro acima do permissível na tolerância dimensional de projeto produzem excesso no volume do jato de água. Já os que saem com diâmetro abaixo da tolerância redundam em jato com baixa vazão (água pingando). Assim que são detectadas as falhas por quebra da agulha, por inspeção aleatória, dá-se a parada da máquina para manutenção corretiva.

Todos os efeitos apresentados contribuem para a perda da uniformidade da ducha, o que coincide como mote promocional do produto, uma das principais especificações de projeto do modelo Mega Banho, e essas não conformidades geram insatisfação ao cliente final.

$\mathrm{Na}$ figura 4.15, apresentam-se os resultados em que as falhas frequentemente originam, via de regra a quebra da agulha. 


\begin{tabular}{|l|l|c|}
\hline Modo Potencial de Falha & \multicolumn{1}{|c|}{ Efeitos } & S \\
\hline Não encaixar & $\begin{array}{l}\text { Não monta o molde de } \\
\text { injeção }\end{array}$ & 1 \\
\hline Não alinhar & Deformação da agulha & 1 \\
\hline Não furar & $\begin{array}{l}\text { Sem furo } \\
\text { Furo cego }\end{array}$ & 7 \\
\hline Furar não conforme & $\begin{array}{l}\text { Furo incompatível com a } \\
\text { tolerância geométrica } \\
\text { Furo com diâmetro } \\
\text { incompativel com a } \\
\text { tolerância dimensional }\end{array}$ & 8 \\
\hline Furar não conforme & $\begin{array}{l}\text { Furar com estado de } \\
\text { superficie incompatível }\end{array}$ & 5 \\
\hline $\begin{array}{l}\text { Dilatar linearmente em } \\
\text { excesso a agulha }\end{array}$ & $\begin{array}{l}\text { Quebra da agulha - Parada da } \\
\text { máquina }\end{array}$ & 9 \\
\hline $\begin{array}{l}\text { Dilatação superficial } \\
\text { excessiva }\end{array}$ & $\begin{array}{l}\text { Furo com diâmetros efetivos } \\
\text { em valores que extrapolam a } \\
\text { tolerância dimensional }\end{array}$ & 5 \\
\hline $\begin{array}{l}\text { Não suportar variação de } \\
\text { temperatura }\end{array}$ & $\begin{array}{l}\text { Quebra da agulha - Parada da } \\
\text { máquina }\end{array}$ & 9 \\
\hline $\begin{array}{l}\text { Exceder tensão máxima do } \\
\text { material }\end{array}$ & $\begin{array}{l}\text { Quebra da agulha - Parada da } \\
\text { máquina }\end{array}$ & 9 \\
\hline $\begin{array}{l}\text { Desgaste prematuro da } \\
\text { agulha }\end{array}$ & $\begin{array}{l}\text { Quebra da agulha - Parada da } \\
\text { máquina }\end{array}$ & 9 \\
\hline
\end{tabular}

Figura 4.15: Relação entre Modos Potenciais de Falha, seus Efeitos, e Severidade.

A partir do estudo das causas pode-se verificar que os mecanismos potenciais de falha relacionam-se às propriedades mecânicas do material utilizado para confecção da agulha, no caso o Aço 1045. Sabe-se notadamente que a qualidade da análise via FMEA é diretamente proporcional ao conhecimento da equipe, portanto ainda que não fora executado ensaio metalográfico, devido a natureza típica de circunstâncias, relacionaram-se os efeitos a uma especificação incorreta de material, demasiadamente sensível as sobrecargas ao qual está predisposto a escoamento, instabilidade elástica, deformações, desgaste, fadiga, e ruptura ou fratura. O elevado índice de dureza da agulha pode ocasionar inclusive o desgaste das "paredes" da mavica, local onde esta se aloja a agulha, provocando uma folga axial, e consequentemente furos fora dos padrões dimensionais.

A figura 4.16, mostra as causas, e as relações de ocorrências, que devido à preponderância na avaliação com escala qualitativa de valores muito altos, indicam a necessidade de se fazer alterações no projeto da agulha. Tem-se ainda a estimativa para detecção, cuja correspondência ao sistema convencional, de acordo com os parâmetros 
apresentados na seção de metodologia permite inferir que são incipientes, havendo inspeções aleatórias da qualidade, um sistema ineficiente haja vista que as falhas somente são detectadas após um determinado lote de peças já ter sido fabricado com especificações não conformes. Não há em execução qualquer atividade no que diz respeito à avaliação para os controles de prevenção e detecção.

\begin{tabular}{|c|c|c|c|c|}
\hline Causas Potenciais & $\mathbf{O}$ & D & RPN & Ações Recomendadas \\
\hline $\begin{array}{l}\text { Deformação permanente do } \\
\text { material }\end{array}$ & 3 & 4 & 12 & \multirow{2}{*}{$\begin{array}{l}\text { Aplicar tolerância dimensional e } \\
\text { geométrica compativel com material } \\
\text { considerando a temperatura de } \\
\text { operação. } \\
\text { Reprojeto da forma da agulha }\end{array}$} \\
\hline Folga Axial & 3 & 4 & 12 & \\
\hline Quebra da agulha & 7 & 8 & 392 & Verificar se houve quebra de agulha \\
\hline $\begin{array}{l}\text { Material excede deformação } \\
\text { axial e deformação lateral }\end{array}$ & 4 & 8 & 256 & $\begin{array}{l}\text { Utilizar material com melhor índice de } \\
\text { tenacidade }\end{array}$ \\
\hline Superfície irregular da agulha & 4 & 4 & 80 & $\begin{array}{l}\text { Utilizar material com melhor índice de } \\
\text { elasticidade }\end{array}$ \\
\hline Material parcialmente elástico & 7 & 9 & 567 & \multirow[b]{2}{*}{$\begin{array}{l}\text { Utilizar material com melhor resistência } \\
\text { à estricção }\end{array}$} \\
\hline $\begin{array}{l}\text { Tensões do sistema excedem } \\
\text { limites do material }\end{array}$ & 4 & 9 & 180 & \\
\hline Fadiga do material & 7 & 9 & 567 & \multirow{2}{*}{ Utilizar Material mais dúctil } \\
\hline Material frágil & 7 & 9 & 567 & \\
\hline $\begin{array}{l}\text { Baixo valor de deformação do } \\
\text { material }\end{array}$ & 8 & 9 & 648 & $\begin{array}{l}\text { Utilizar material com melhor índice de } \\
\text { resistência a choques mecânicos e } \\
\text { variações de temperatura }\end{array}$ \\
\hline
\end{tabular}

Figura 4.16: Relação entre causas potenciais de falhas, ocorrências, detecção, e ações.

Para estabelecer a hierarquia das melhorias necessárias e definição de suas respectivas estratégias utilizou-se o modo tradicional de cálculo do Grau de Prioridade de Risco (Risk Priority Number - RPN) para cada modo de falha. Pode-se constatar, portanto que os maiores valores de risco estão associados a falhas que ocasionam a quebra da agulha, que por sua vez remetem ao comprometimento do material ao qual é fabricada. A discussão sobre esta questão, com o ferramenteiro e com o pessoal responsável pela manutenção das máquinas injetoras, gerou as ações recomendadas. Uma análise sobre as propostas de solução apontou as seguintes diretrizes:

- Pelo tipo das falhas priorizadas pelo RPN os esforços serão direcionados no sentido de minimizar as ocorrências de falha. De acordo com esta premissa estabeleceu-se que os problemas potenciais encontrados devem ser solucionados através de alterações no projeto da agulha; 
- Considera-se que há uma sequência de eventos que estão relacionados às propriedades mecânicas do material da agulha, incompatível com os esforços, sendo este o principal fator gerador das falhas. O novo componente, portanto deverá ser confeccionado com material mais dúctil.

- Para a obtenção de melhores especificações ao projeto do novo componente utilizarse-á a aplicação de uma análise FEA da agulha atual, com o objetivo de verificar a distribuição de tensões e consequentes variações de deslocamentos e deformação do material sob circunstâncias de simulação do ambiente operacional.

No Apêndice 1 deste estudo encontra-se disponível um quadro completo da FMEA realizada.

\subsection{Dados operacionais de tempos até ocorrência de falha para agulha convencional}

Com o propósito de se obter os dados de confiabilidade do sistema fez-se um levantamento do Tempo até Falha (TTF) do componente agulha de injeção, possibilitando quantificar a Taxa de Falha - h(t), e o Tempo Médio até Falhar - MTTF. Esses resultados servirão como referência para efeitos comparativos, e processo de validação do novo componente, conforme disposto nos processos metodológicos, após a sua implementação, cumprindo uma das metas estabelecidas para este estudo de caso.

Sobre as prerrogativas da amostra ressalta-se que, a coleta dos dados ocorreu num período de três meses compreendidos entre os dias 01 de março e 31 de abril. Uma máquina injetora foi notadamente escolhida para este estudo por apresentar maiores números de parada para manutenção, dado coletado pelo histórico fornecido pela empresa.

A primeira medição do Tempo até Falha considerou como $t=0$ a 00:00h do dia 01 de março, e a suspensão de dados deu-se ao final de 2208 horas. Os registros de falhas são descritos em minutos.

A agulha caracteriza-se como um componente não reparável, e para cada ocorrência tem-se que $\mathrm{t}=\mathrm{o}$, e para o cômputo da falha seguinte adicionou-se o período referente à manutenção, dado que esta é a condição sine qua non para retorno da atividade.

Ainda que ocorresse quebra de mais de uma unidade do componente considerou-se como falha a detecção da não conformidade e subsequente parada da máquina injetora. 
A tabela 4.1, mostra detalhadamente os dados relacionados à quantidade de falhas, o número de agulhas quebradas por falhas (paradas) e o Tempo até Falhar das ocorrências.

Tabela 4.1: Levantamento de falhas por ocorrências e quantidade de agulhas quebradas Modelo de Agulha Convencional

\begin{tabular}{|c|c|c|c|c|c|c|c|c|c|c|c|c|c|c|}
\hline \multicolumn{15}{|c|}{$\begin{array}{l}\text { Falhas por ocorrências e quantidade de agulhas quebradas } \\
\text { Modelo Convencional de Agulha }\end{array}$} \\
\hline \multicolumn{5}{|c|}{ Março } & \multicolumn{5}{|c|}{ Abril } & \multicolumn{5}{|c|}{ Maio } \\
\hline.$\tilde{\theta}$ & 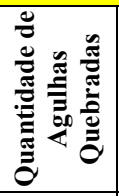 & 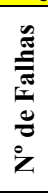 & ס & 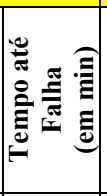 & 苟 & 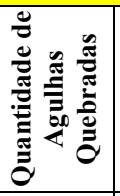 & 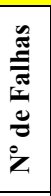 & 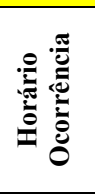 & 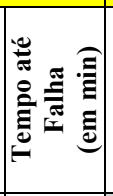 & $\stackrel{\frac{\pi}{\theta}}{\theta}$ & 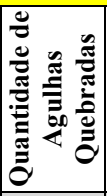 & 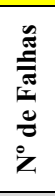 & ס & 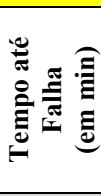 \\
\hline 1 & 1 & 1 & $10: 03$ & 603 & 1 & 0 & 0 & $\mathrm{x}$ & $\mathrm{x}$ & 1 & 1 & 1 & 08:06 & 1562 \\
\hline 2 & 2 & 1 & $15: 25$ & 1762 & 2 & 3 & 1 & $04: 48$ & 1951 & 2 & 1 & 1 & $10: 40$ & 1594 \\
\hline 3 & 0 & 0 & $\mathrm{x}$ & $\mathrm{x}$ & 3 & 0 & 0 & $\mathrm{x}$ & $\mathrm{x}$ & 3 & 3 & 1 & $06: 16$ & 1176 \\
\hline 4 & 1 & 1 & $22: 12$ & 3287 & 4 & 3 & 1 & $15: 29$ & 3521 & 4 & 1 & 1 & $17: 35$ & 2119 \\
\hline 5 & 3 & 1 & $12: 54$ & 882 & 5 & 0 & 0 & $\mathrm{x}$ & $\mathrm{x}$ & 5 & 2 & 1 & $14: 12$ & 1237 \\
\hline 6 & 0 & 0 & $\mathrm{x}$ & $\mathrm{x}$ & 6 & 3 & 1 & $16: 53$ & 2964 & 6 & 0 & 0 & $\mathrm{x}$ & $\mathrm{x}$ \\
\hline 7 & 3 & 2 & $\begin{array}{l}12: 07 \\
20: 03\end{array}$ & $\begin{array}{c}2833 \\
476 \\
\end{array}$ & 7 & 2 & 2 & $\begin{array}{l}12: 46 \\
21: 18\end{array}$ & $\begin{array}{l}1193 \\
1232\end{array}$ & 7 & 3 & 1 & $07: 29$ & 2477 \\
\hline 8 & 2 & 1 & $18: 25$ & 1342 & 8 & 0 & 0 & $\mathrm{x}$ & $\mathrm{x}$ & 8 & 0 & 0 & $x$ & $\mathrm{x}$ \\
\hline 9 & 1 & 1 & 13:07 & 1122 & 9 & 1 & 1 & $06: 15$ & 1977 & 9 & 2 & 1 & $00: 28$ & 2459 \\
\hline 10 & 1 & 1 & $14: 01$ & 1494 & 10 & 1 & 1 & $23: 42$ & 1047 & 10 & 1 & 1 & $21: 16$ & 1248 \\
\hline 11 & 0 & 0 & $\mathrm{x}$ & $\mathrm{x}$ & 11 & 0 & 0 & $\mathrm{x}$ & $\mathrm{x}$ & 11 & 0 & 0 & $\mathrm{x}$ & $\mathrm{x}$ \\
\hline 12 & 1 & 1 & $07: 30$ & 2489 & 12 & 6 & 1 & 07:03 & 1881 & 12 & 1 & 1 & $20: 55$ & 2859 \\
\hline 13 & 1 & 1 & $16: 20$ & 1970 & 13 & 2 & 1 & $08: 57$ & 1494 & 13 & 2 & 1 & $13: 49$ & 1014 \\
\hline 14 & 3 & 2 & $\begin{array}{l}13: 20 \\
18: 40 \\
\end{array}$ & $\begin{array}{c}1260 \\
380 \\
\end{array}$ & 14 & 0 & 0 & $\mathrm{x}$ & $\mathrm{x}$ & 14 & 1 & 1 & $07: 20$ & 1051 \\
\hline 15 & 2 & 1 & $14: 37$ & 1197 & 15 & 2 & 1 & 19:11 & 3494 & 15 & 1 & 1 & 23:00 & 940 \\
\hline 16 & 4 & 2 & $\begin{array}{l}11: 26 \\
22: 08\end{array}$ & \begin{tabular}{c|c}
1249 \\
642
\end{tabular} & 16 & 2 & 1 & $11: 00$ & 949 & 16 & 3 & 2 & $\begin{array}{l}10: 33 \\
21: 57\end{array}$ & $\begin{array}{l}693 \\
684\end{array}$ \\
\hline 17 & 0 & 0 & $\mathrm{x}$ & $\mathrm{x}$ & 17 & 2 & 1 & $14: 30$ & 1650 & 17 & 2 & 1 & $14: 31$ & 684 \\
\hline 18 & 3 & 1 & $03: 56$ & 1788 & 18 & 0 & 0 & $\mathrm{x}$ & $\mathrm{x}$ & 18 & 3 & 1 & 04:03 & 812 \\
\hline 19 & 0 & 0 & $\mathrm{x}$ & $\mathrm{x}$ & 19 & 1 & 1 & $02: 03$ & 2133 & 19 & 2 & 1 & $17: 36$ & 813 \\
\hline 20 & 1 & 1 & $07: 54$ & 3118 & 20 & 1 & 1 & $18: 42$ & 2440 & 20 & 4 & 2 & $\begin{array}{l}13: 24 \\
20: 47\end{array}$ & $\begin{array}{c}1188 \\
443\end{array}$ \\
\hline 21 & 2 & 1 & $20: 45$ & 771 & 21 & 0 & 0 & $\mathrm{x}$ & $\mathrm{x}$ & 21 & 1 & 1 & 11:03 & 443 \\
\hline 22 & 2 & 2 & $\begin{array}{l}12: 12 \\
16: 28\end{array}$ & $\begin{array}{l}927 \\
256\end{array}$ & 22 & 3 & 1 & $04: 26$ & 2024 & 22 & 1 & 1 & 15:09 & 1686 \\
\hline 23 & 3 & 1 & 11:09 & 1121 & 23 & 1 & 1 & $10: 09$ & 1783 & 23 & 0 & 0 & $\mathrm{x}$ & $\mathrm{x}$ \\
\hline 24 & 4 & 1 & $06: 20$ & 431 & 24 & 1 & 1 & $05: 38$ & 1169 & 24 & 2 & 1 & $03: 29$ & 2180 \\
\hline 25 & 1 & 1 & $19: 21$ & 781 & 25 & 0 & 0 & $\mathrm{x}$ & $\mathrm{x}$ & 25 & 1 & 1 & $16: 25$ & 2216 \\
\hline 26 & 2 & 1 & $11: 26$ & 975 & 26 & 2 & 1 & $12: 00$ & 3262 & 26 & 2 & 2 & $\begin{array}{l}15: 02 \\
21: 39\end{array}$ & $\begin{array}{c}1357 \\
397\end{array}$ \\
\hline
\end{tabular}

\begin{tabular}{|c|c|c|c|c|c|c|c|c|c|c|c|c|}
\hline \multicolumn{13}{|c|}{ Continuação da Tabela 4.1} \\
\hline 27 & 1 & 1 & 05:50 & 110 & & $03: 15$ & 915 & 27 & 0 & 0 & $\mathrm{x}$ & $\mathrm{x}$ \\
\hline
\end{tabular}




\begin{tabular}{|c|c|c|c|c|c|c|c|c|c|c|c|c|c|c|}
28 & 1 & 1 & $21: 08$ & 918 & 28 & 3 & 2 & $\begin{array}{c}14: 44 \\
22: 37\end{array}$ & $\begin{array}{c}2129 \\
473\end{array}$ & 28 & 3 & 1 & $02: 07$ & 1708 \\
\hline 29 & 0 & 0 & 0 & $\mathrm{x}$ & 29 & 1 & 1 & $12: 50$ & 853 & 29 & 0 & 0 & $\mathrm{x}$ & $\mathrm{x}$ \\
\hline 30 & 5 & 3 & $\begin{array}{r}00: 29 \\
11: 23\end{array}$ & $\begin{array}{c}1641 \\
654\end{array}$ & 30 & 2 & 1 & $06: 04$ & 1034 & 30 & 3 & 1 & $13: 32$ & 3565 \\
& & & 1751 & & & & & & & & & \\
\hline 31 & 1 & 1 & $20: 17$ & 1623 & $\mathrm{x}$ & $\mathrm{x}$ & $\mathrm{x}$ & $\mathrm{x}$ & $\mathrm{x}$ & 31 & 1 & 1 & $12: 05$ & 1353 \\
\hline TOT & $\mathbf{5 1}$ & 31 & $\mathrm{X}$ & & TOT & $\mathbf{4 4}$ & 23 & $\mathrm{x}$ & & TOT & $\mathbf{4 7}$ & 28 & $\mathrm{x}$ & \\
\hline
\end{tabular}

Fonte: Corona (2011)

\subsection{Ajustes de Distribuição de Probabilidade ao Modelo de Agulha Convencional}

Para o ajuste em consonância aos dados apresentados utilizou-se o software Proconf, obtendo-se assim os parâmetros de distribuição, e as informações pertinentes à construção dos gráficos baseados nos TTF. A verificação do ajuste realizou-se através dos testes de aderência de qui-quadrado e do modelo analítico de Kolmogorov-Smirnov, sendo que para que a hipótese não seja rejeitada o resultado deve ser aprovado para ambos os testes. Por fim, estabeleceu-se um nível de intervalo de confiança de 95\% para todos os casos.

O modelo de distribuição Exponencial apresentou um parâmetro de localização de 185,8 minutos, e parâmetro de inclinação $\lambda$ de 0,0008 , com MTTF de 1484,1 minutos. O teste de aderência do $\chi^{2}$ obteve um Nível de Significância de 0,0012, já o teste de KolmogorovSmirnov resultou no Nível de Significância de 0,0001. A plotagem de probabilidade está demonstrada na figura 4.17, e os resultados corroboram que a hipótese de que a população segue o modelo Exponencial é rejeitada.

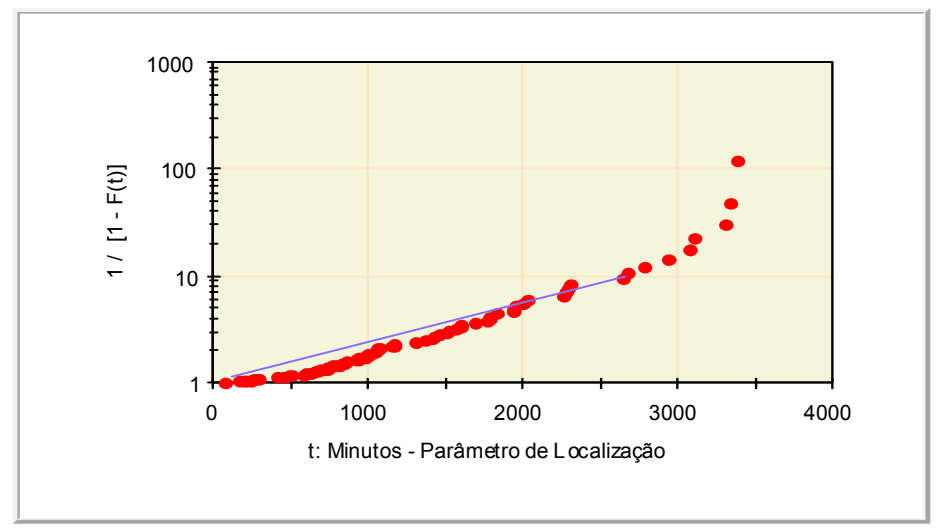

Figura 4.17: Papel de probabilidade Exponencial para operação do sistema de injeção

A modelagem da distribuição Weibull apresentou para o parâmetro de localização o valor de 185,81, o parâmetro de forma $\beta$ de 1,62, o que significa que há deterioração do componente com $\mathrm{h}(\mathrm{t})$ crescente e com tendência a linearidade. Como parâmetro de escala 
tem-se que $\alpha$ é de 1454,74 , e MTTF de 1482,35 minutos. Nos testes de aderência obtiveramse os seguintes resultados: para o teste de $\chi^{2}$ o Nível de Significância de 0,35 , e para o modelo analítico de Kolmogorov-Smirnov o Nível de Significância de 0,20. Pelos resultados demonstrados conclui-se que a hipótese de que a população segue o modelo Weibull não pode ser rejeitada. A plotagem em papel de probabilidade Weibull apresenta-se na figura 4.18.

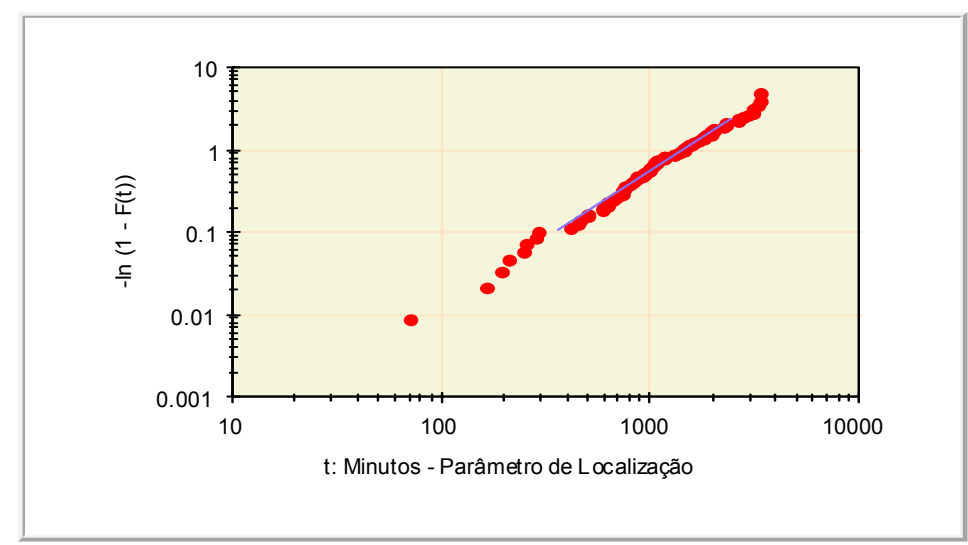

Figura 4.18: Papel de probabilidade Weibull para operação do sistema de injeção

Conforme a modelagem para o papel de probabilidade Normal demonstrado na figura 4.19, tem-se os seguintes parâmetros: $\mu=1484$,1minutos, e $\sigma=811,93$. No cálculo dos testes de aderência de $\chi^{2}$ obteve-se Nível de Significância de 0,0923, e no de KolmogorovSmirnov o Nível de Significância 0,0001, porquanto a hipótese de que a população segue o modelo Normal deve ser rejeitada.

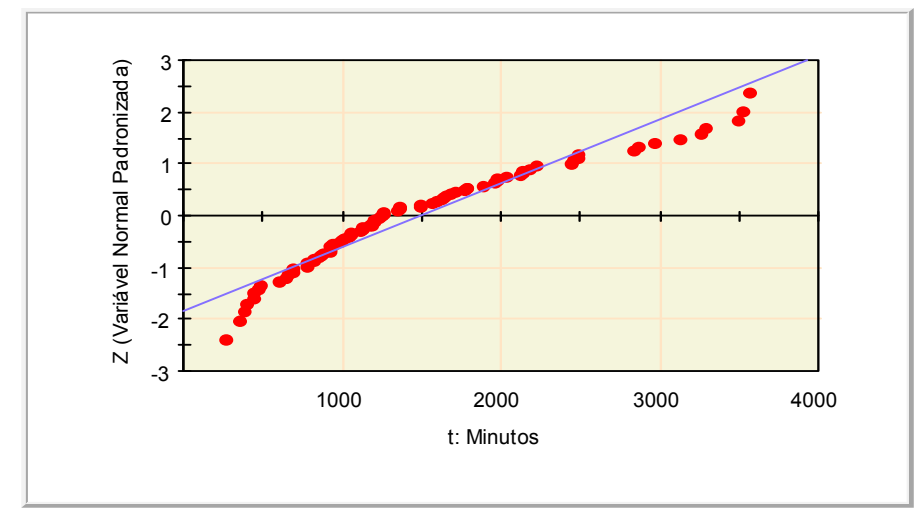

Figura 4.19: Papel de probabilidade Normal para operação do sistema de injeção

Aplicando-se o modelo de papel de probabilidade Lognormal obteve-se o parâmetro de escala $\mu$ de logaritmos dos dados de 7,1425 , e parâmetro de forma $\sigma^{2}=0,36$, cujo MTTF resultou em 1512,14 minutos. Os testes de aderência resultaram para o $\chi^{2}$ o Nível de Significância de 0,6172, e para Kolmogorov-Smirnov o Nível de Significância de 0,3521. 
Desta forma pode-se inferir que a hipótese de que a população segue o modelo Lognormal não pode ser rejeitada. A plotagem em papel de probabilidade Lognormal, e representação das funções de distribuição acumulada (CDF), densidade de probabilidade de falha (PDF), taxa de falha (h), e confiabilidade (R), estão apresentadas nas figuras, 4.20, 4.21, 4.22, 4.23, e 4.24.

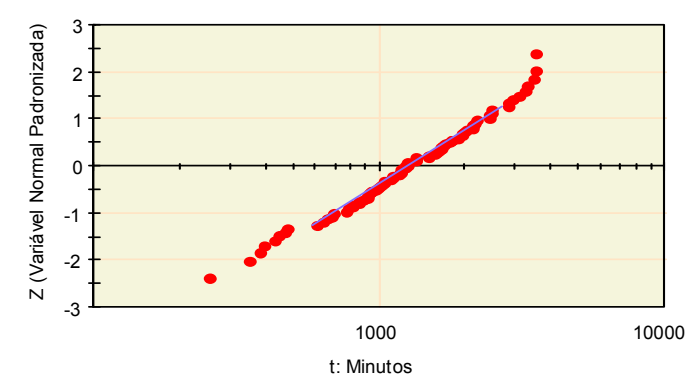

Figura 4.20: Papel de probabilidade Lognormal para operação do sistema de injeção

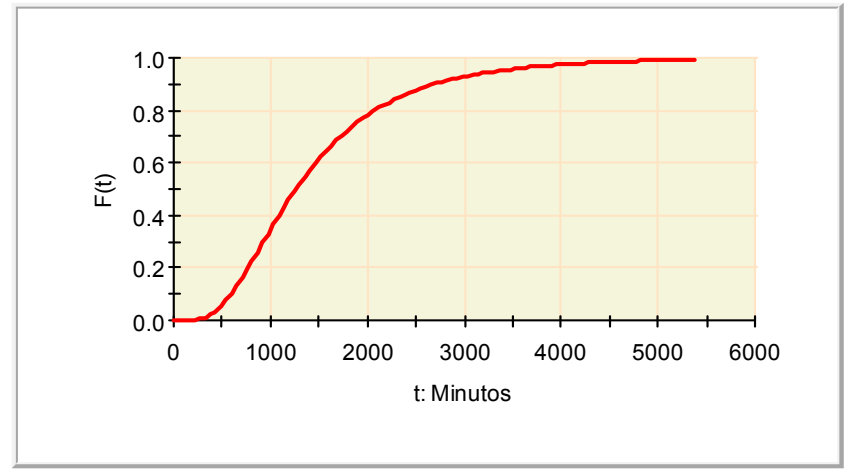

Figura 4.21: Densidade acumulada de falha para distribuição Lognormal

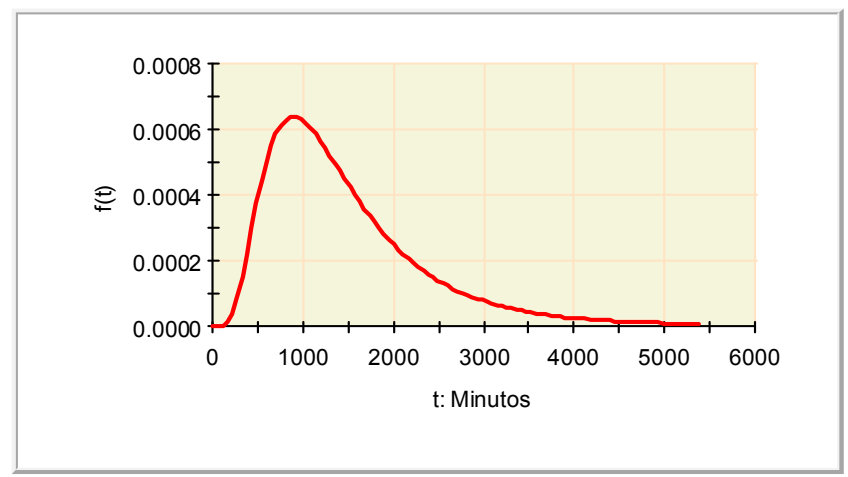

Figura 4.22: Densidade de probabilidade de falha para distribuição Lognormal 


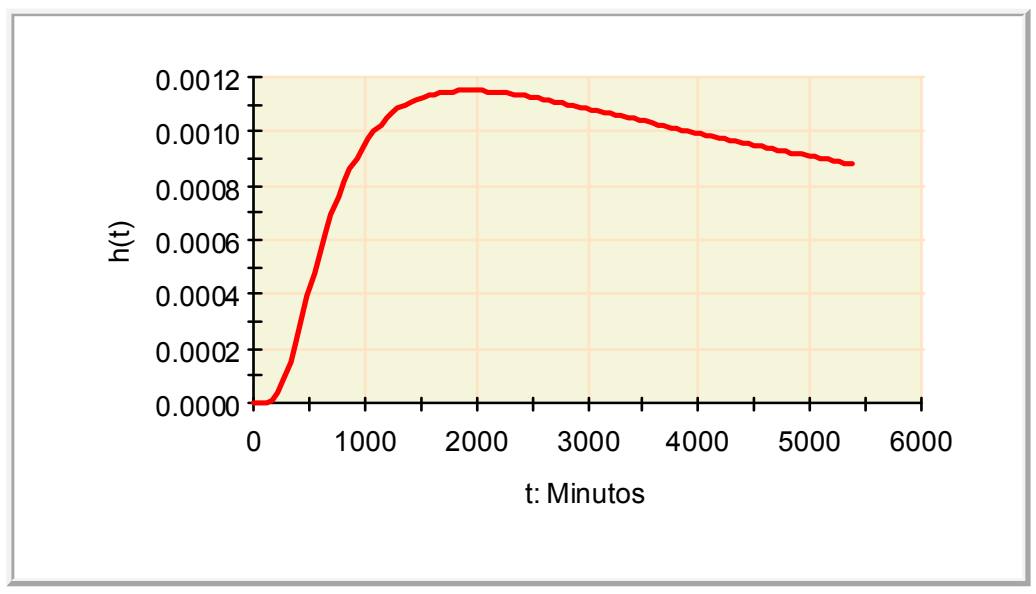

Figura 4.23: Taxa de falha para distribuição Lognormal

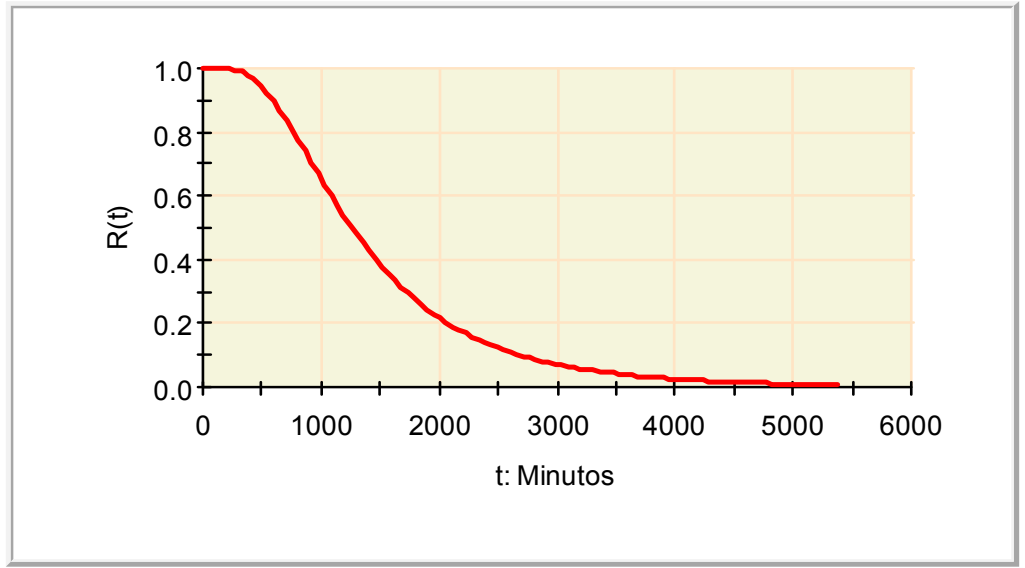

Figura 4.24: Confiabilidade para distribuição Lognormal

A partir dos ajustes de dados pode-se verificar que os modelos Weibull e Lognormal não tiveram a hipótese rejeitada, porém este último apresentou melhor desempenho nos índices dos testes de aderência, tornando-se o modelo de referência para a amostra. Neste modelo para uma confiabilidade de 95\% obteve-se um MTTF de 1503,3 minutos.

\subsection{Modelagem e Simulação de Novo Produto}

De acordo com as diretrizes estipuladas na FMEA, com a utilização do ambiente CAD do software Solidworks fez-se uma modelagem da agulha, e com o Simulation, aplicativo CAE do mesmo software, introduziram-se as especificações técnicas para realização de um estudo estático (FEA), com o objetivo de verificar o comportamento do componente no ambiente operacional virtual. 
Como mostra a figura 4.25, aplicou- se no modelo o AISI Aço 1045, material disponível na biblioteca de materiais do software, ao tempo em que foram anexadas as propriedades mecânicas dispostas na tabela 4.2.

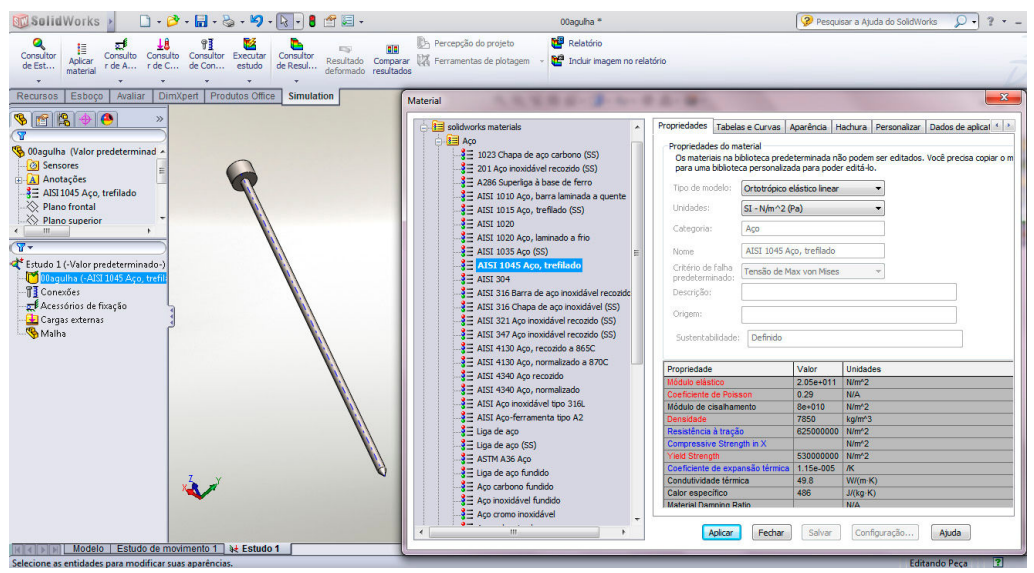

Figura 4.25: Modelagem e aplicação de material e especificações técnicas da agulha convencional

Tabela 4.2: Propriedades do Aço 1045

\begin{tabular}{|c|c|c|}
\hline \multicolumn{2}{|c|}{ Propriedades } & Componente \\
\hline Nome: & AISI 1045 Aço, trefilado & \\
\hline Tipo de modelo: & Linear elástico isotrópico & \\
\hline Critério de falha predeterminado: & Tensão de von Mises máxima & \\
\hline Limite de escoamento: & $5.3 \mathrm{e}+008 \mathrm{~N} / \mathrm{m}^{2}$ & Corpo sólido \\
\hline Resistência à tração: & $6.25 \mathrm{e}+008 \mathrm{~N} / \mathrm{m}^{2}$ & Agulha \\
\hline Módulo elástico: & $2.05 \mathrm{e}+011 \mathrm{~N} / \mathrm{m}^{2}$ & \\
\hline Coeficiente de Poisson: & 0.29 & Convencional \\
\hline Massa específica: & $7850 \mathrm{~kg} / \mathrm{m}^{3}$ & \\
\hline Módulo de cisalhamento: & $8 \mathrm{e}+010 \mathrm{~N} / \mathrm{m}^{2}$ & \\
\hline Coeficiente de expansão térmica: & $1.15 \mathrm{e}-005 /$ Kelvin & \\
\hline
\end{tabular}

Fonte: Base de dados software SolidWorks - Simulation 2011

Para a realização da análise estática deve-se aplicar os acessórios de fixação, estes são responsáveis pelas restrições dos graus de liberdade referentes à rotação e translação. Para este caso utilizou-se o recurso de geometria fixa na cabeça da agulha (superfície plana), sendo este o suporte do componente, de modo que não haverá deslocamento sem que haja uma deformação plástica, ainda que a agulha esteja acoplada à mavica, restringindo-se os graus de liberdade.

Não se aplicou aqui qualquer recurso avançado de geometria de referência para o corpo. Notadamente o excesso de restrições aplicadas ao modelo tem como consequência uma estrutura rígida em demasia, e este estado por sua vez distorce as relações de deformação e tensão. A figura 4.26, demonstra as especificações relatadas. 


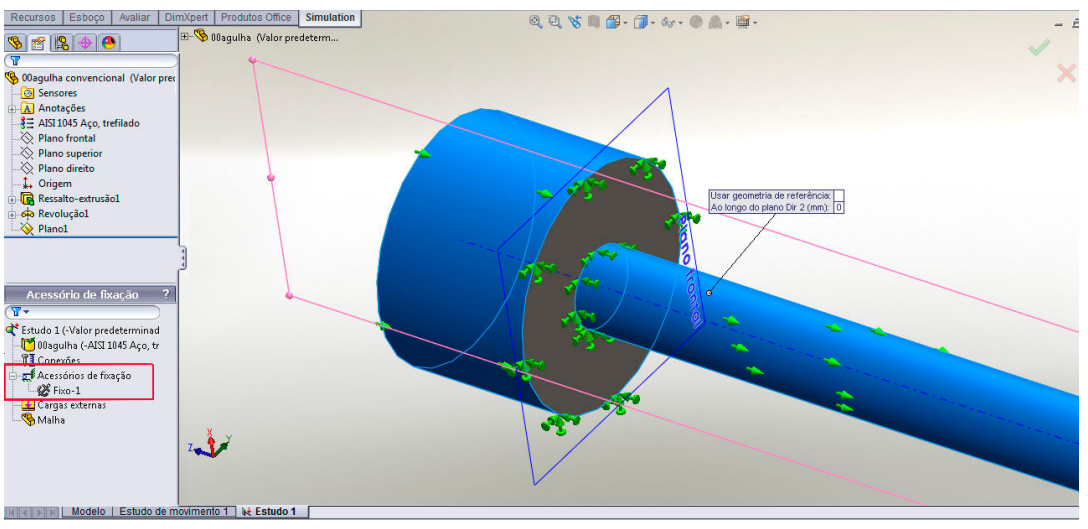

Figura 4.26: Pré-processamento - Aplicação de acessórios de fixação

Com a aplicação efetuada garante-se que o deslocamento ocorra em direção à carga nas superfícies cilíndricas, uma vez que os esforços longitudinais correspondem ao movimento de soltura do polímero solidificado, e à força de tração axial que causa a deformação com o consequente alongamento do corpo. Para delimitação destas definições considera-se que o componente integra a parte fixa do molde, havendo grau de liberdade somente no sentido de rotação axial.

Na etapa seguinte dá-se a aplicação das cargas solicitantes. De acordo com o manual de especificações técnicas do fabricante da injetora o sistema hidráulico encarregado pela abertura e extração do produto exerce uma pressão é $50000 \mathrm{~N} / \mathrm{mm}^{2}$. Para determinar o direcionamento da carga de pressão utilizou-se como referência o esforço solicitante no sentido longitudinal, normal à face interna da cabeça da agulha. A figura 4.27, demonstra a aplicação.

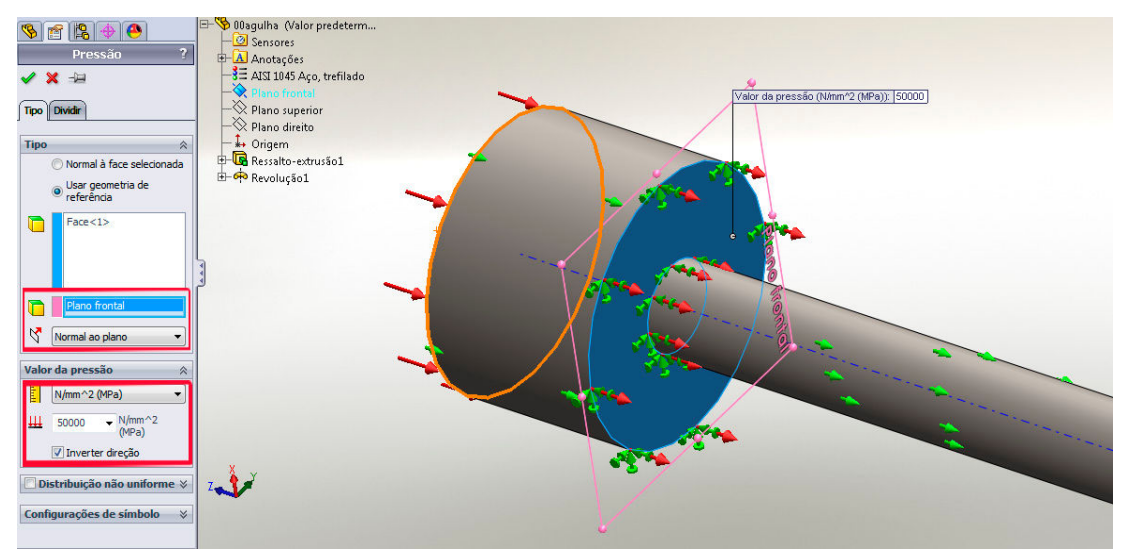

Figura 4.27: Aplicação de Carga - Pressão

A temperatura de operação durante o processo pode atingir até $200^{\circ} \mathrm{C}$, relativo a este parâmetro a temperatura do componente será uniformemente elevada / reduzida à temperatura 
de referência à deformação de $28^{\circ} \mathrm{C}$ (temperatura ambiente). A carga foi aplicada em todas as faces da agulha conforme demonstram as figuras 4.28 e 4.29 .

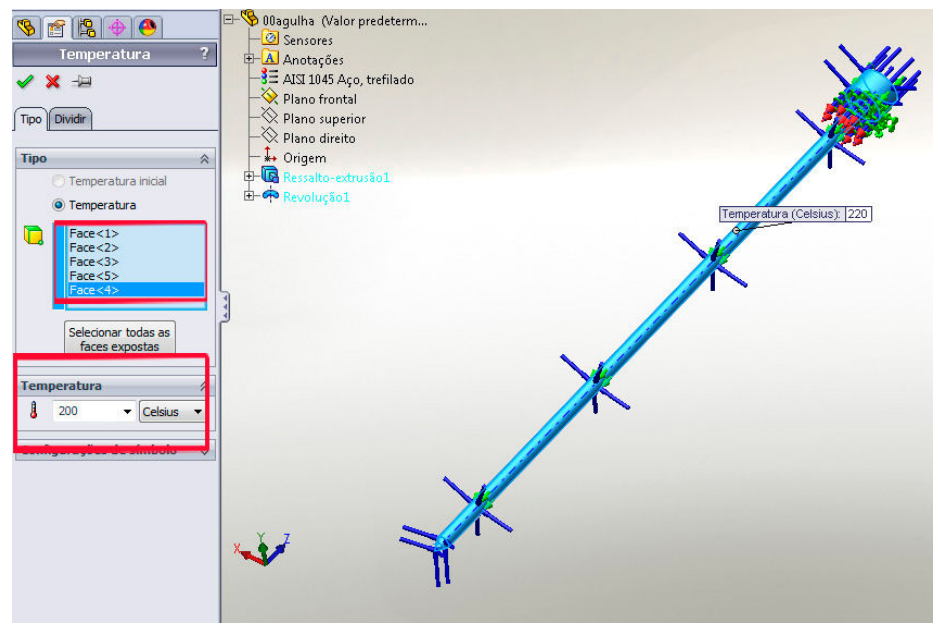

Figura 4.28: Aplicação de Carga - Temperatura

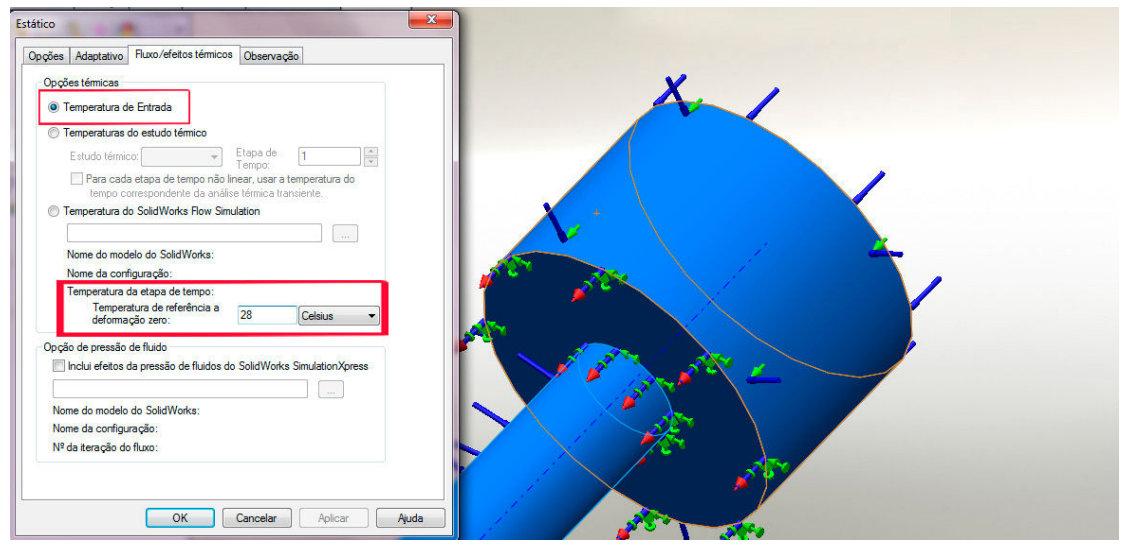

Figura 4.29: Aplicação de Carga - Efeitos Térmicos

$\mathrm{Na}$ última fase de pré-processamento fez-se a geração da malha da geometria, o processo de divisão do modelo matemático em elementos finitos através de discretização, sendo, portanto as cargas aplicadas aos nós. Aplicaram-se os seguintes parâmetros: uma densidade de malha com refinamento (melhor precisão dos resultados), Tamanho Máximo de Elemento - 0.37369447mm, Tamanho de Elemento Mínimo - 0.07473889mm, Número mínimo de elementos em um círculo - 8, e taxa de crescimento de elemento 1.6. A figura 4.30 mostra detalhes sobre a aplicação, e na figura 4.31, demonstra-se o resultado. 


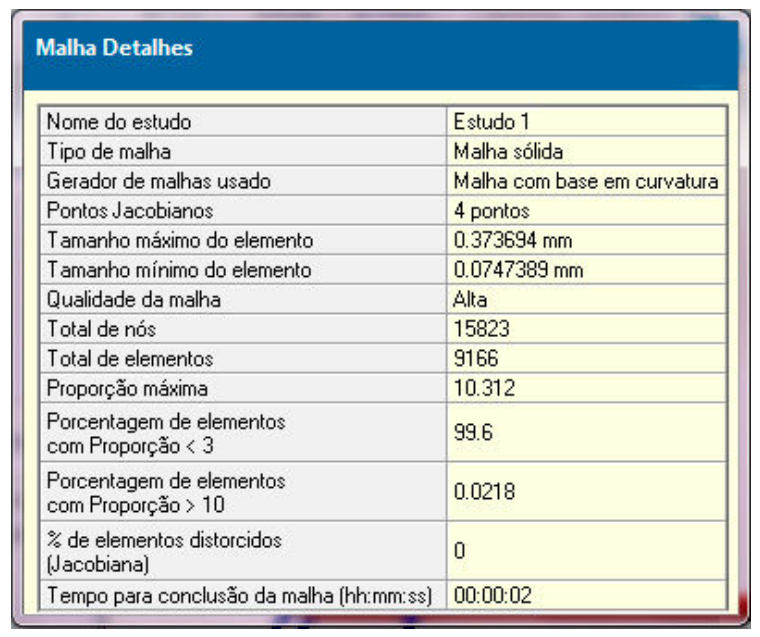

Figura 4.30: Características da aplicação de malha sólida em modelo convencional

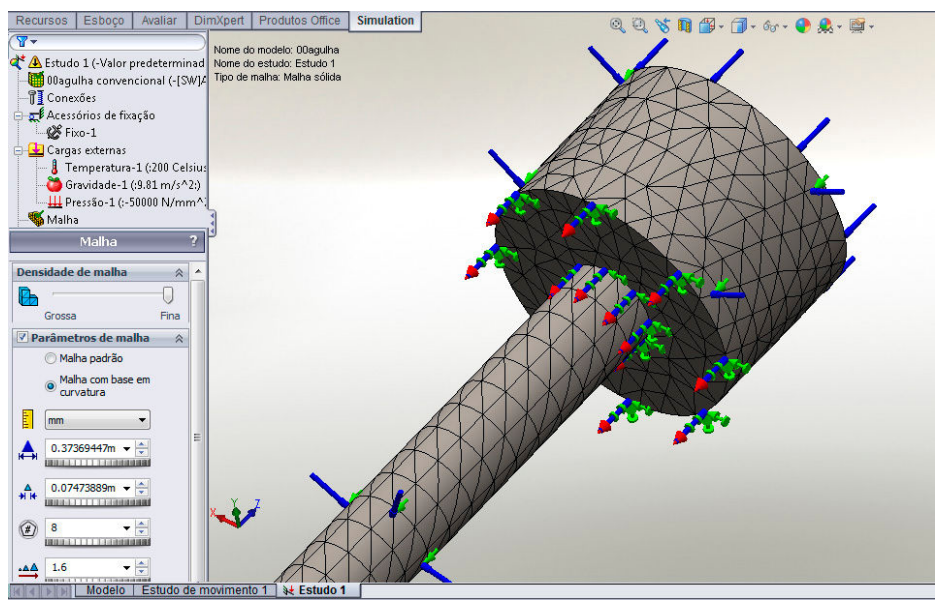

Figura 4.31: Aplicação de Malha Sólida

Concluída a análise através do aplicativo solver do Simulation tem-se então a fase de pós-processamento com a plotagem dos resultados de tensão, deslocamentos, e deformação, a partir de uma representação de 15.823 nós, 9.166 elementos, e 46.548 graus de liberdade (Degree Of Freedom - DOF).

A figura 4.32, mostra o valor máximo da tensão de Von Mises de $651 \mathrm{Mpa}$. Resultado que excede o limite de escoamento do material, 530Mpa (demonstrado pela seta vermelha do diagrama). O valor mínimo de tensão distribuída foi de $475 \mathrm{Mpa}$, localizado na cabeça da agulha, e não há registro de qualquer ocorrência de falhas nesta parte do componente. A utilização de plotagem ISO permitiu verificar que as partes do componente onde a tensão de Von Mises está entre $530 \mathrm{Mpa}$ e $651 \mathrm{Mpa}$ são exatamente a cabeça e o entorno da aresta da terminação do corpo, o que pode contribuir significativamente para a ocorrência de falha. 


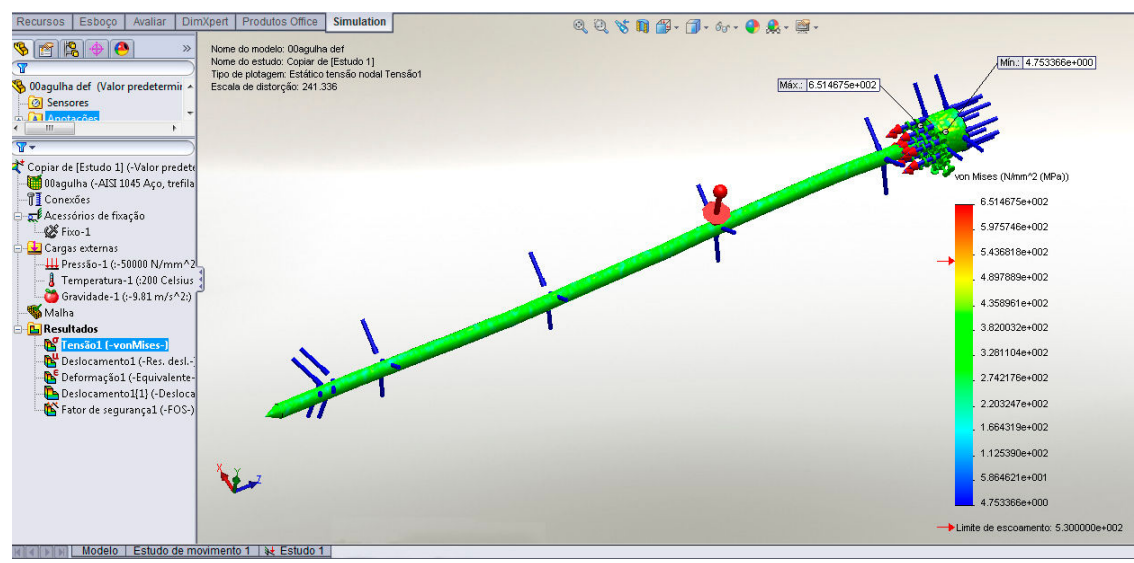

Figura 4.32: Plotagem da tensão de nós dos elementos

$\mathrm{Na}$ figura 4.33, demonstra-se a plotagem dos resultados para o deslocamento. $\mathrm{O}$ valor resultante máximo, concentrado na terminação do corpo é de $0,0218699 \mathrm{~mm}$. O resultado para a distribuição é consistente com o esperado uma vez que poder-se-ia inferir empiricamente que a falha da agulha relacionava-se ao deslocamento excessivo da extremidade.

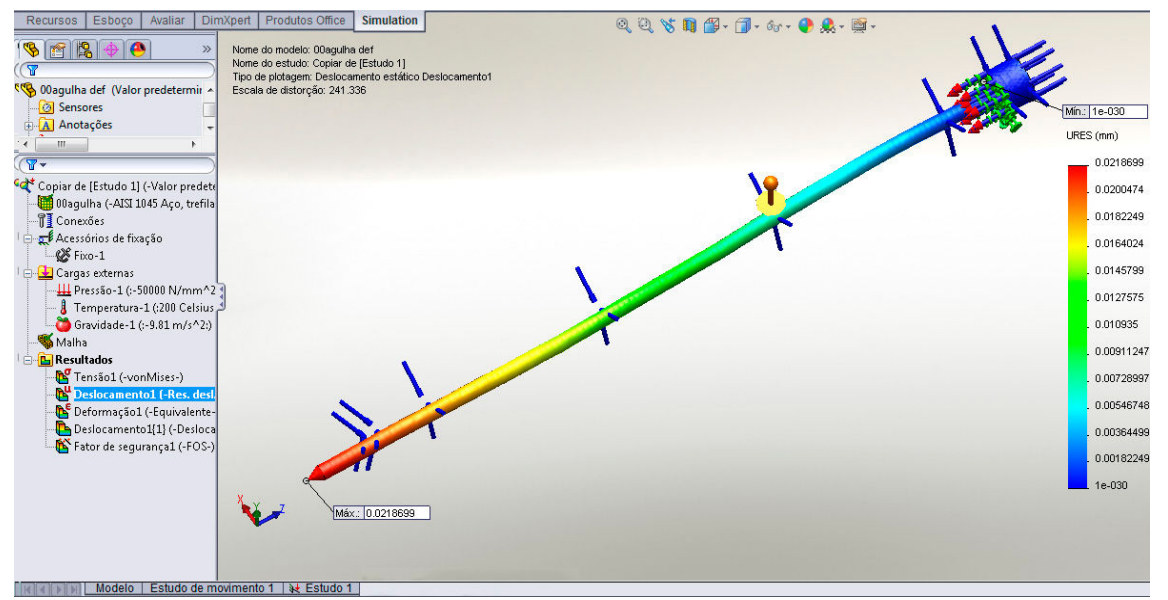

Figura 4.33: Plotagem de deslocamento

Nestes casos a mudança para um novo tipo de material é uma oportunidade de melhoria, utilizando-se um material com módulo elástico de menor valor, propiciando uma redução na rigidez. Outra oportunidade verificada é a adição de filetes nos cantos vivos.

De acordo com as plotagens pode-se evidenciar que a extremidade da agulha, parte significativa para execução de um produto compatível com as especificações de qualidade, sofre tensões acima do limite de escoamento, desta forma ainda que as forças iniciais sejam removidas quando cessa o movimento de extração pelo sistema hidráulico da injetora, a agulha não retorna à sua forma original. A cada espalhador que é produzido tem-se deslocamentos que são potencializados ainda pela ação da carga de temperatura, mesmo sem 
a ação da pressão de extração, submetendo o componente a um pré-tensionamento. A deformação gradativa com diminuição da seção circular transversal devido aos esforços reduz a capacidade de absorção da carga, e após a estricção, a agulha sofre ruptura. A figura 4.34, mostra a plotagem de deformação do componente.

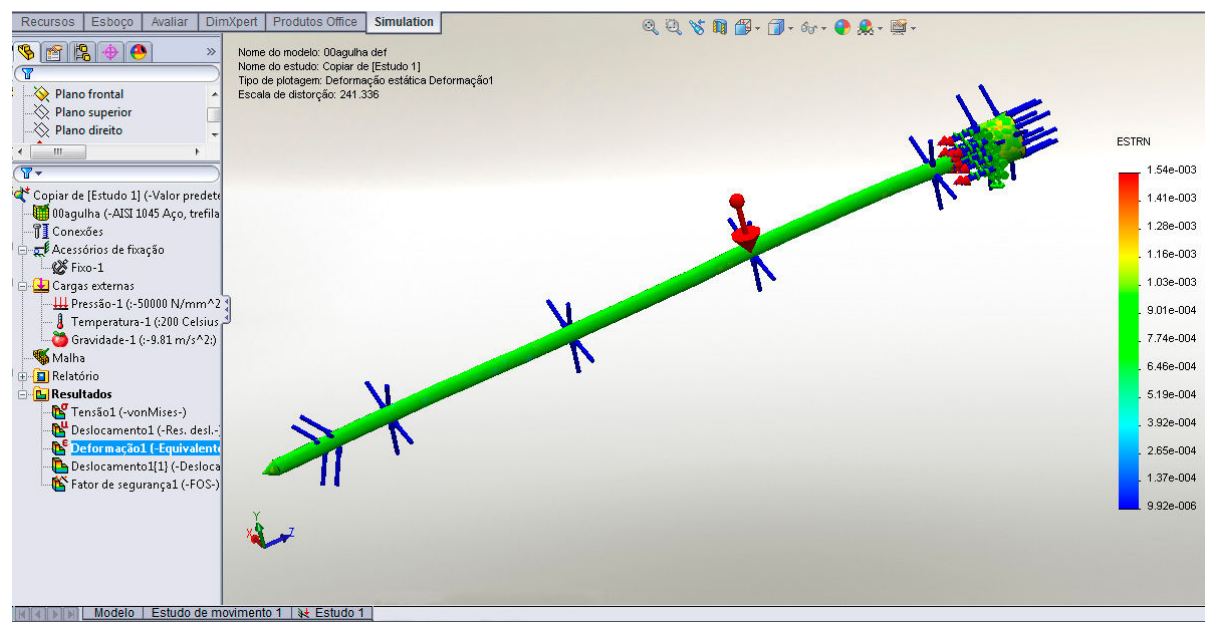

Figura 4.34: Plotagem de deformação

Com os resultados da FMEA e da FEA elaborou-se uma especificação de projeto para modelagem de um novo componente com os seguintes requisitos:

Comprimento máximo da agulha $-51 \mathrm{~mm}$

Comprimento máximo da cabeça $-2 \mathrm{~mm}$

Diâmetro do local de acoplamento da mavica $-2 \mathrm{~mm}$

Diâmetro da agulha $-1 \mathrm{~mm}$

Tolerância Dimensional - $\pm 0,02$

Material - Aço VND - (Equivalência DIN 1.2510 / ANSI e ABNT O1).

A simulação deve apresentar resultados positivos referentes à exposição ao calor, pressão de extração e a ação da força de gravidade.

A indicação para o tipo material deu-se após discussão focal com o pessoal envolvido na manutenção do sistema. Componentes que utilizam o VND são utilizados nesta indústria, e são comumente empregados na fabricação de ferramentas, principalmente quando estas serão submetidas ao trabalho a quente, e contínuas solicitações mecânicas.

Com os parâmetros das condições de uso apresentados deu-se a concepção de alternativas para solução do problema, como mostra a figura 4.35 . 


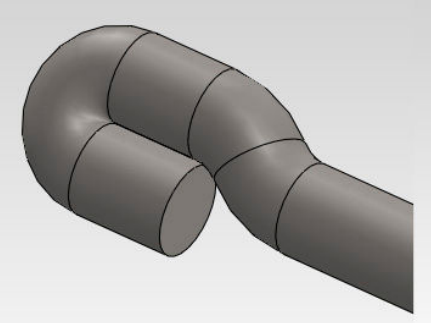

1

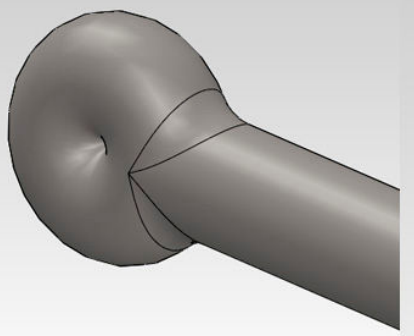

2

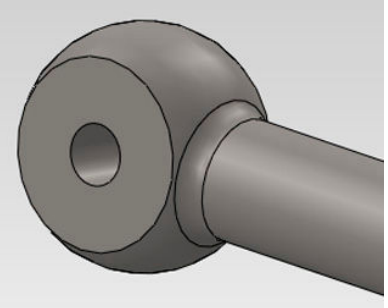

3

Figura 4.35: Alternativas de solução

Após a modelagem, a simulação $\mathrm{CAE}$ apresentou os melhores resultados para a alternativa 3. Porquanto o novo componente foi submetido à FEA, adotando-se os procedimentos análogos aos executados para a agulha convencional. O novo estudo permitirá a análise comparativa de performance operacional virtual. Na biblioteca do software consta o material requerido, o qual foi aplicando anexado às suas propriedades mecânicas (ainda que seja possível adicionar novos materiais personalizados, inclusive alterando a composição química), como demonstra a figura 4.36 .

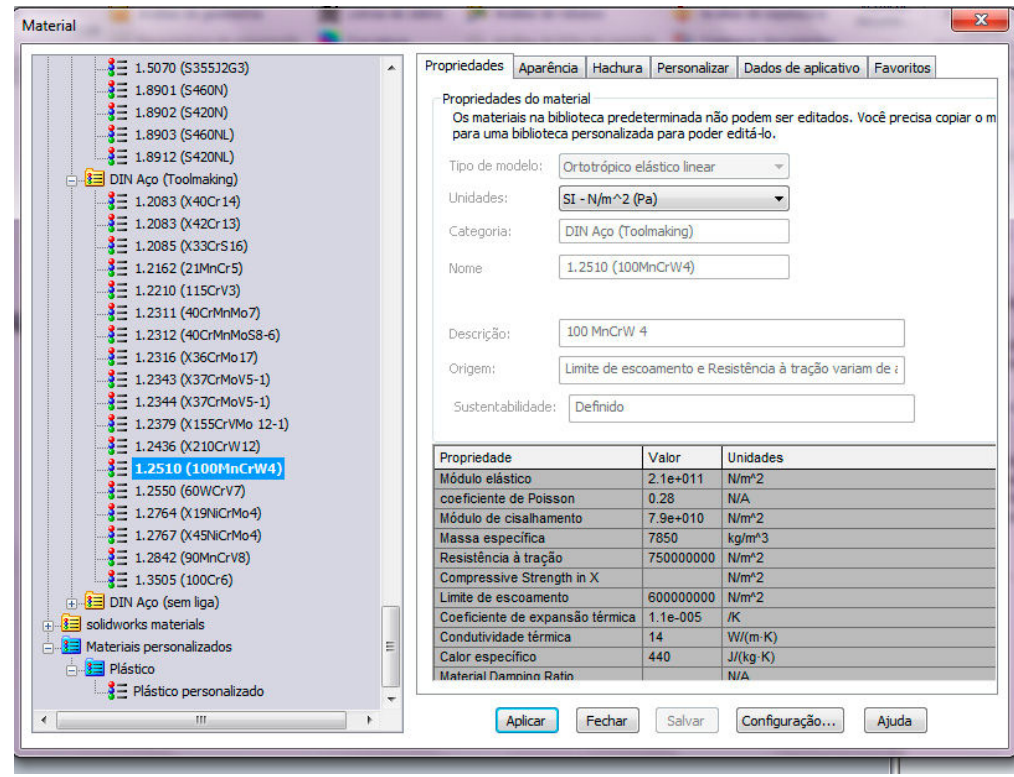

Figura 4.36: Aplicação de material - VND (DIN 1.2510)

Para o novo componente utilizou-se recursos avançados de acessório de articulação fixa na cabeça, e de faces cilíndricas com restrições de translação nos sentidos radial, circunferencial, e axial, no corpo da agulha, como demonstra a figura 4.37. 


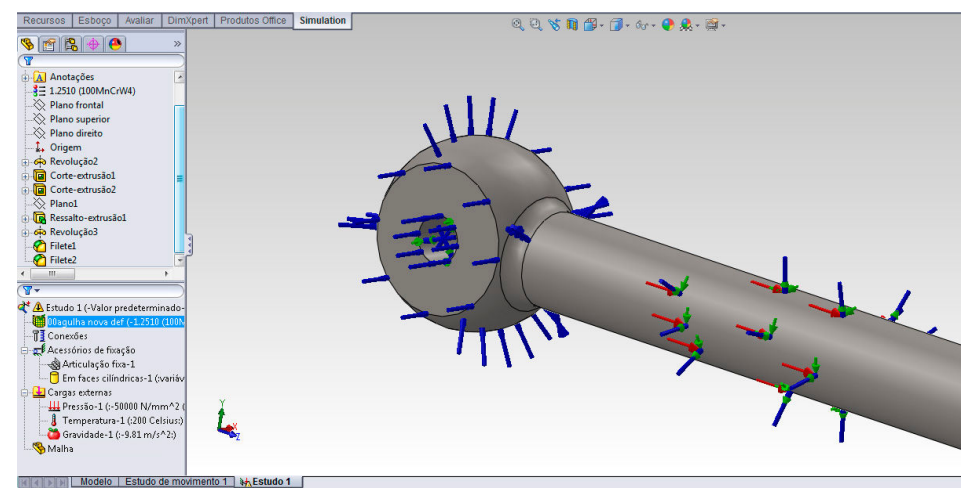

Figura 4.37: Aplicação de restrição no novo componente

As cargas de temperatura, pressão e gravidade seguem estritamente as definições prédeterminadas no modelo convencional. Para as definições de malha optou-se por uma densidade fina com base em curvatura, cujos parâmetros estipulados são o Tamanho Máximo de Elemento - 0.34373186mm, Tamanho de Elemento Mínimo - 0.06874637mm, Número mínimo de elementos em um círculo - 8, e taxa de crescimento de elemento 1.6. demonstrados na figura 4.38 .

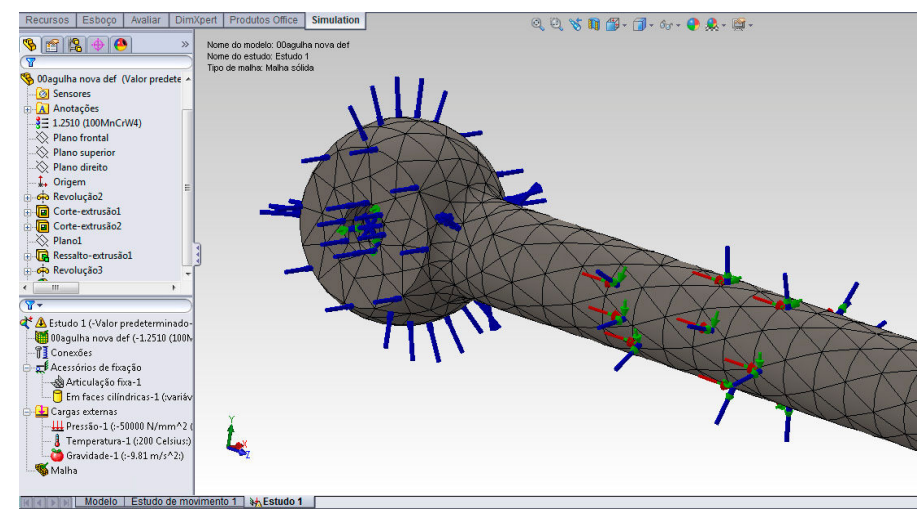

Figura 4.38: Geração de malha do novo componente

A figura 4.39, mostra os detalhes da aplicação da malha.

\begin{tabular}{|l|l|}
\hline Malha Detalhes & \\
\hline Nome do estudo & Estudo 1 [-Valor predeterminado-) \\
\hline Tipo de malha & Malha sólida \\
\hline Gerador de malhas usado & Malha com base em curvatura \\
\hline Pontos Jacobianos & 4 pontos \\
\hline Tamanho máximo do elemento & $0.172708 \mathrm{~mm}$ \\
\hline Tamanho mínimo do elemento & $0.0575687 \mathrm{~mm}$ \\
\hline Qualidade da malha & Alta \\
\hline Total de nós & 97368 \\
\hline Total de elementos & 63746 \\
\hline Proporção máxima & 5.3901 \\
\hline $\begin{array}{l}\text { Porcentagem de elementos } \\
\text { com Proporção< 3 }\end{array}$ & 99.7 \\
\hline $\begin{array}{l}\text { Porcentagem de elementos } \\
\text { com Proporção > 10 }\end{array}$ & 0 \\
\hline $\begin{array}{l}\text { \% de elementos distorcidos } \\
\text { Jacobiana) }\end{array}$ & 0 \\
\hline Tempo para conclusão da malha (hh:mm:ss) & $00: 00: 05$ \\
\hline Nome do computador & RiCARDO0LIVEIRA \\
\hline
\end{tabular}


Figura 4.39: Detalhes da aplicação de malha sólida em novo componente

Para os resultados referentes à tensão, deslocamentos, e deformação, obteve-se uma representação de 97.368 nós, 63.746 elementos, e 226.860 graus de liberdade (DOF). A figura 4.40, mostra o resultado de valor máximo da tensão de Von Mises no componente de 215 Mpa, índice muito aquém do limite de escoamento do material que é de $600 \mathrm{MPa}$. O valor mínimo de tensão foi de 3,3 Mpa localizado à cabeça da agulha.

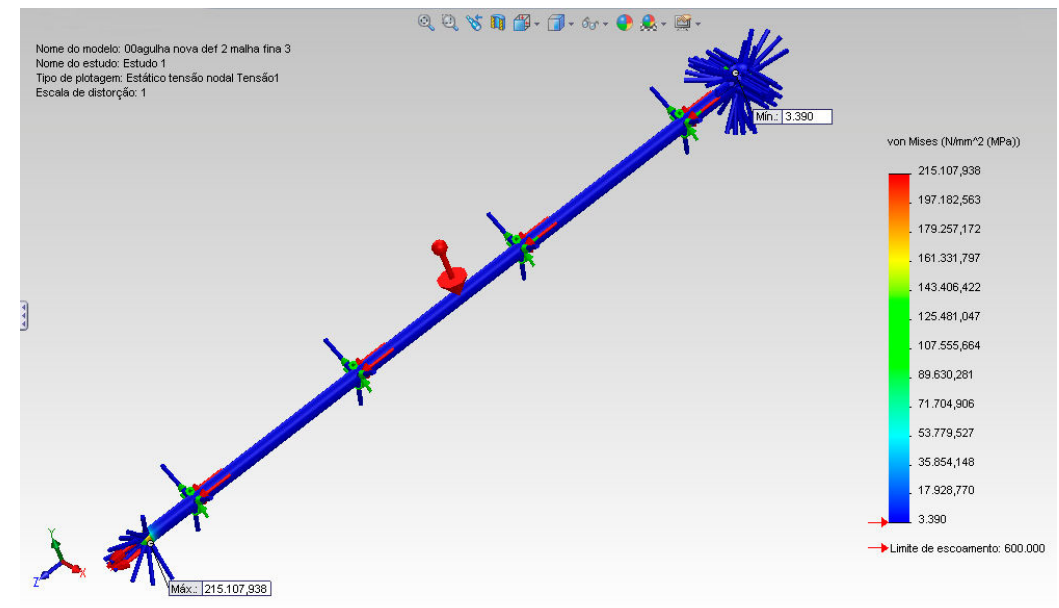

Figura 4.40: Plotagem da tensão de nós dos elementos

Com o recurso de plotagem ISO é possível visualizar em detalhe as tensões na terminação do corpo do componente. A modificação do material e da forma, agora em configuração de domo, permitiu uma melhor distribuição de tensão, como mostra a figura 4.41 .

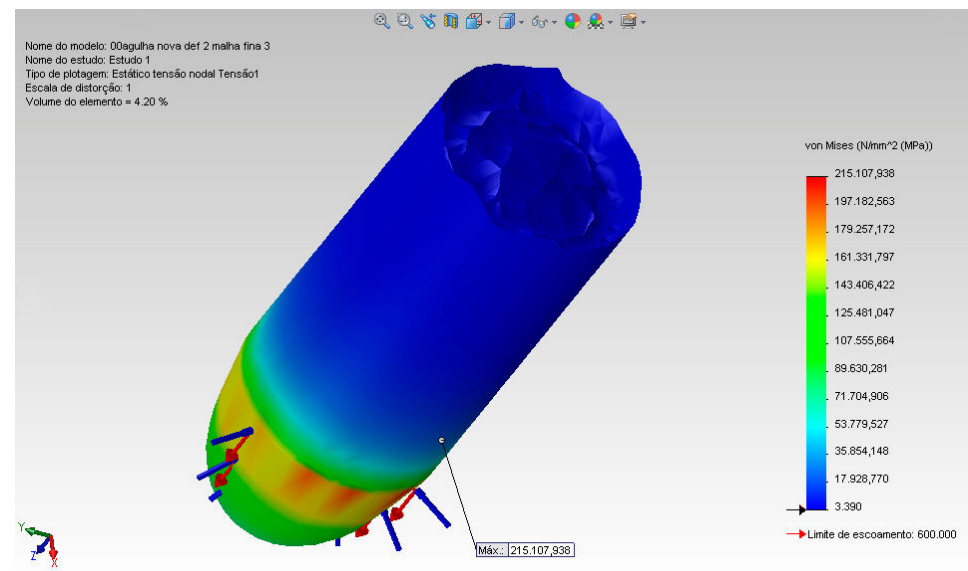

Figura 4.41: Recorte ISO da Plotagem de tensão na terminação do corpo da agulha 
$\mathrm{Na}$ figura 4.42, tem-se a plotagem para os resultados do deslocamento. O valor resultante máximo, concentrado na terminação do corpo é de $0,301791 \mathrm{~mm}$.

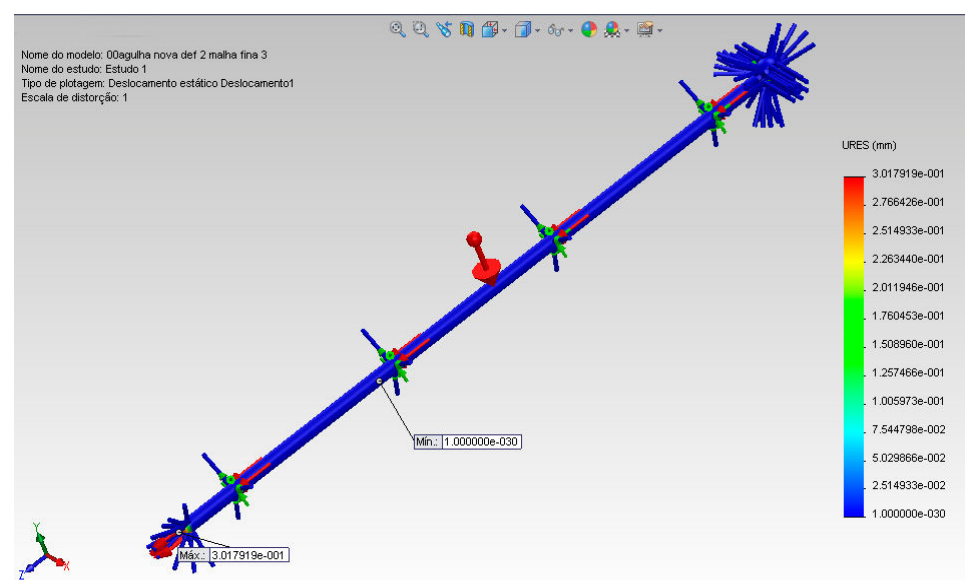

Figura 4.42: Plotagem de deslocamento do novo componente

Ainda que haja um valor superior à agulha convencional as propriedades mecânicas do material conferem estabilidade ao novo componente, sujeitando-o a suportar maiores valores de deformação sem que haja ruptura. A figura 4.43, demonstra a plotagem dos resultados.

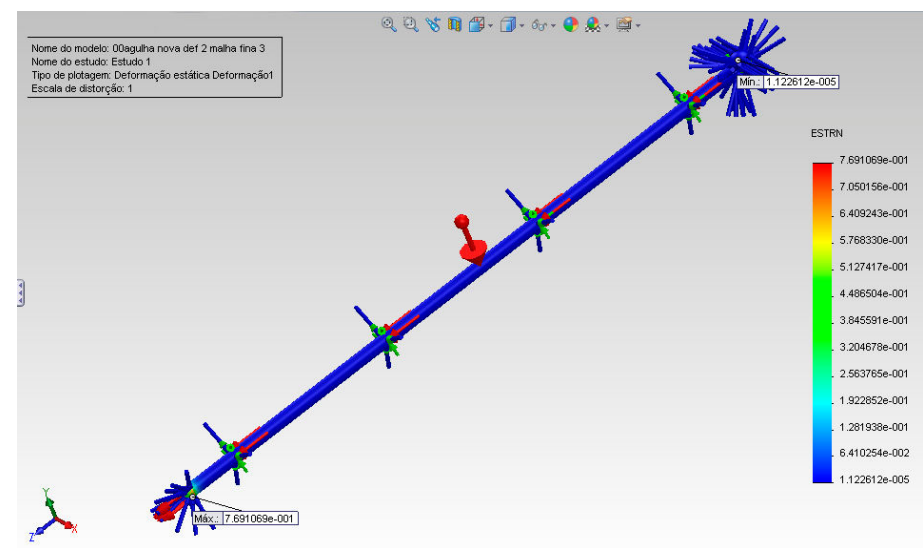

Figura 4.43: Plotagem de deformação do novo componente

O módulo elástico do VND, de maior valor do que o do Aço 1045 deve possibilitar maiores valores para as deformações, sendo, portanto adequado à situação. Considerando-se as propriedades volumétricas dos dois modelos tem-se que a massa para a agulha convencional é de $0,40897 \mathrm{~g}$, já o modelo novo tem $0,3264 \mathrm{~g}$, e para os valores de volume os resultados são para o modelo convencional de 52,09807 $\mathrm{mm}^{3}$, e no modelo novo 41,58397 $\mathrm{mm}^{3}$. As demais propriedades do material estão explicitadas na Tabela 4.3. 
Tabela 4.3: Propriedades do Aço 1.2510

\begin{tabular}{|c|c|c|}
\hline \multicolumn{2}{|c|}{ Propriedades } & Componente \\
\hline Nome: & $1.2510(100 \mathrm{MnCrW} 4)$ & \\
\hline Tipo de modelo: & Linear elástico isotrópico & \\
\hline Critério de falha predeterminado: & Tensão de von Mises máxima & \\
\hline Limite de escoamento: & $6 \mathrm{e}+008 \mathrm{~N} / \mathrm{m}^{2}$ & \\
\hline Resistência à tração: & $7.5 \mathrm{e}+008 \mathrm{~N} / \mathrm{m}^{2}$ & Corpo sólido \\
\hline Módulo elástico: & do VND & Agulha Nova \\
\hline Coeficiente de Poisson: & 0.28 & \\
\hline Massa específica: & $7850 \mathrm{~kg} / \mathrm{m}^{3}$ & \\
\hline Módulo de cisalhamento: & $7.9 \mathrm{e}+010 \mathrm{~N} / \mathrm{m}^{2}$ & \\
\hline Coeficiente de expansão térmica: & $1.1 \mathrm{e}-005$ /Kelvin & \\
\hline
\end{tabular}

Fonte: Base de dados software SolidWorks - Simulation 2011

A partir dos resultados da FEA pode-se estabelecer que o novo componente deve ser conformado por processo de fundição e suas especificações de dimensões e forma devem estar de acordo com o desenho técnico apresentado na figura 4.44.
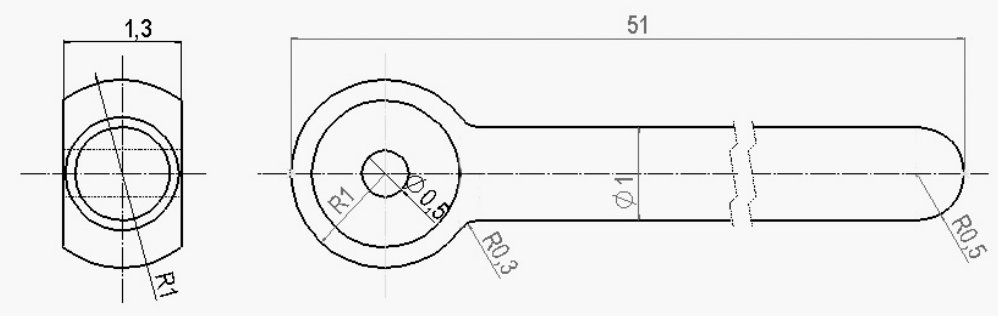

Figura 4.44: Vistas Ortogonais do novo componente

Devido às limitações de tempo para execução deste estudo foi construído um protótipo da agulha por processo artesanal, com material e dimensões apropriados, e formas muito próximas ao modelo original, como mostra a figura 4.45. A introdução no processo fabril do espalhador deu-se de modo paulatino, de modo que após 15 dias de pré-teste, em que foram utilizados os dois tipos de agulha simultaneamente, uma máquina passou a rodar exclusivamente com novas agulhas. 


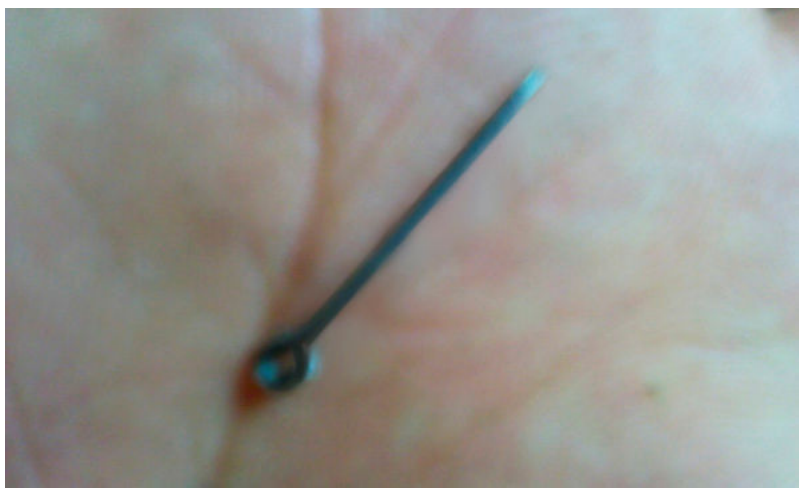

Figura 4.45: Protótipo da nova agulha

\subsection{Dados operacionais de tempos até ocorrência de falha para o novo componente}

A coleta de dados para o cálculo da confiabilidade deu-se a partir das 00:00h do dia 01 de julho e transcorreu por um período de três meses, semelhante à coleta anterior. Os dados das amostras estão disponibilizados na Tabela 4.4.

Tabela 4.4: Levantamento de falhas por ocorrências de agulhas quebradas Modelo de Agulha Novo 


\begin{tabular}{|c|c|c|c|c|c|c|c|c|c|c|c|c|c|c|}
\hline \multicolumn{5}{|c|}{ Julho } & \multicolumn{5}{|c|}{ Agosto } & \multicolumn{5}{|c|}{ Setembro } \\
\hline$\ddot{~}$ & 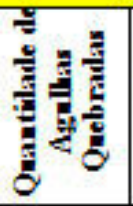 & 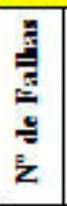 & $\begin{array}{l}8 \\
8 \\
8 \\
8\end{array}$ & 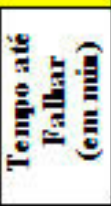 & $\ddot{~}$ & 要 & 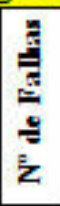 & $\begin{array}{l}38 \\
38 \\
38 \\
8\end{array}$ & 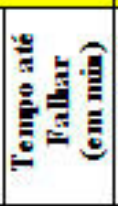 & $\ddot{H}$ & 照 & 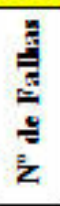 & $\begin{array}{l}3 \\
38 \\
38 \\
3\end{array}$ & $\begin{array}{l}0 \\
0\end{array}$ \\
\hline 1 & 1 & 1 & $14: 22$ & 867 & 1 & $Q$ & Q & $\mathrm{x}$ & $\mathrm{x}$ & 1 & 1 & 1 & 21:46 & 3261 \\
\hline 2 & 2 & 1 & Q9:36 & 1151 & 2 & Q & Q & $\mathrm{x}$ & $\mathrm{x}$ & 2 & $Q$ & $Q$ & $\mathrm{x}$ & $\mathrm{x}$ \\
\hline 3 & 1 & 1 & $23: 15$ & 2264 & 3 & Q & $Q$ & $\mathrm{x}$ & $\mathrm{x}$ & 3 & $Q$ & $Q$ & $\mathrm{x}$ & $\mathrm{x}$ \\
\hline 4 & Q & $Q$ & $\mathrm{x}$ & $\mathrm{x}$ & 4 & 2 & 1 & Q1:52 & 4682 & 4 & Q & Q & $\mathrm{x}$ & $\mathrm{x}$ \\
\hline 5 & 1 & 1. & $05: 43$ & 1828 & 5 & Q & Q & $\mathrm{x}$ & $\mathrm{x}$ & 5 & 2 & 1 & $08: 16$ & 4950 \\
\hline 6 & 1 & 1 & $13: 03$ & 1880 & 6 & 1 & 1 & Q6:42 & 3167 & 6 & 1 & 1 & $19: 25$ & 2109 \\
\hline 7 & Q & Q & $\mathrm{x}$ & $\mathrm{x}$ & 7 & $Q$ & Q & $\mathrm{x}$ & $\mathrm{x}$ & 7 & 1 & 1 & $23: 12$ & 1667 \\
\hline \& & 2 & 1 & $10: 12$ & 2589 & \& & Q & Q & $\mathrm{x}$ & $\mathrm{x}$ & 8 & 1 & 1 & 14:02 & 897 \\
\hline 2 & Q & $Q$ & $\mathrm{x}$ & $\mathrm{x}$ & 2 & 1 & 1 & Q8:12 & 4417 & 2 & Q & $Q$ & $\mathrm{x}$ & $\mathrm{x}$ \\
\hline 10 & \& & Q & $\mathrm{x}$ & $\mathrm{x}$ & 10 & Q & Q & $\mathrm{x}$ & $\mathrm{x}$ & 10 & 1 & 1 & $07: 20$ & 2591 \\
\hline 11 & Q & $Q$ & $\mathrm{x}$ & $\mathrm{x}$ & 11 & 2 & 1 & 14:38 & 3259 & 11 & Q & Q & $x$ & $\mathrm{x}$ \\
\hline 12 & Q & Q & $\mathrm{x}$ & $\mathrm{x}$ & 12 & Q & Q & $\mathrm{x}$ & $\mathrm{x}$ & 12 & Q & Q & $\mathrm{x}$ & $\mathrm{x}$ \\
\hline 13 & 1 & 1 & 13:34 & 7402 & 13 & Q & Q & $\mathrm{x}$ & $\mathrm{x}$ & 13 & Q & $Q$ & $\mathrm{x}$ & 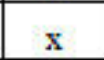 \\
\hline 14 & 1 & 1 & Q2:10 & 636 & 14 & 1 & 1 & 12:31 & 4613 & 14 & 2 & 1 & $23: 46$ & 6746 \\
\hline 15 & 1 & 1 & $16: 25$ & 855 & 15 & 1 & 1 & $20: 40$ & 1509 & 15 & 1 & 1 & $18: 36$ & 1130 \\
\hline 16 & Q & Q & $\mathrm{x}$ & $\mathrm{x}$ & 16 & 1 & 1 & Q6:15. & 575 & 16 & Q & $Q$ & $\mathrm{x}$ & $\mathrm{x}$ \\
\hline 17 & 1 & 1 & $20: 50$ & \begin{tabular}{|l|}
3145 \\
\end{tabular} & 17 & Q & Q & $\mathrm{x}$ & $\mathrm{x}$ & 17 & $Q$ & Q & $\mathrm{x}$ & $\mathrm{x}$ \\
\hline 18 & 1 & 1 & $15: 02$ & 1099 & 18 & $Q$ & Q & $\mathrm{x}$ & $\mathrm{x}$ & 18 & $Q$ & Q & $\mathrm{x}$ & $\mathrm{x}$ \\
\hline 19 & Q & Q & $\mathrm{x}$ & $\mathrm{x}$ & 19 & 1 & 1 & Q4:05 & 4190 & 19 & 1 & 1 & Q1:12 & 4721 \\
\hline 20 & 2 & 2 & $\begin{array}{l}03: 18 \\
22: 45 \\
\end{array}$ & $\begin{array}{l}2169 \\
1167 \\
\end{array}$ & 20 & 1 & 1 & 11:02 & 1862 & 20 & 2 & 1 & $14: 23$ & 1386 \\
\hline 21 & $Q$ & $Q$ & $\mathrm{x}$ & $\mathrm{x}$ & 21 & Q & 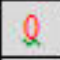 & $\Lambda$ & $\mathrm{x}$ & 21 & 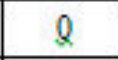 & Q & $\Lambda$ & $\mathrm{x}$ \\
\hline 22 & $Q$ & Q & $\mathrm{x}$ & $\mathrm{x}$ & 22 & 1. & 1 & Q5:12 & 2532 & 22 & Q & Q & $\mathrm{x}$ & $\mathrm{x}$ \\
\hline 23 & 1 & 1 & $08: 37$ & \begin{tabular}{|l|}
3472 \\
\end{tabular} & 23 & 1 & 1 & Q1:28 & 1209 & 23 & 1 & 1 & Q4:11 & 3708 \\
\hline 24 & 1 & $d$ & $23: 06$ & 869 & 24 & $Q$ & Q & $\mathrm{x}$ & $\mathrm{x}$ & 24 & Q & Q & $\mathrm{x}$ & $\mathrm{x}$ \\
\hline 25 & 1 & 1 & $20: 12$ & 1273 & 25 & Q & Q & $\mathrm{x}$ & $\mathrm{x}$ & 25 & 1 & $d$ & $21 \cdot 30$ & 2479 \\
\hline 26 & 2 & Q & $\mathrm{x}$ & $\mathrm{x}$ & 26 & 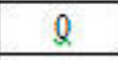 & Q & $\mathrm{x}$ & $\mathrm{x}$ & 26 & $Q$ & Q & $\mathrm{x}$ & $\mathrm{x}$ \\
\hline 27 & 1 & 1 & Q0:15 & 1676 & 27 & 1 & 1 & $07: 52$ & 6144 & 27 & 2 & 1 & 19.58 & 2788 \\
\hline 28 & 2 & 1 & $21: 15$ & 1260 & 28 & Q & Q & $\mathrm{x}$ & $\mathrm{x}$ & 28 & Q & Q & $\mathrm{x}$ & $\mathrm{x}$ \\
\hline 29 & 1 & 1 & $23: 28$ & 1573 & 29 & 1 & 1 & Q0:16 & 2424 & 29 & Q & $Q$ & $\mathrm{x}$ & $\mathrm{x}$ \\
\hline 30 & l & $Q$ & $\mathrm{x}$ & $\mathrm{x}$ & 30 & 1 & 1 & $16 \cdot 35$ & 1011 & 30 & 1 & 1 & Q8:52 & 3417 \\
\hline 31 & 1 & 1 & 19.53 & \begin{tabular}{|l|}
2665 \\
\end{tabular} & 31 & Q & Q & $\mathrm{x}$ & $\mathrm{x}$ & & & & & \\
\hline TOT & 23 & 20 & $\mathrm{x}$ & & TOT & 16 & 14 & $\mathrm{x}$ & & TOT & 18 & 14 & $\mathrm{x}$ & $\mathrm{x}$ \\
\hline
\end{tabular}

Fonte: Corona (2011) 
Uma vez implementado o sistema a partir da intervenção com proposta do novo modelo de agulha deve-se então realizar um novo estudo de ajuste de distribuição com o intuito de determinar a confiabilidade, dessa forma pode-se comparar estatisticamente os dois modelos, e verificar se as opções de melhoria tiveram efeito significativo para o processo de injeção. Dessa forma submeteu-se a nova amostra a exatamente os mesmos procedimentos utilizados para os testes da agulha convencional.

O modelo Exponencial para o novo componente apresentou um parâmetro de Localização de 446,5 minutos, e parâmetro de inclinação $\lambda$ de 0,0005, e MTTF de 2568,4 minutos. O teste de aderência do $\chi^{2}$ obteve Nível de Significância de 0,6284, e o teste de Kolmogorov-Smirnov resultou em um Nível de Significância de 0,0321. Assim, a hipótese de que a população segue o modelo Exponencial é rejeitada. A plotagem de probabilidade está demonstrada na figura 4.46 .

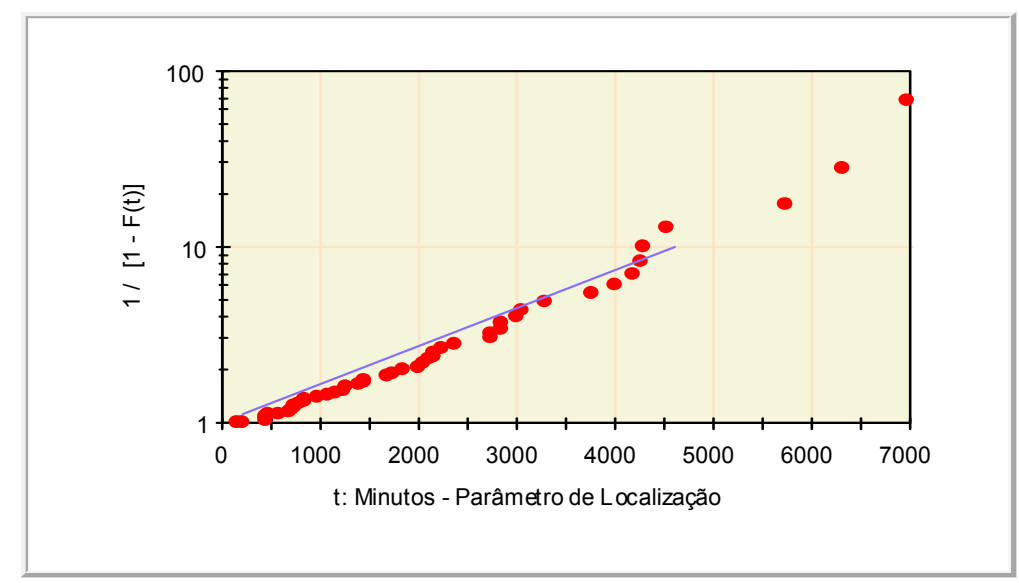

Figura 4.46: Papel de probabilidade exponencial para operação do sistema de injeção

Conforme a modelagem para o papel de probabilidade Normal demonstrado na figura 4.47, tem-se os seguintes parâmetros: $\mu=2568,417$, e $\sigma=1594,2$. No cálculo dos testes de aderência de $\chi^{2}$ obteve-se Nível de Significância de 0,0025, e no de Kolmogorov-Smirnov o Nível de Significância de 0,0028 , porquanto a hipótese de que a população segue o modelo Normal deve ser rejeitada. 


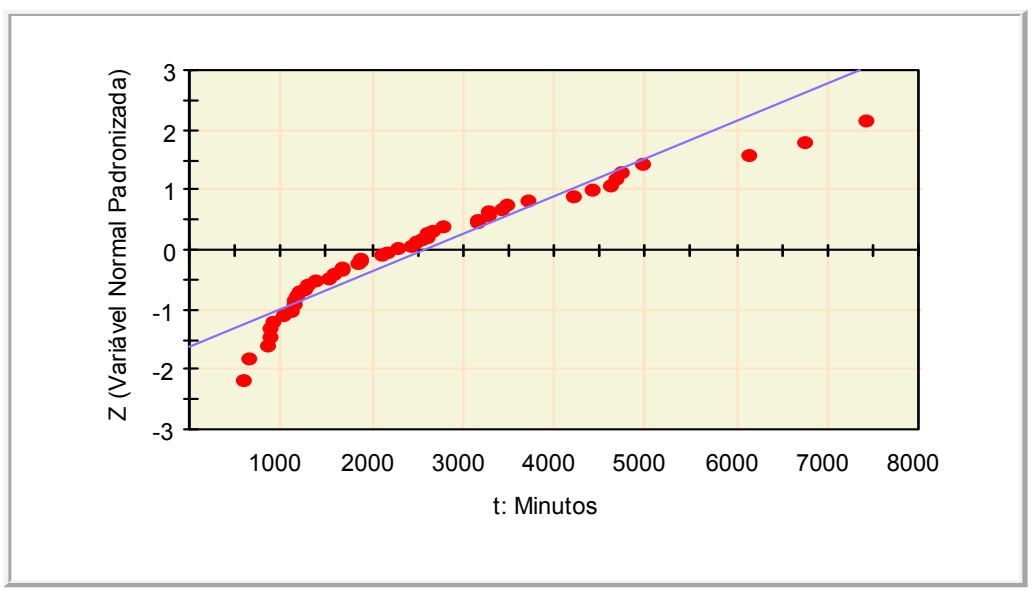

Figura 4.47: Papel de probabilidade Normal para operação do sistema de injeção

Aplicando-se o modelo de papel de probabilidade Lognormal obteve-se o parâmetro de escala $\mu$ de logaritmos dos dados de 7,6575, e parâmetro de forma $\sigma^{2}=0,4225$. O MTTF resultou em 2621 minutos. Os testes de aderência resultaram para o $\chi^{2}$ o Nível de Significância de 0,3227, e para Kolmogorov-Smirnov o Nível de Significância de 0,2668. Desta forma pode-se inferir que a hipótese de que a população segue o modelo Lognormal não pode ser rejeitada. A plotagem em papel de probabilidade Lognormal, está apresentada na figura 4.48.

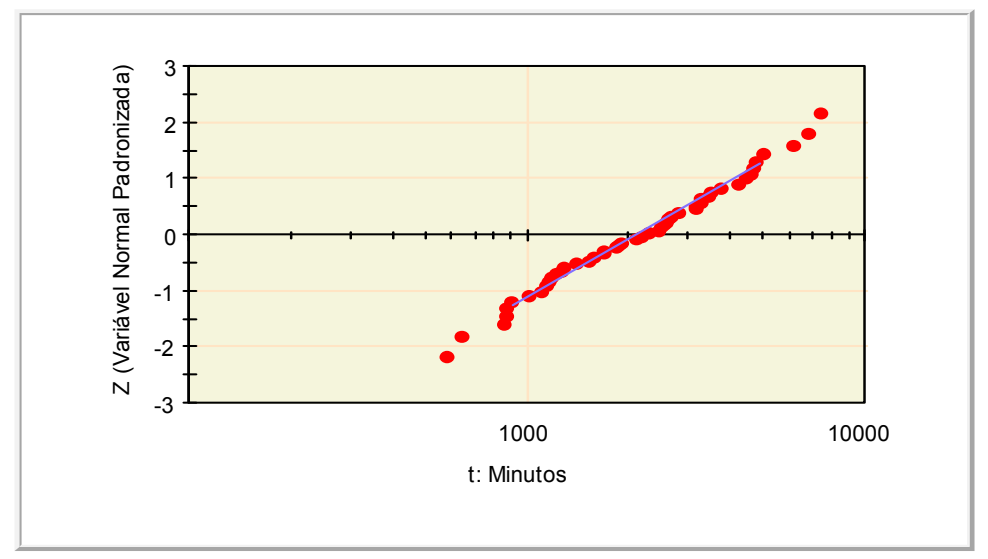

Figura 4.48: Papel de probabilidade lognormal para operação do sistema de injeção

A análise de distribuição Weibull resultante do parâmetro de localização de 446,544 minutos teve como parâmetro de forma $\beta$ o valor de 1,34 , o que significa que $h(t)$ continua crescente, porém praticamente constante. Para o parâmetro de escala $\alpha$ obteve-se 2307,35 , e o MTTF 2565,567 minutos. Nos testes de aderência obtiveram-se os seguintes resultados: para o teste de $\chi^{2}$ o Nível de Significância de 0,803, e para o modelo analítico de KolmogorovSmirnov o Nível de Significância de 0,37. Pelos resultados demonstrados conclui-se que a 
hipótese de que a população segue o modelo Weibull não pode ser rejeitada. A plotagem em papel de probabilidade Weibull, e representação das funções de distribuição acumulada (CDF), densidade de probabilidade de falha (PDF), taxa de falha (h), e confiabilidade (R), estão apresentadas nas figuras 4.49, 4.50, 4.51, 4.52, e 4.53.

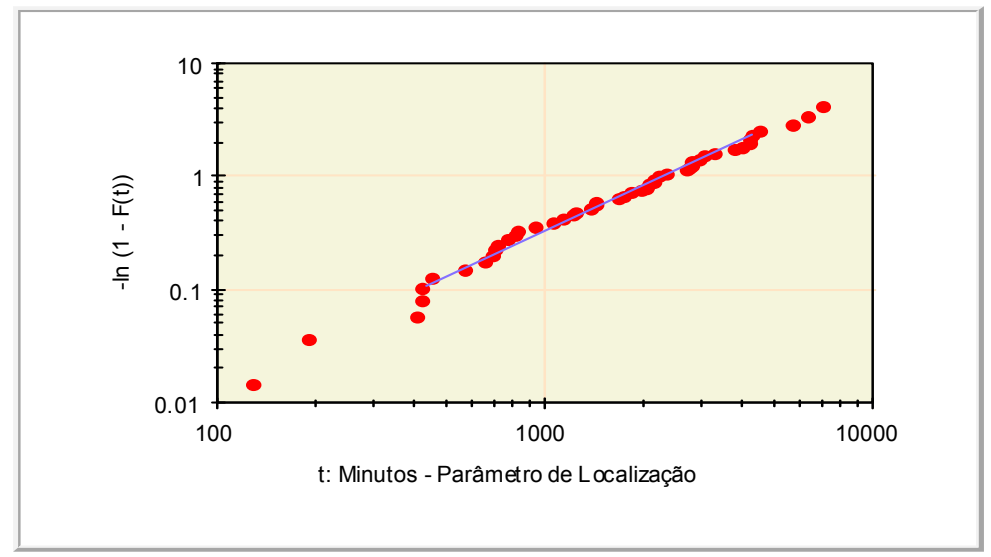

Figura 4.49: Papel de probabilidade Weibull para operação do sistema de injeção

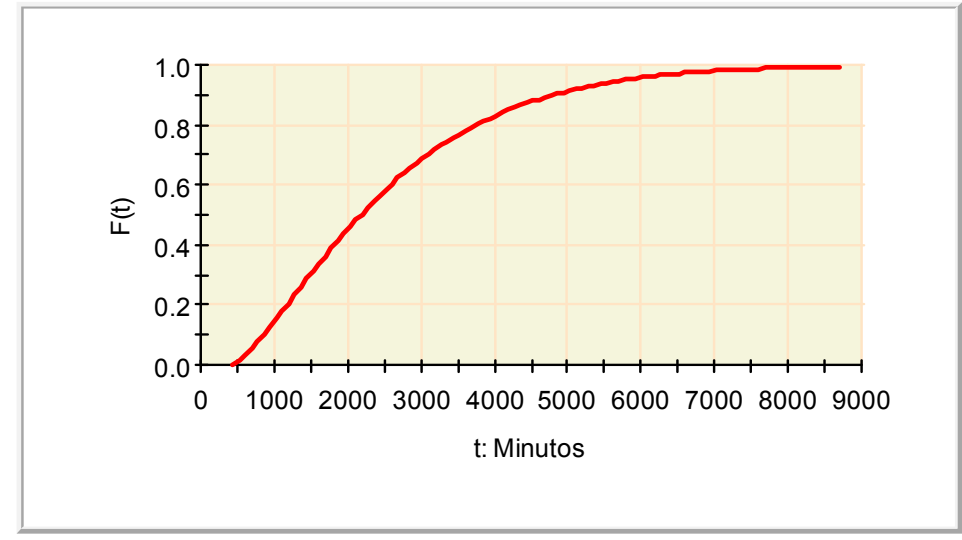

Figura 4.50: Densidade acumulada de falha para distribuição Weibull

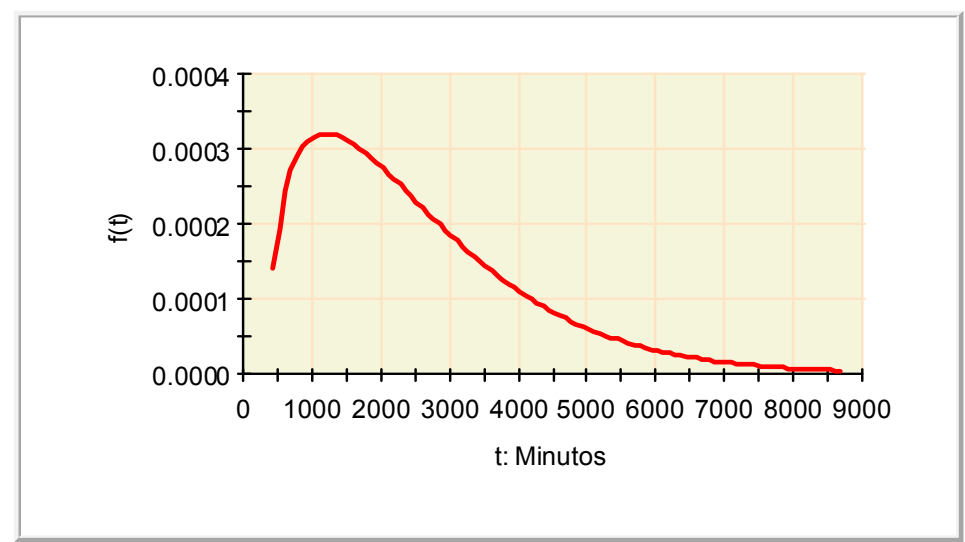

Figura 4.51: Densidade de probabilidade de falha para distribuição Weibull 


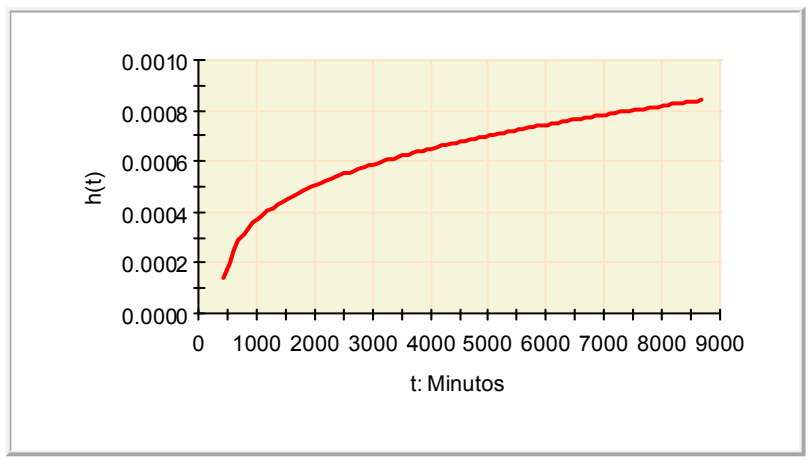

Figura 4.52: Taxa de falha para distribuição Weibull

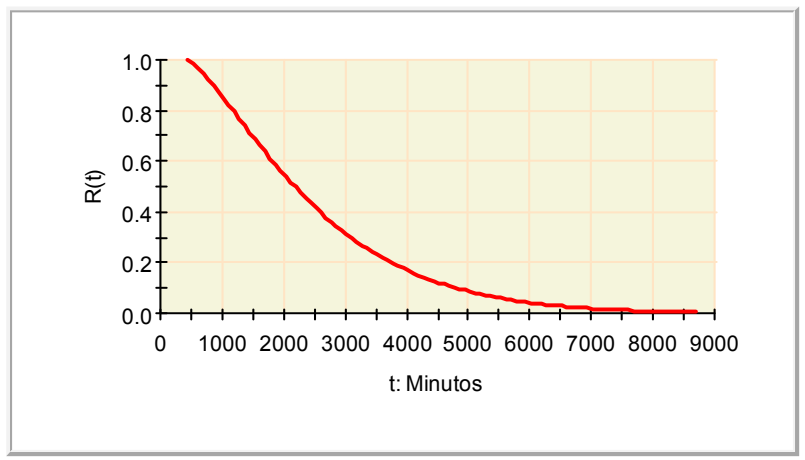

Figura 4.53: Confiabilidade para distribuição Weibull

Com os ajustes de dados para o novo componente pode-se verificar que não obtiveram a hipótese rejeitada os modelos Weibull e Lognormal. Após análises dos resultados dos $p$-value dos testes de aderência constata-se que o modelo Weibull agora é o que melhor descreve o comportamento da amostra.

Os resultados das melhorias implementadas no novo componente demonstram um aumento significativo na performance do sistema. A princípio, sobrepondo os dados coletados nas tabelas de ocorrências, é notável o decréscimo no número de falhas, como mostra a figura 4.54 .

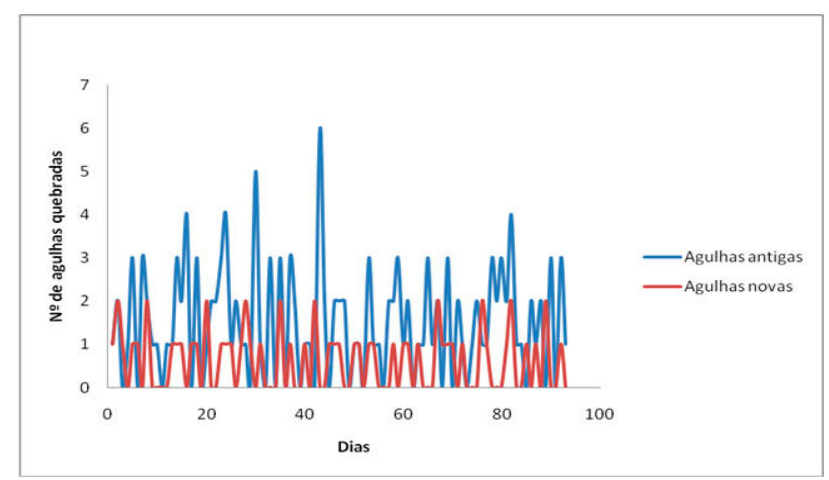

Figura 4.54: Agulhas quebradas - Modelo Convencional x Modelo Novo 
Após as análises comprova-se que em detrimento aos resultados do modelo de agulha convencional em que uma confiabilidade de $95 \%$ obteve o tempo de 480,5 minutos, para o novo modelo obteve-se o tempo de 682,5 minutos, o que significa um aumento de $21,2 \%$. A figura 4.55, mostra a sobreposição da performance da função confiabilidade para os dois modelos, e denota-se que o tempo de vida do modelo de agulha convencional é inferior ao do modelo de agulha novo em maior parte do tempo.

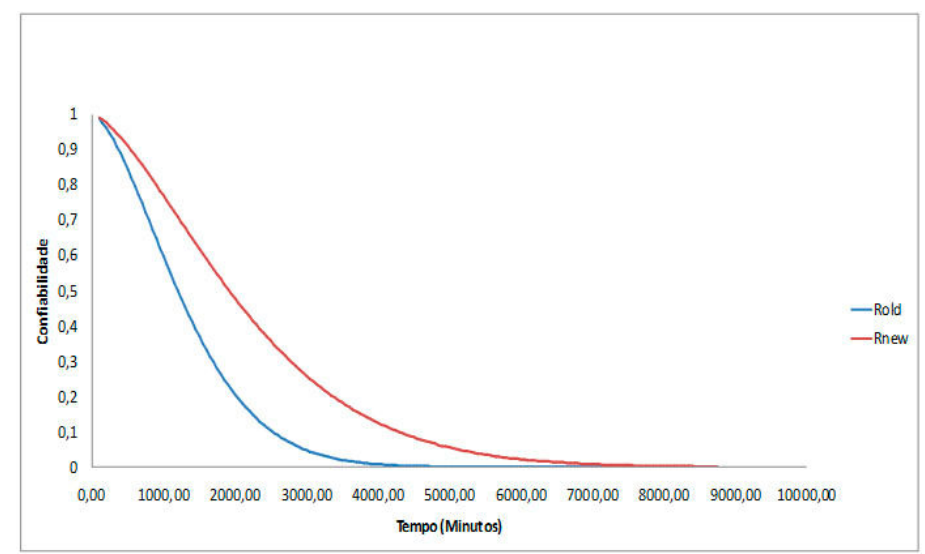

Figura 4.55: Funções de Confiabilidade - Modelo Convencional x Modelo Novo

Considerando-se o MTTF de 1503,3 minutos para o modelo convencional e o resultado de modelagem Weibull para o novo componente de 2565,5 minutos. A autonomia em média do sistema passa, portanto, de 25 horas para mais de 44 horas, isso quer dizer que no período de final de semana, crítico por apresentar as maiores perdas devido a falhas e consequente máquina parada, pode-se fazer um estudo de viabilidade de custos para a mudança do plano de manutenção, eventualmente preventiva. O novo índice para o MTTF pode suportar a decisão.

Foram registradas para o primeiro período de coleta de dados, referentes ao modelo convencional 82 paradas para manutenção da injetora somente em relação à substituição de agulhas quebradas. Com as ações de implementação do novo modelo durante mesmo período de três meses registraram-se 48 paradas para reposição do componente, uma redução de paradas da ordem de 58,5\%. Tomando-se como referência as paradas somente em turno do ferramenteiro, seria amortizado o custo de oportunidade de R $\$ 1.625 .560,00$, como ocorreram mais falhas no modelo convencional durante os períodos de folga da manutenção este montante deve demonstrar-se muito maior, representando significativo impacto sobre os custos de produção. O custo para produção do protótipo foi de $\mathrm{R} \$ 0,75$. 
Através da análise descritiva aplicou-se o teste $t$ de Student, para comparação das duas médias relativas ao número de agulhas quebradas. A hipótese nula é: "não existem diferenças significativas entre os dois grupos (Modelo Convencional e Modelo Novo)". Isto é, as duas amostras podem ser consideradas como procedentes da mesma população. A tabela 4.5, apresenta a distribuição de frequência, e na sequência a tabela 4.6, demonstra os resultados do teste.

Tabela 4.5: Distribuição de Frequência do $\mathrm{N}^{\mathrm{o}}$ de agulhas quebradas

\begin{tabular}{|c|c|c|}
\hline $\begin{array}{c}\mathbf{N}^{0} \text { de agulhas quebradas } \\
\text { Modelo Convencional }\end{array}$ & $\mathbf{N}$ & $\mathbf{\%}$ \\
\hline 0 & 21 & 22,83 \\
\hline 1 & 29 & 31,52 \\
\hline 2 & 21 & 22,83 \\
\hline 3 & 16 & 17,39 \\
\hline 4 & 3 & 3,26 \\
\hline 5 & 1 & 1,09 \\
\hline 6 & 1 & 1,09 \\
\hline $\mathbf{N}^{\mathbf{0}}$ de agulhas quebradas & & \\
\hline Modelo Novo & & \\
\hline 0 & 45 & 48,9 \\
\hline 1 & 37 & 40,2 \\
\hline 2 & 10 & 10,9 \\
\hline
\end{tabular}

Tabela 4.6: Teste $T$ de Student para igualdade de médias

\begin{tabular}{|c|c|c|r|r|}
\hline $\mathbf{N}^{\mathbf{o}}$ de agulhas quebradas & N & Média & $\begin{array}{r}\text { Desvio } \\
\text { Padrão }\end{array}$ & p-value \\
\hline Modelo Convencional & 92 & 1,54 & 1,27 & \multirow{2}{*}{$<0,001$} \\
\hline Modelo Novo & 92 & 0,62 & 0,68 & \\
\hline
\end{tabular}

Conforme pode-se observar na Tabela 4.6, o p-value é menor que 0,001, isto é, rejeitase a hipótese nula (que os grupos Modelo Convencional e Modelo Novo são iguais). O que corrobora para existência de diferenças entre os grupos no número de agulhas quebradas.

As Figuras 4.56 e 4.57, mostram um comparativo da distribuição dos dados de falhas do modelo convencional e do modelo novo em que demonstra-se graficamente que a taxa de falha do modelo projetado é inferior ao do modelo de agulha convencional. 


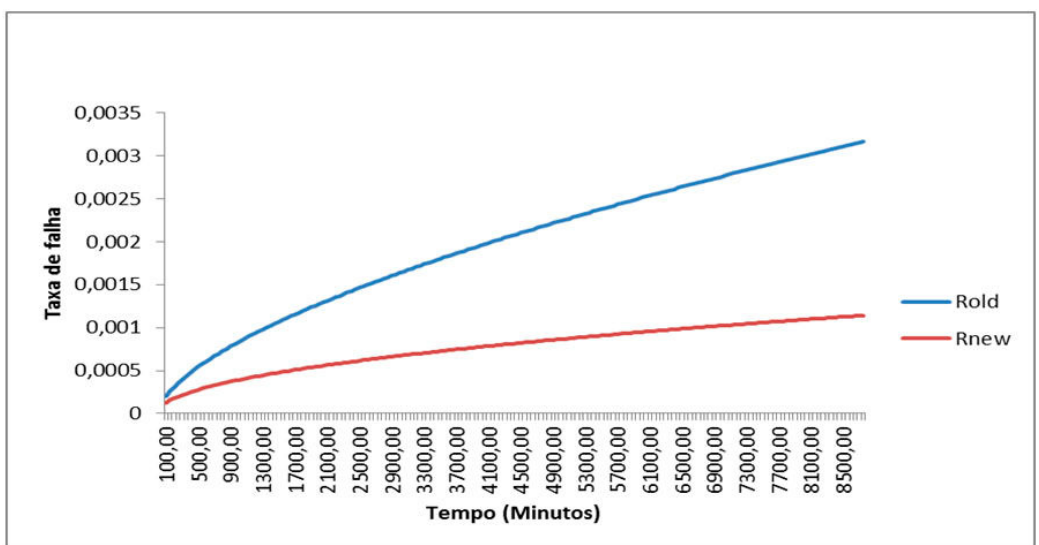

Figura 4.56: Funções de Taxa de Falha - Modelo Convencional x Modelo Novo

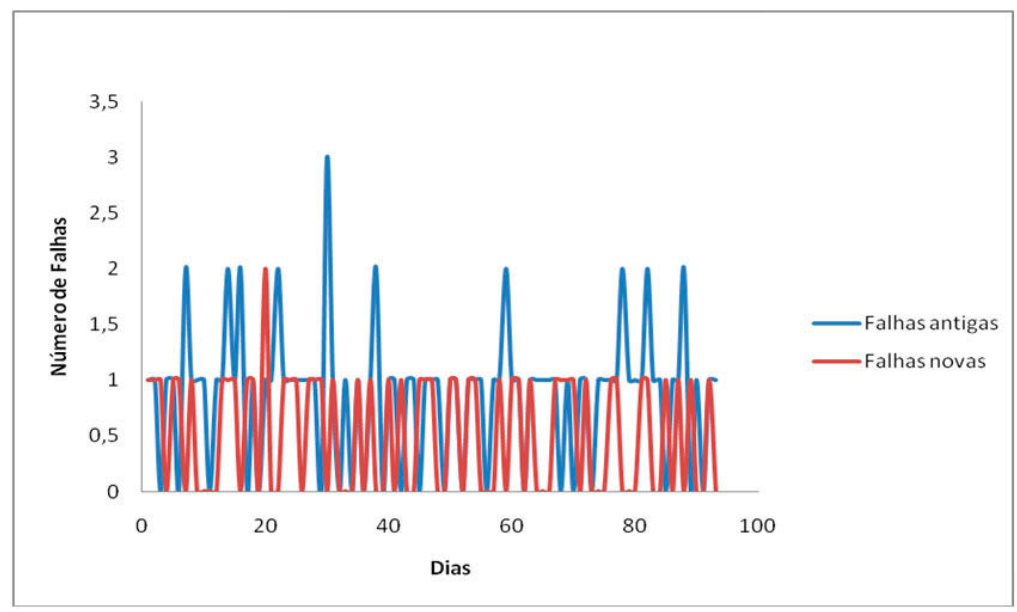

Figura 4.57: Comparação do número de falhas dos modelos convencional e novo 


\section{CONCLUSÃO}

O estudo apresentado buscou fundamentalmente demonstrar que a utilização de recursos tecnológicos de simulação computacional em plataforma CAD e CAE podem contribuir de maneira expressiva para o aumento da confiabilidade no desenvolvimento de novos produtos. As ferramentas disponibilizadas nos aplicativos possibilitam a construção de formas indistintamente do seu nível de complexidade, e não obstante, os cálculos para análise de estruturas tornaram-se extremamente difíceis nesse contexto, de certo que o equacionamento matemático por meios analíticos tornam-se paulatinamente inviáveis devido a fatores paradigmáticos de produtividade, precisão, e eficácia.

A análise por elementos finitos, em consonância à informatização acelerada dos processos industriais diminuiu significativamente as discrepâncias entre o virtual e o real, ainda que no processo de discretização haja limitações para representação fidedigna do ambiente operacional, no ambiente de simulação pode-se constatar que as soluções por aproximação evitam demasiado emprego de recursos no desenvolvimento de protótipos, reduzindo desta forma o tempo de desenvolvimento de novas soluções e dos custos incorridos, consolidando-se como alternativa viável para resolução dos problemas projetuais.

O produto concebido no estudo com emprego destes recursos resultou na construção de um componente que utiliza-se de menor quantidade de material, e de menor custo para sua construção do que a alternativa convencional, implicando diretamente na redução dos custos com matéria prima. Porém os melhores resultados residem no incremento da produtividade haja vista que houve queda na taxa de falhas. O novo formato para a cabeça da agulha propiciou ainda um melhor posicionamento para inserção e extração do componente na mavica, este fato deve redundar na diminuição do tempo de reparo.

Nos critérios de desempenho, como o valor de MTTF pode-se constatar a melhoria em todos os índices observados, substancialmente neste em que houve o acréscimo de 70,64\%, impactando na redução dos custos de manutenção e oportunidade para deflagração de um plano mais consistente de operacionalização durante os dias críticos para ocorrências de falha. Houve um incremento na confiabilidade do sistema de 42,12\%, a um nível de confiança de $95 \%$, para o modelo convencional obteve-se um tempo de 8 horas ao passo que o modelo novo aumentou para 11,37 horas. 
Um planejamento de manutenção preventiva pode considerar a troca de todas as agulhas no período que antecede a folga dos responsáveis. Com os resultados obtidos obteve-se a autonomia das agulhas para suportar o intervalo dos finais de semana. A nova agulha utilizando-se de processo artesanal tem um custo de $\mathrm{R} \$ 0,17$.

Estudos posteriores podem ater-se a outras variáveis do ambiente a fim de facultar melhorias ao sistema, como a verificação das zonas de quebra das agulhas, dividindo-as por quadrantes, ou ainda determinar o tempo de vida do componente e relacioná-la ao seu posicionamento no molde de injeção.

Uma oportunidade é o estudo das tensões de cisalhamento sobre a agulha quando da extração do espalhador. A carga cíclica decorrente do processo de extração do produto acabado inevitavelmente enfraquecendo o material, ainda que se tenha um sistema em que as tensões estejam compatíveis com limites aceitáveis. A flutuação das tensões causam rachaduras no material, principalmente nas situações que ocorrem neste estudo de caso, uma vez que há atrito no carregamento e descarregamento entre a face do componente agulha e o produto acabado. Um estudo de fadiga por processos convencionais pode auxiliar na determinação de um número de ciclo tolerável ao sistema.

Finalmente há de se ressaltar que a construção por processo industrial do modelo de agulha proposto pode apresentar melhorias para redução do número de falhas. Cortes, dobras e as imperfeições do processo artesanal podem ter contribuído para redução de índices esperados. 


\section{REFERÊNCIAS BIBLIOGRÁFICAS}

AÇO ESPECIAL COMERCIAL LTDA. Informativo Comercial. Disponível em: $<\mathrm{http}$ //www.acoespecial.com.br/produtos_ferramenta_trabalho_frio.html $>$ Acessado em 28 mai. 2011.

AKIN. J.E. Finite element analysis with error estimators: an introduction to the fem and adaptive error analysis for engineering students. Great Britain. Elsevier. 2005

ALENCAR, L.H. Metodologia Científica. 18 dez. 2010. 31p. Notas de aula. Digitalizado.

AlMEIDA, A.T.; CAMPELlO, F. (Org.) et. al. Gestão da Manutenção na direção da competitividade. Recife: Editora Universitária da UFPE. 2001.

BAUER, E. ZHANG, X. KIMBER, D.A. Practical system reliability. IEEE Press e john Wiley \& sons, inc. publication. New Jersey. EUA. 2009.

BRITO, M.L. Aprenda a moldar em plásticos. 1a edição. São Paulo. 1986.

COMINATTO, A.C. Influências das variáveis do ciclo no produto final. São Paulo. Astra S.A. Indústria e Comércio, 1997.

COOK, R. D. Finite element modeling for stress analysis. John Wiley \& Sons. USA. 1995.

CORONA. Duchas Corona Site Institucional. Disponível em: $<$ http://www.corona.com.br>.Acessado em 14 mai 2011. Acessado em 14 mai 2011.

DASSAULT SYSTÈMES SOLIDWORKS CORPORATION. Training Solidworks Simulation 2011. Concord, Massachusetts, EUA. 2011.

DENG, Y.M. et. al. A CAD-CAE Integrated Injection Molding Design System. Artigo. Disponível em: $\quad<$ http://www.scopus.com/record/display.url?eid=2-s2.00036093651\&origin=inward\&txGid=-Mno77nvAt8bWFPSnBi7Z4S\%3a2> Acessado em 21 jan. 2011.

DIAS, A. Projeto para Confiabilidade: conceitos e fundamentos. Disponível em: $<$ http://alvarestech.com/temp/PDP2011/emc6605.ogliari.prof.ufsc.br/Restrito/IFM\%20cap\%2 016\%20projeto\%20para\%20confiabilidade.pdf>. Acessado em 28 jul. 2011.

DROGUETT, E. L. Análise da confiabilidade de componentes não reparáveis. 10 mar. 2011. 85p. Notas de aula. Digitalizado.

Análise da confiabilidade de componentes e sistemas reparáveis. 10 mar. 2011. 10p. Notas de aula. Digitalizado.

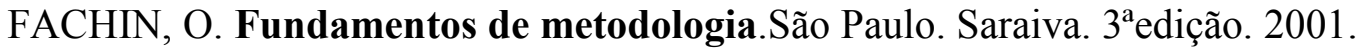

FIALHO. A.B. (a)Cosmos: Plataforma CAE do solidworks 2008. São Paulo. Érica. $1^{\text {a }}$ edição. 2008. 
. A.B. (b) SolidWorks Office Premium 2008: Teoria e prática no desenvolvimento de produtos industriais - plataforma para projetos CAD/CAE/CAM. São Paulo. Érica. $1^{\mathrm{a}}$ edição. 2008.

FILHO, A.A. Elementos finitos: a base da tecnologia CAE. São Paulo. Érica. $5^{\text {a }}$ edição. 2007.

Elementos finitos: a base da tecnologia CAE - Análise dinâmica. São Paulo. Érica. $2^{\mathrm{a}}$ edição. 2008.

FOGLIATTO,F.S. RIBEIRO,J.L.D. Confiabilidade e Manutenção Industrial. Rio de Janeiro. Elsevier Editora. 1 ${ }^{a}$ Edição. 2009.

GALDAMES, E.V.C. CARPINETTI, L.C.R. Aplicação da técnica de planejamento e análise de experimentos no processo de injeção plástica. $1^{a}$ edição. São Carlos. Gestão e Produção, 2004.

GERDAU. Manual de aços. 2003. Disponível em $<$ http://www.dem.feis.unesp.br/maprotec/educ/lmcm1/catalogo_acos_gerdau.pdf $>$. Acessado em 3 abr. 2011.

GERE, J. M. Mechanics of Materials. Brooks/Cole-Thomson Learning. $6^{\text {a }}$ edição. Belmont, USA. 2004.

GLANVILL, A.B. DENTON, E.N. Princípios básicos e projetos - Moldes de injeção. $1^{\mathrm{a}}$ edição. São Paulo. Editora Edgard Blucher. 1994.

GNEDENKO, B. USHAKOV, I. Probabilistic reliability engineering. John Wiley \& Sons Inc. New York. USA.1995.

GROSS, D. et al. Engineering Mechanics 2 - Mechanics of Materials. Editora Springer. Heidelberg, Alemanha. 2011.

HAIR, J.F. et al. Fundamentos de métodos de pesquisa em administração. Porto Alegre. Bookman. 2005.

HAMADA, M. S. et al. Bayesian Reliability. Springer. New York. USA. 2008.

HARADA, J. Moldes para injeção de termoplásticos: projetos e princípios básicos. $2^{\mathrm{a}}$ edição. São Paulo. 2004.

HELMAN, H. ANDERY, P.R.P. Análise de falhas: aplicação dos métodos de FMEA e FTA. Fundação Christiano Ottoni, Escola de Engenharia da UFMG. $1^{\mathrm{a}}$ edição. Belo Horizonte. 1995.

IRESON, W. G. et al. Handbook of reliability engineering and management. McGrawHill. $2^{\text {a }}$ Edição. EUA. 1995.

JUNIOR, I. M. et al. Gestão da qualidade. $8^{\text {a }}$ edição. Publicações FGV Management, FGV. Rio de Janeiro. 2008. 
KUO, W. ZUO, M. J. Optimal reliability modeling - principles and applications. John Wiley \& Sons, Inc., Hoboken, New Jersey 2003.

LAKATOS, E.M. MARCONI, M.A. Fundamento de metodologia científica. São Paulo. Atlas. 2001.

LEEMIS, L. Reliability: probabilistic models and statistical methods. Nova York: PrenticeHall, 1995.

LEVIN, M. A. KALAL, T. T. Improving product reliability - Strategies and Implementation. Wiley Series in Quality and Reliability Engineering. Teradyne, Inc., California, USA. 2003.

LEWIS, E. E. Introduction to Reliability Engineering. John Wiley \& Sons, Inc..2 ${ }^{\text {a }}$ Edição. Illinois. EUA. 1994.

MCPHERSON, J.W. Reliability Physics and Engineering: Time-To-Failure Modeling. Springer. New York. USA. 2010.

MURTHY, P. RAUSAND, M. OSTERAS T. Product Reliability - Specification and Performance. Springer. New Jersey. USA. 2008.

NAKASONE, Y. et al. Engineering Analysis With ANSYS Software. MPG Books Ltd., Cornwall. Inglaterra. 2006.

NELSON, W. How to analyze reliability data. Vol 6. ASQC Quality Press. Milwaukee. USA. 1983.

NORTON, R. L. Projeto de máquinas - Uma abordagem integrada. Bookman. São Paulo. 2004.

PADILLA, A. BASELGA, J. BRAVO, J. Comparison of Gauge Deformation Determined by Simulation of the Injection Process With Real Process Values. Artigo. Información Tecnológica-Vol. $17 \mathrm{~N}^{\circ} 4$ - 2006, pág. 53-58. La Serena. Chile. Disponível em: $<\mathrm{http}: / /$ www.scielo.cl/scielo.php?script=sci_arttext\&pid=S0718-

07642006000400010\&lng=en\&nrm=iso $>$ Acessado em 10 jan. 2011.

PALADY, P. FMEA: Análise dos modos de falha e efeitos: prevendo e prevenindo problemas antes que ocorram. São Paulo. IMAM. 4a edição. 2007.

PARK, H.S. DANG, X.P. Structural optimization based on CAD/CAE integration and metamodeling techniques. Artigo Disponível em: $<$ http://www.sciencedirect.com/science?_ob=ArticleURL\&_udi=B6TYR-50B5PRN$1 \&$ user $=10 \&$ coverDate $=10 \% 2 \mathrm{~F} 31 \% 2 \mathrm{~F} 2010 \&$ rdoc $=1 \& \_\mathrm{fmt}=$ high \&_orig $=$ search\&_origin $=$ search\&_sort $=\mathrm{d} \&$ docanchor $=\&$ view $=\mathrm{c} \&$ acct $=$ C00005022 $1 \&$ \&version $=1 \&$ urlVersion $=0$ \&_userid $=10 \& \mathrm{md} 5=86 \mathrm{e} 743070 \mathrm{~d} 6 \mathrm{a} 347 \mathrm{aa} 748 \mathrm{c} 9117 \mathrm{cab} 68 \mathrm{a} 9 \&$ searchtype $=\mathrm{a}>$. Acessado em 27 dez. 2010.

PIAZZA, G. Introdução à engenharia da confiabilidade. Caxias do Sul. EDUCS. 2000. 
PROVENZA, F. Moldes para plásticos. $4^{\mathrm{a}}$ edição. São Paulo. Editora Atlas. 2005.

RAUSAND, M. HOYLAND, A. System reliability theory: models, statistical methods, and applications. $2^{\mathrm{a}}$ edição. John Wiley \& Sons, Inc. Hoboken: New Jersey. 2004.

RENDER. Curso. Análise de Elementos Finitos. Mídia Digital. Joinville. SC. 2011

RICHARDSON, R.J. Pesquisa Social: Métodos e Técnicas. São Paulo. Atlas. $3^{\text {a }}$ edição. 2007.

RICHTER, P.E. LOPES, L.F.D. A confiabilidade relacionada ao desenvolvimento de produtos e à gestão da qualidade total. Disponível em: $<$ http://www.abepro.org.br/biblioteca/ENEGEP2004_Enegep0206_0088.pdf > Acessado em 20 dez. 2010.

ROZENFELD, H. et al. Gestão de desenvolvimento de produtos: uma referência para a melhoria do processo. São Paulo. Saraiva. 2006.

SAUNDERS, S.C. Reliability, life testing and the prediction of service lives: For Engineers and Scientists. Springer. New York. USA. 2007.

SCAPIN, C.A. Análise sistêmica de falhas. Instituto de Desenvolvimento Gerencial, Tecnologia e Serviços - INDG TecS. Minas Gerais. 1999.

SOARES, J. C. Processo de Injeção de Plásticos. Treinamento operacional em máquinas injetoras. Corona. 2005.

SOLIDWORKS SIMULATION 2011. Propriedades dos Materiais. Software. Solidworks Corporation. Dassault Systèmes. Concord, Massachusetts, EUA. 2011.

TIMOSHENKO, S.P. Resistência dos materiais. Livros Técnicos e Científicos Editora. Volume 1. São Paulo. 1979.

TIMOSHENKO, S.P. GERE, J. E. Mecânica dos sólidos. Livros Técnicos e Científicos Editora. Volume 1. São Paulo. 1983.

VERGARA, S.C. Projetos e relatórios de pesquisa em administração. $5^{\text {a }}$ edição. São Paulo. Atlas, 2004.

VILLARES METALS (a). Catálogo. Aços para moldes. Disponível em: $<$ http://www.villaresmetals.com.br/portuguese/files/Cat_Acos_Moldes.pdf $>$. Acessado em 24 mai. 2011.

(b). Catálogo. Institucional. Disponível em: $<$ http://www.villaresmetals.com.br/portuguese/files/Cat_Institucional_09.pdf $>$. Acessado em 24 mai. 2011.

YOUNIS, W. Up and Running with Autodesk Inventor Simulation 2010: A Step by Step Guide to Engineering Design Solutions. Elsevier. Canadá. 2009. 
ZIENKIEWICZ, O. C. et al. The Finite Element Method: It's Basis and Fundamentals. $6^{\text {a }}$ edição. Burlington, Massachusetts. EUA. 2005. 
1 - AÇOS CONSTRUÇÃO MECÂNICA CARBONO SAE J-403

\section{1 - AÇOS CARBONO}

\begin{tabular}{|c|c|c|c|c|}
\hline \multirow{2}{*}{ SAE/AISI } & \multicolumn{4}{|c|}{ COMPOSIÇÁA QUIMICA (\%) } \\
\hline & C & Mn & P Máx. & S Máx. \\
\hline 1043 & $0,40-0,47$ & $0,70-1,00$ & 0,030 & 0,050 \\
\hline 1044 & $0,43-0,50$ & $0,30-0,60$ & 0,030 & 0,050 \\
\hline 1045 & $0,43-0,50$ & $0,60-0,90$ & 0,030 & 0,050 \\
\hline
\end{tabular}

\section{5 - AÇOS GERDAU E EQUIVALÊNCIAS COM NORMAS}

5.1 - AÇOS CONSTRUÇÃO MECÂNICA

5.1.1 - AÇOS CARBONO NÃO RESSULFURADOS

\begin{tabular}{|c|c|c|c|c|c|c|}
\hline $\begin{array}{l}\text { QUAL. } \\
\text { GERDAU }\end{array}$ & $\begin{array}{l}\text { ABNT/SAE } \\
\text { AISI/ASTM }\end{array}$ & DIN & UNI & JIS & BS & AFNOR \\
\hline 1045 & 1045 & $\begin{array}{c}\text { (C45/C45E/C45R/ } \\
\text { Cq45/Cf45) }\end{array}$ & (C45/C46) & (S 45C) & $080 \mathrm{~A} 47$ & (C45) \\
\hline 1050 & 1050 & (C50/C50E/C50R) & (C50)C51) & (S 50C) & (080A52) & $\mathrm{xC50}$ \\
\hline 1060 & 1060 & (C60/C60E/C60R) & C53) & (S 58C) & - & - \\
\hline 1084 & $1080 / 1084$ & (C85/85Mn3) & (C60/C61) & - & 080A83 & $(\times 80)$ \\
\hline NORMAS & - & - & - & G 4051 & 970 part1 & $33-101$ \\
\hline
\end{tabular}

6 - CARACTERISTICAS MECÂNICAS DOS PRODUTOS GERDAU AÇOS FINOS PIRATINI

6.1 - DUREZAS (HB) - Construção Mecânica Ligado e Construção Mecânica Carbono

\begin{tabular}{l|c|c|c} 
Qualidade & Laminado/Normalizado & Recozido & Esferoidizado \\
\hline SAE 1030 & $140-205$ & máx 170 & máx 160 \\
SAE 1035 & $150-220$ & máx 174 & máx 163 \\
SAE 1040 & $155-230$ & máx 177 & máx 166 \\
SAE 1045 & $165-250$ & máx 180 & máx 169 \\
SAE 1050 & $179-265$ & - & máx 184 \\
SAE 1060 & $200-272$ & - & máx 198 \\
SAE 1070 & $210-290$ & máx 220 & máx 202
\end{tabular}

6.2 - Propriedades Mecânicas de Material Beneficiado - Aços Construção Mecânica Ligado e Construção Mecânica Carbono

\begin{tabular}{|c|c|c|c|c|c|}
\hline \multicolumn{6}{|c|}{ Bitola $<40 \mathrm{~mm}$} \\
\hline Qualidade & $\mathrm{RT}\left(\mathrm{N} / \mathrm{mm}^{2}\right)$ & $\operatorname{LE}\left(\mathrm{N} / \mathrm{mm}^{2}\right)$ & $\operatorname{Al}(\%)$ & Est(\%) & Dur(HB) \\
\hline SAE 1035 & $600-750$ & $\min .370$ & $\min .19$ & $\min .45$ & $180-228$ \\
\hline SAE 1040 & $630-780$ & $\min .400$ & $\min .18$ & $\min .40$ & $187-232$ \\
\hline SAE 1045 & $650-800$ & $\min .430$ & $\min .16$ & $\min .40$ & $195-234$ \\
\hline SAE 1050 & $700-850$ & $\min .400$ & $\min .15$ & $\min .35$ & $215-253$ \\
\hline SAE 1060 & $800-950$ & $\min .520$ & $\min .13$ & $\min .30$ & $240-285$ \\
\hline
\end{tabular}

Figura 7.1: Propriedades mecânicas Aço SAE 1045

Fonte: Catálogo de Aços (GERDAU, 2003) 


\section{CVILLARES METALS}

\section{ACOS PARA TRABALHO AQUENTE}

Tempera:

Revenimento:

Curva de

Revenimento:

O aquecimento para tempera deve ser entre 840 e $860^{\circ} \mathrm{C}$.

Recomenda-se pre-aquecer as ferramentas.

Restriar em cleo apropriado com agitaçấ0 e aquecido entre 40 e $70^{\circ} \mathrm{C}$.

As ferramentas devem ser revenldas imedlatamente apos a tempera, tăo logo atinjam $60^{\circ} \mathrm{C}$. Fazer, no minimo, 2 revenimentos e entre cada revenimento as peças devem restriar lentamente ate a temperatura amblente. Temperaturas de revenimento devem ser escolhida, conforme a dureza deselada (curva aba'xo). tempo de cada revenimento deve ser, de no minimo, 2 horas. Para pecas malores que $70 \mathrm{~mm}$, deve-se calcular o tempo em funçăo de sua dimensăo. Considerar 1 hora para cada polegada de espessura.

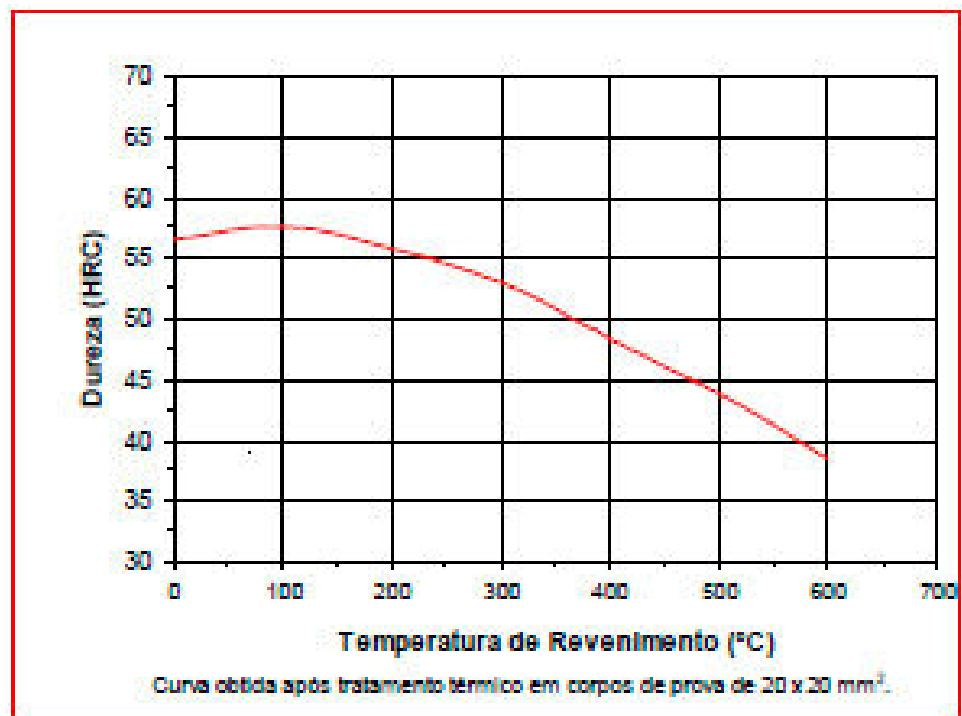

Figura 7.2: Propriedades do Aço VCO (Complemento)

Fonte: Villares Metals (b), 2011 


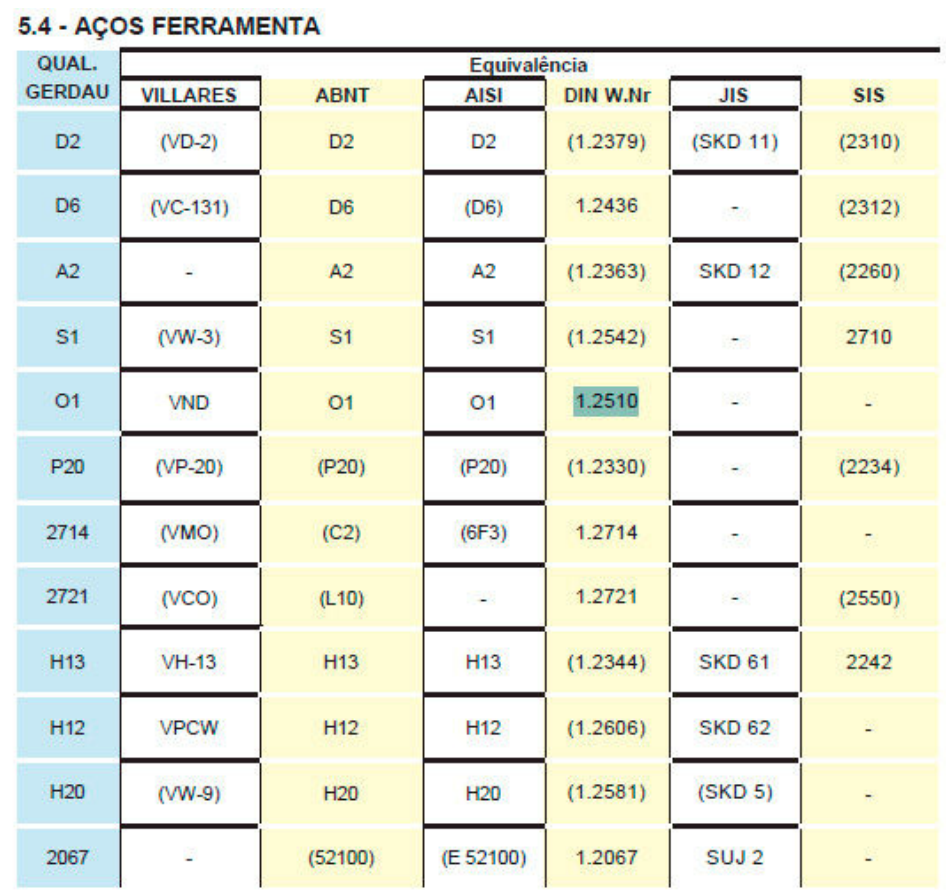

Figura 7.3: Propriedades do Aço VND

Fonte: Catálogo de Aços (GERDAU, 2003)

\section{Parâmetros de FMEA}

De acordo com Palady (2007):

\section{Escala de Severidade}

\begin{tabular}{|l|c|}
\hline \multicolumn{1}{|c|}{ Descrição da Escala de Severidade } & Grau \\
\hline Efeito não percebido pelo cliente & $\mathbf{1}$ \\
\hline $\begin{array}{l}\text { Efeito bastante insignificante, percebido pelo cliente; } \\
\text { entretanto, não faz com que o cliente procure o serviço. }\end{array}$ & $\mathbf{2}$ \\
\hline $\begin{array}{l}\text { Efeito insignificante, que perturba o cliente, mas não faz com } \\
\text { que o cliente procure o serviço. }\end{array}$ & $\mathbf{3}$ \\
\hline $\begin{array}{l}\text { Efeito bastante insignificante, mas perturba o cliente, fazendo } \\
\text { com que o cliente procure o serviço. }\end{array}$ & $\mathbf{4}$ \\
\hline $\begin{array}{l}\text { Efeito menor, inconveniente para o cliente; entretanto não faz } \\
\text { com que o cliente procure o serviço. }\end{array}$ & $\mathbf{5}$ \\
\hline $\begin{array}{l}\text { Efeito menor, inconveniente para o cliente, fazendo com que o } \\
\text { cliente procure o serviço. }\end{array}$ & $\mathbf{6}$ \\
\hline $\begin{array}{l}\text { Efeito moderado, que prejudica o desempenho do projeto } \\
\text { levando a uma falha grave ou a uma falha que pode impedir a } \\
\text { execução das funções do projeto. }\end{array}$ & $\mathbf{7}$ \\
\hline $\begin{array}{l}\text { Efeito significativo, resultando em falha grave; entretanto, não } \\
\text { coloca a segurança do cliente em risco e não resulta em custo } \\
\text { significativo da falha. }\end{array}$ & $\mathbf{8}$ \\
\hline
\end{tabular}




\begin{tabular}{|l|c|}
\hline $\begin{array}{l}\text { Efeito crítico que provoca a insatisfação do cliente, interrompe } \\
\text { as funções do projeto, gera custo significativo da falha e impõe } \\
\text { um leve risco de segurança (não ameaça a vida nem provoca } \\
\text { incapacidade permanente) ao cliente. }\end{array}$ & $\mathbf{9}$ \\
\hline $\begin{array}{l}\text { Perigoso, ameaça a vida ou pode provocar incapacidade } \\
\text { permanente ou outro custo significativo da falha que coloca em } \\
\text { risco a continuidade operacional da organização. }\end{array}$ & $\mathbf{1 0}$ \\
\hline
\end{tabular}

Quadro 7.3: Descrição da escala de severidade Fonte: Palady (2007)

\section{Escala de Avaliação de Ocorrência}

\begin{tabular}{|l|c|}
\hline \multicolumn{1}{|c|}{ Descrição da Escala de Severidade } & Grau \\
\hline Extremamente remoto, altamente improvável & $\mathbf{1}$ \\
\hline Remoto, improvável & $\mathbf{2}$ \\
\hline Pequena chance de ocorrência & $\mathbf{3}$ \\
\hline Pequeno número de ocorrências & $\mathbf{4}$ \\
\hline Espera-se um número ocasional de falhas & $\mathbf{5}$ \\
\hline Ocorrência moderada & $\mathbf{6}$ \\
\hline Ocorrência frequente & $\mathbf{7}$ \\
\hline Ocorrência elevada & $\mathbf{8}$ \\
\hline Ocorrência muito elevada & $\mathbf{9}$ \\
\hline Ocorrência certa & $\mathbf{1 0}$ \\
\hline
\end{tabular}

Quadro 7.4: Descrição da escala de ocorrência

Fonte: Palady (2007)

\section{Escala de Deteç̧ão}

\begin{tabular}{|l|c|}
\hline \multicolumn{1}{|c|}{ Descrição da Escala de Deteç̧ão } & Grau \\
\hline $\begin{array}{l}\text { Sistema de revisão de projeto bastante eficaz, programas amadurecidos de } \\
\text { qualidade e confiabilidade, controles de processo estado da arte. }\end{array}$ & $\mathbf{1}$ \\
\hline $\begin{array}{l}\text { Revisões de projeto eficazes, implementação de programas de qualidade e } \\
\text { confiabilidade, controles de processo altamente automatizados. }\end{array}$ & $\mathbf{2}$ \\
\hline Continuação do Quadro 7.5 & \\
\hline
\end{tabular}




\begin{tabular}{|l|c|}
\hline $\begin{array}{l}\text { Ênfase nas revisões de projeto, programas de qualidade totalmente desenvolvidos } \\
\text { e implementados, treinamento em andamento e implementação parcial de } \\
\text { programas de confiabilidade, processo automatizado para a maioria das } \\
\text { operações. }\end{array}$ & $\mathbf{3}$ \\
\hline $\begin{array}{l}\text { Programa de qualidade em vigor, conscientização da confiabilidade, sem um } \\
\text { programa formal, revisões de projeto parcialmente implementadas, um mix de } \\
\text { controles de processo automatizados e com intervenção humana. }\end{array}$ & $\mathbf{4}$ \\
\hline $\begin{array}{l}\text { Programas de qualidade desenvolvidos, mas ainda não totalmente } \\
\text { implementados, ausência de revisão formal de projeto, alguns controles de } \\
\text { processo automatizados, dependendo da adesão aos procedimentos operacionais. }\end{array}$ & $\mathbf{5}$ \\
\hline $\begin{array}{l}\text { Implementação dos estágios iniciais do programa de qualidade, poucos controles } \\
\text { de processo automatizados, implementação parcial de procedimentos } \\
\text { operacionais. }\end{array}$ & $\mathbf{6}$ \\
\hline $\begin{array}{l}\text { Implementação parcial de métodos de qualidade, planos de inspeção de amostras } \\
\text { e auditorias aleatórias, 100\% de inspeção. }\end{array}$ & $\mathbf{7}$ \\
\hline $\begin{array}{l}\text { Totalmente dependente da auto inspeção do operador com inspeção periódica do } \\
\text { controle de qualidade, métodos de qualidade não implementados, ausência de } \\
\text { procedimentos formais. }\end{array}$ & $\mathbf{8}$ \\
\hline $\begin{array}{l}\text { Totalmente reativo aos problemas identificados durante a fabricação, ausência de } \\
\text { programas formais, alguma conscientização da qualidade do produto. }\end{array}$ & $\mathbf{9}$ \\
\hline $\begin{array}{l}\text { Ausência de sistemas implementados, nenhuma conscientização da qualidade, } \\
\text { definição inconsistente da qualidade do produto - baseada em julgamento } \\
\text { individual. }\end{array}$ & $\mathbf{1 0}$ \\
\hline
\end{tabular}

Quadro 7.5: Descrição da escala de detecção

Fonte: Palady (2007) 


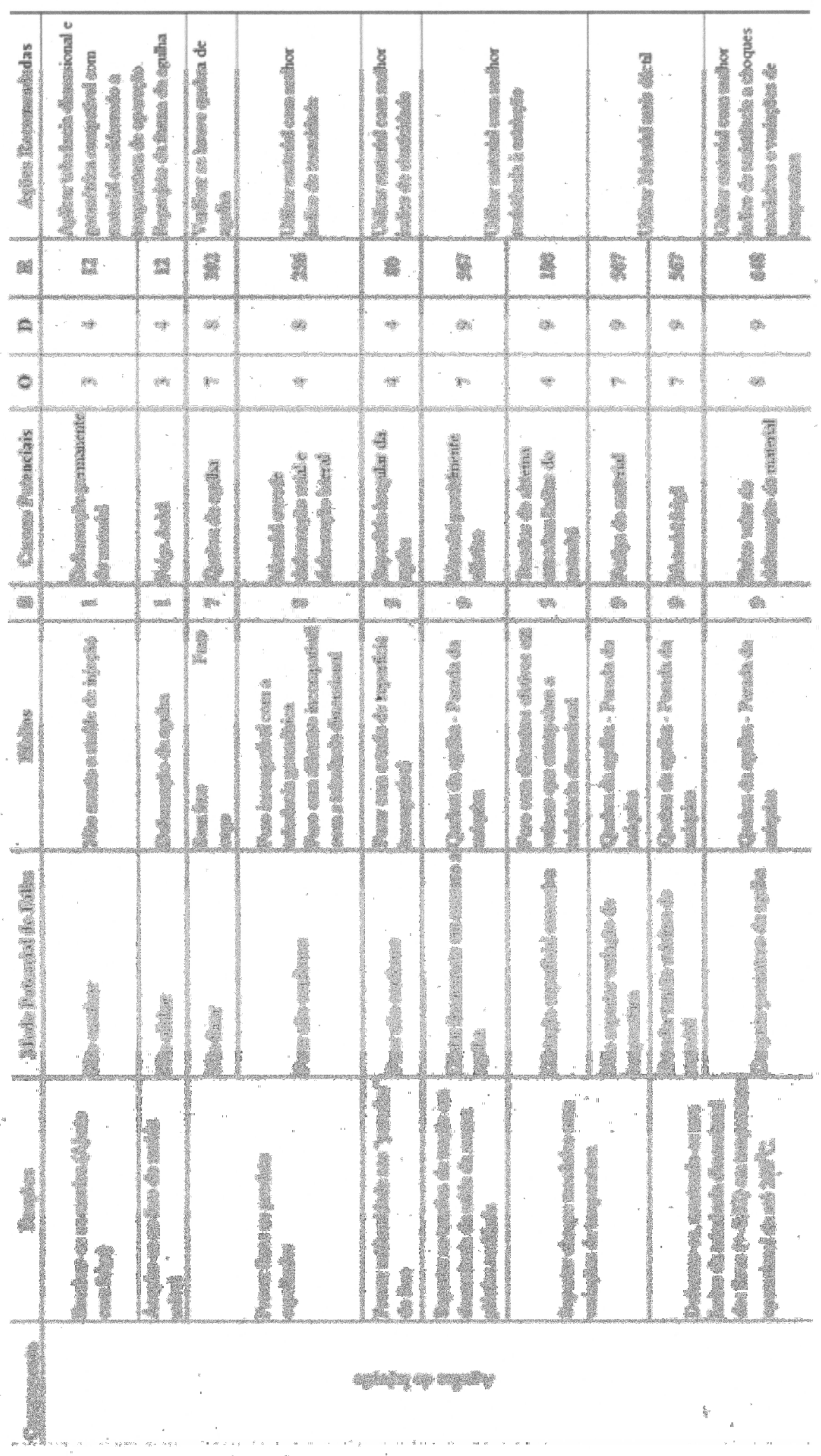

Figura 8.1: FMEA do componente agulha de injeção. 